\title{
Caring for Corporate Sustainability
}

\author{
Maria Eidenskog
}

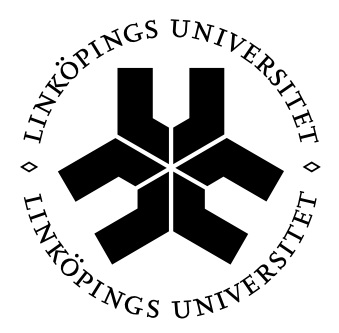

\section{Linköping University \\ FACULTY OF ARTS AND SCIENCES}

Linköping Studies in Arts and Science No. 644

Department for Thematic Studies - Technology and Social Change Linköping 2015 
Linköping Studies in Arts and Science • No. 644

At the Faculty of Arts and Sciences at Linköping University, research and doctoral studies are carried out within broad problem areas. Research is organized in interdisciplinary research environments and doctoral studies mainly in graduate schools. Jointly, they publish the series Linköping Studies in Arts and Science. This thesis comes from the Department of Thematic Studies - Technology and Social Change.

Distributed by:

Department for Thematic Studies - Technology and Social Change

Linköping University

SE-581 83 Linköping

Sweden

Phone: $+46(0) 13-281000$

Maria Eidenskog

Caring for Corporate Sustainability

Edition 1:1

ISBN 978-91-7519-069-3

ISSN 0282-9800

(C) Maria Eidenskog

Department for Thematic Studies - Technology and Social Change 2015

Printed by LiU-Tryck, 2015

Cover by Daniel Eidenskog 
This thesis is based on work conducted within the interdisciplinary graduate school Energy Systems. The national Energy Systems Programme aims at creating competence in solving complex energy problems by combining technical and social

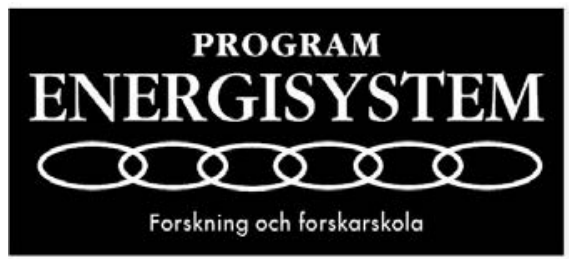
sciences. The research programme analyses processes for the conversion, transmission and utilisation of energy, combined together in order to fulfil specific needs.

The research groups that constitute the Energy Systems Programme are the Department of Engineering Sciences at Uppsala University, the Division of Energy Systems at Linköping Institute of Technology, the Research Theme Technology and Social Change at Linköping University, the Division of Heat and Power Technology at Chalmers University of Technology in Göteborg as well as the Division of Energy Processes at the Royal Institute of Technology in Stockholm. Associated research groups are the Division of Environmental Systems Analysis at Chalmers University of Technology in Göteborg as well as the Division of Electric Power Systems at the Royal Institute of Technology in Stockholm.

www.liu.se/energi 



\section{Contents}

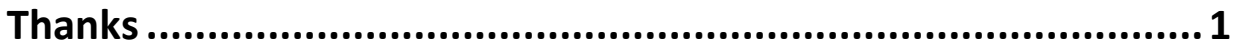

1. Introduction: Sustainability as care practice...........................5

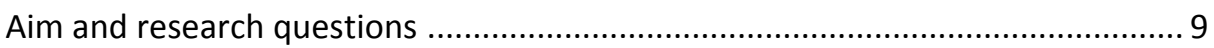

Sustainability - the making of wor(I)ds ............................................................. 9

A research landscape: Situating and relating the thesis....................................... 14

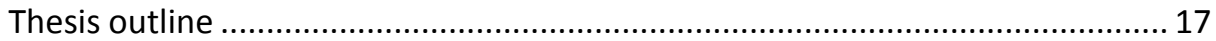

2. Methodology ............................................................... 21

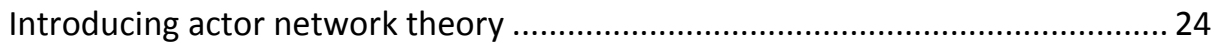

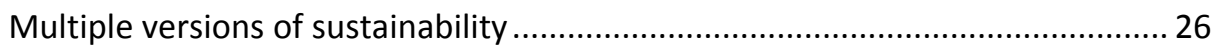

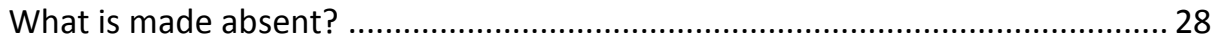

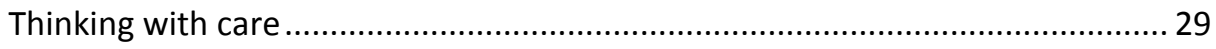

Studying sustainability as care practices: The theoretical approach ................... 32

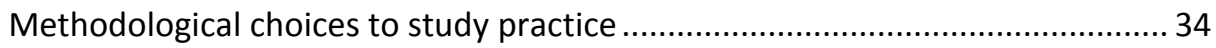

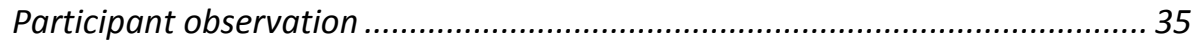

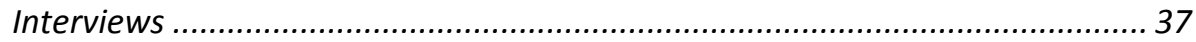

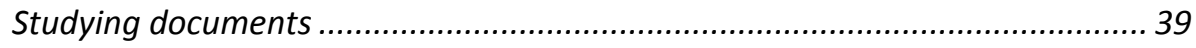

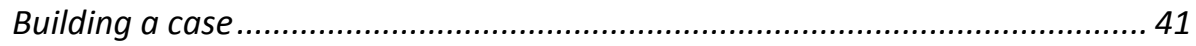

Handling the material and creating caring text .............................................. 43

Concluding methodology: Creating stories, telling science.................................. 46

3. The hinterland of sustainability at HygieneTech .....................49

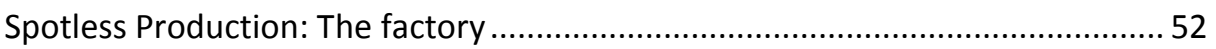

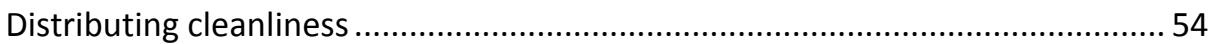

\section{Corrosive sustainability: Chemicals, labels and sustainability .... 57}

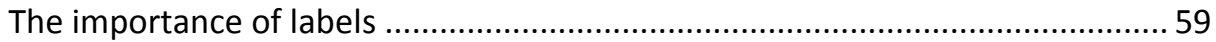

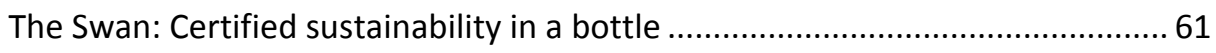

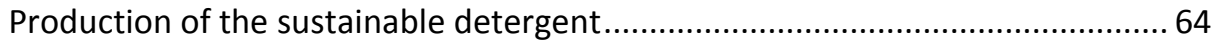




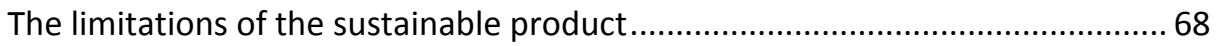

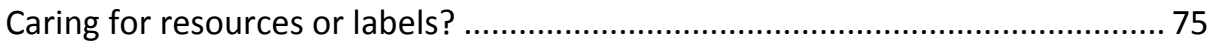

Certified sustainability as care enabler............................................................. 77

5. Paperwork: The making of sustainability on paper.................. 81

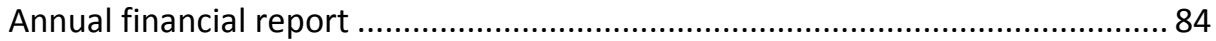

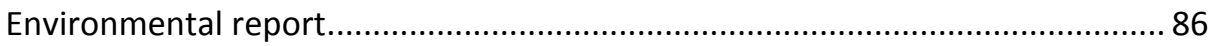

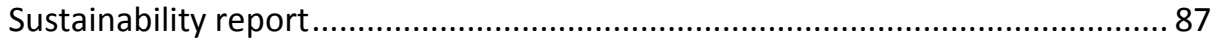

Introducing sustainability as resource saving ........................................... 88

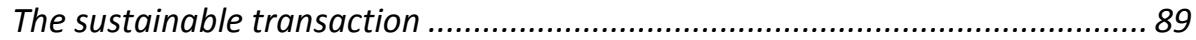

Social responsibility: A different story .................................................... 91

Making sustainability ......................................................................... 93

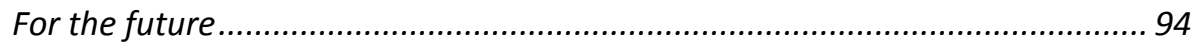

Piecing together sustainability in reporting practices ..................................... 96

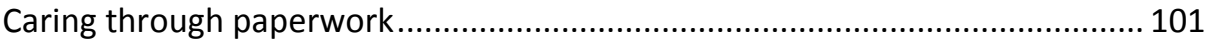

6. Caring standards: Working with ISO 26000 ............................. 105

ISO 26000: A standard for social responsibility ........................................... 108

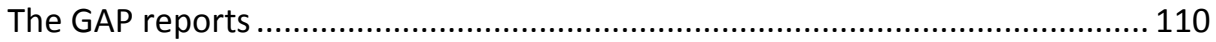

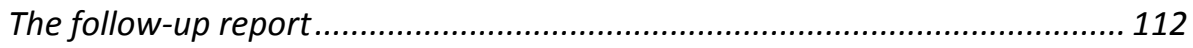

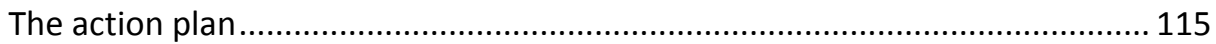

Translating the standard: A time trouble? ................................................ 118

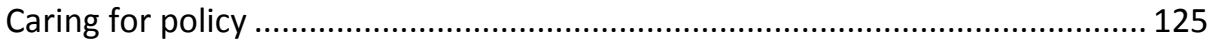

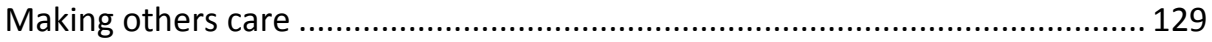

Standard care as caring (for) paperwork ..................................................... 131

7. Selling sustainability, service or detergents ......................... 135

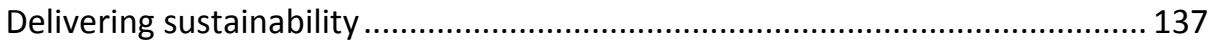

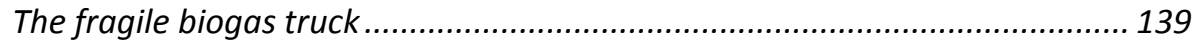

Selling the cheapest product at a high price .................................................... 143

The need for guerrilla marketing .............................................................. 147 
The everyday practice of selling sustainability ................................................ 152

8. Enacting sustainability through care of water ..................... 157

A water project for everyone............................................................................ 159

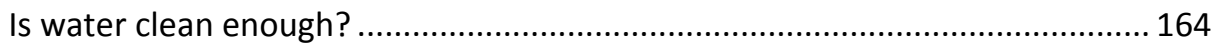

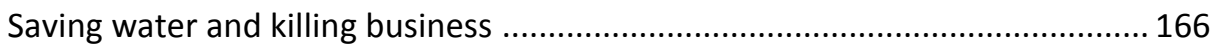

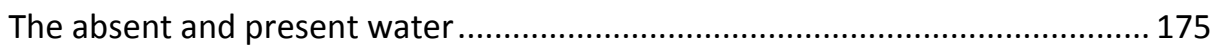

9. Conclusions: Enacting sustainability in care practices at HygieneTech ................................................................. 179

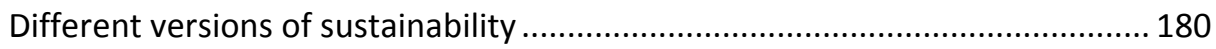

The lives of different versions of sustainability ................................................ 186

Sustainability made absent ............................................................................. 190

Keeping the cares together through professional caring ................................. 193

For the future: Some final thoughts on care and sustainability ......................... 197

References ................................................................ 199 



\section{Thanks}

The words in this book are mine, but the inspiration behind them and the arguments put forward have sprung from endless conversations, collaborations and joint wonderings. I owe thanks to many wonderful people that has made this thesis possible and in this section I would like to mention some individuals that have made important contributions during different stages of creating this study.

To all the employees at HygieneTech: THANK YOU! The open and understanding mindset that you showed during these years of collaborations enabled this text and inspired me to write engaged stories. I am very grateful for all the questions you have answered and for taking time to talk to me and explain your realities. A special thanks goes to the person in this thesis named Therese who patiently handled all my requests, pointing me to new questions and inspired me with her passion for sustainability.

I remember my first meeting with Jenny Palm, who later came to be my main supervisor. I was invited to her office after I sent a mail with some questions about doing a PhD at Tema. We had a nice talk in which I asked sneaky questions about the most strategic way to get a position at Tema while Jenny informed me about the possibility that the energy shortage in the world might be miraculously solved and render a $\mathrm{PhD}$ in Energy systems rather worthless. Despite the somewhat odd first conversation, this came to be the start of a successful relationship. Jenny's straightforward ways and her pragmatism in case of problems have been great assets in our collaboration and I owe much of my academic wisdom to her. Jenny always helps me keep sight on the target and not get lost in details or problems. Thanks for all supportive conversations, text comments and the advice to turn discrepancies between theory and reality into study objects rather than problems.

Likewise, I remember the first conversations I had with Lotta Björklund Larsen, who came to be my co-supervisor in 2012. I have stronger memories about the place, since it was at a railway station in Oxford, than I have about the topic (even though I am convinced it involved taxes!). In Lotta I found a partner in crime when it came to my thinking about style, method and theory. We shared several interests (such as ANT, ethnography and dogs!) and most importantly, I found a conversation partner that tended to details as well as idealistic visions in a way that supported my writing process very positively. In the later stages of writing, we became office neighbours and I have often knocked on her door to get invaluable feedback on any topic. Thanks Lotta for inspiration, great comments and friendly support during tough times! 
This work was carried out under the auspices of the Energy Systems Programme, financed by the Swedish Energy Agency. I gratefully acknowledge them for the financial support. Even though energy is not my primary focus in this thesis, it will be a contribution to energy efficiency studies on a larger scale. By turning the lights toward sustainability, I will show how environmental concerns, including energy issues, are made into a part of enacting sustainability in practice. The Energy Systems Programme provided me with a third supervisor, Patrik Thollander, who have been my expert on SMEs and energy issues. Thanks Patrik for all good comments in the early phases of my PhD education. Within the Energy System collaboration, I have learn a great deal of facts about energy, but also about collaborations and about being a researcher. A special thanks to all colleagues in the industrial consortium and to all fellow $\mathrm{PhD}$ students for collaborations, social conversations as well as for generously sharing academic knowledge during meetings, field trips and courses.

I believe that the conversations I have had with colleagues, both within and outside of Tema, has been foundational for my ability to write this thesis and develop myself as a researcher. An early meeting with Kajsa Ellegård, I believe it was during my first year, encouraged me to not judge the people I study and instead believe that they do the best they can, and that our role is to try to understand their situation. This inspired me to search for a theoretical foundation that could make this approach justice and within ValueS, my seminar group at Tema, I found a theoretical discussion that sparked my interest and enabled such approach. I owe thanks to all the member of Values for ideas, text comments, laughter, and conversations. Special thanks to the Values members Rèka Andersson, Lotta Björklund Larsen, Baki Cakici, Anders Hansson, Claes-Fredrik (CF) Helgesson, Linus Johansson Krafve, Francis Lee, Lisa Lindén, Anna Morvall, Johan Nilsson, Karin Thoresson, Anna Wallsten, Steve Woolgar and Teun Zuiderent-Jerak for our shared expedition in the world of STS over the years! Thanks Francis for commenting texts in the final stages of writing and to CF for being my theoretical consultant during my time at Tema. I am also grateful to CF for the opportunity to be part of making the new journal Valuation Studies, an experience that really open the black box of the academic machinery.

Plenty are the eyes that have wandered the pages of my attempts in creating this book. Some of them have had greater impact than others, such as the opponents and readers in different stages of the $\mathrm{PhD}$ education. I am thankful for a great reading and commentary from my $60 \%$ opponent, Renita Thedvall, who guided me through the many choices I had to make with a critical and supportive voice, and from the reading group Wiktoria Glad and Francis Lee. My 90\% seminar turned into a feast of inspiration thanks to the creative and engaged reading from Laura Watts. Thanks for finding the best in my texts! I am also grateful for insightful comments from the final seminar reading group: CF, Ericka Johnson and Olof Hjelm. 
Academia would never work without its supportive processes and in Tema I have been blessed with many very engaged and supportive administrative colleagues. Thank you for all support, which have included human resources as well as technical and administrative issues. A special thanks to Eva Danielsson, Carin Ennergård and Camilla Junström Hammar for practical help as well as guidance through the jungle of university bureaucracy. I would also like to take the opportunity to thank Eva Törnqvist for trusting me with teaching opportunities within CMTS and for advice on handling unexpected student situations. Thanks also to Susan McNish for excellent proofreading!

Dearest PhD colleagues at Tema, you have made me believe in a life in academia after the dissertation. I have found support, intellectual conversations and friendship in the many meetings in fika rooms, courses and pubs during these five years. A special thanks to the members in the D-10 group: Rèka Andersson, Linnea Eriksson, Mathias Hellgren, Linus Johansson Krafve, Lisa Lindén, Anna Wallsten, Katharina Reindl, Hanna Sjögren and Josefin Thoresson. Our meetings outside Tema has done wonders to my mental wellbeing during difficult times and brought joy to the everyday of doing a $\mathrm{PhD}$. Thanks to Rèka for our writing days at the library and important discussions over coffee during the final year of writing. And thanks to Lisa, whom with I have shared office, nerdy conversations on reality making as well uncountable coffee breaks, your expertise in both STS and friendship is exceptional! Thanks also to my friend Susen who has provided me with breaks from campus life with our long lunches in the city.

Being the first academic doctor in the family tree, I am especially grateful to my parents and family for continued support and belief in my choices in work life. My parents have been a source of inspiration: nothing is impossible for my dad and my mother is an expert on finding new ways of experiencing life. During my many years in academia, they have come to terms with that my answer to the question "what will you become?" is "wiser" rather than a title.

Lastly, thanks to my own small family in Sixtorp: Daniel and our dogs Sookie and Polka. Even though I know that our dogs any day would prefer even the smallest bit of treat over being mentioned in a thesis, I want to thank Polka and Sookie for long mindfulness walks and for distracting me from work, reminding me that there are other important things besides a thesis! And Daniel, your support and love has been essential to everything from the beginning to the finishing of this thesis. You encouraged me when I applied for the PhD position and during the struggling times, your faith in my ability has never failed. Thanks for everything, from therapeutic conversations to taking time off from work to make my life easier in the last phase of writing. 



\section{1}

\section{Introduction: Sustainability as care practice}

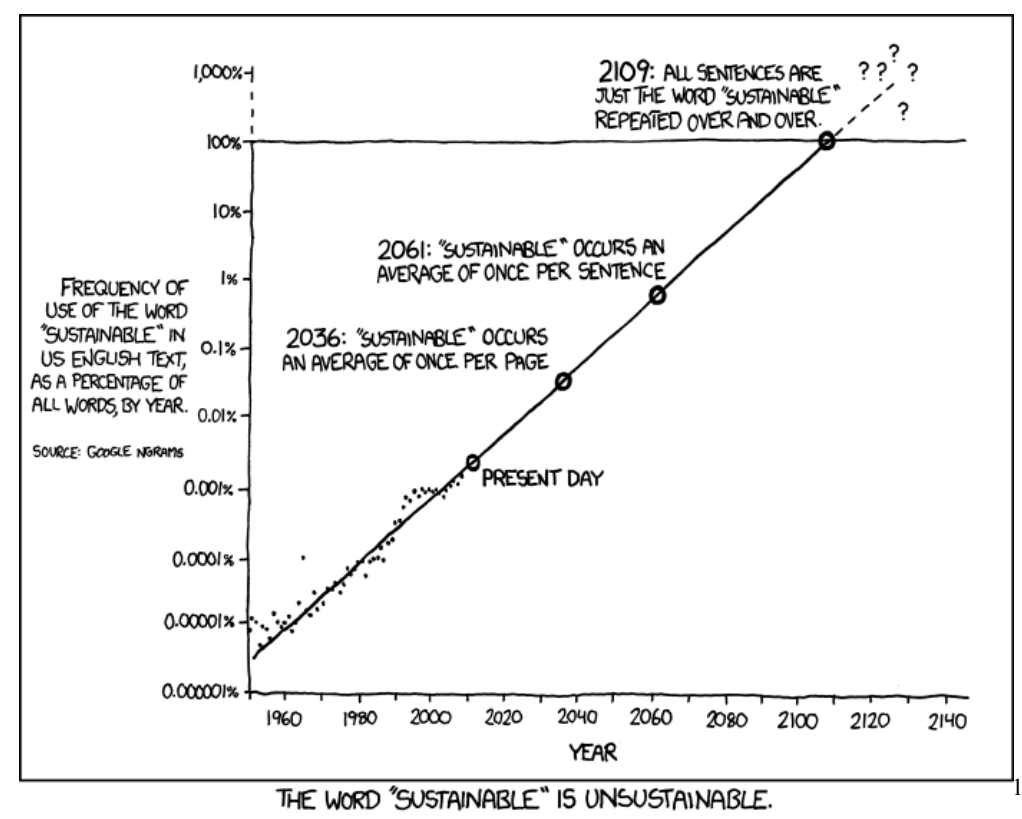

The wonder of sustainability. The increasing popularity of the word brings with it a shimmering, almost mystical, touch to sustainability. Questions about the

\footnotetext{
${ }^{1}$ http://xkcd.com/1007/
} 
word's usefulness are mixed with hopes for a better tomorrow. If sustainability is the future, we might wonder what we can expect the texts in the year 2109 to tell about. Inspired by this enigmatic word, this is a book that wonders about sustainability and about the many possibilities it holds. Even though sustainability is in focus, it is merely a tool in a quest to tell a story about the matters of the world. This is a story of caring, more specifically, of caring for corporate sustainability. This thesis studies sustainability in terms of care and practices, and it retells stories about how sustainability is done within a company.

Sustainability is a concept with manifold meanings and consequences. Understanding how these play out in a corporate setting sheds light on the political consequences of choosing to commit to one version of sustainability over another. According to the proponents of ecological modernization, the industrialized society can reach a balance with the environment by engaging more fully in the market economy (Spaargaren \& Mol 1992; Mol 2001). Sustainability is sometimes understood as following the footsteps of these thinkers and promises us a better tomorrow through achieving equilibrium between economy, ecology and social responsibility. Sustainability can be about making money, being smart and saving resources, while in other settings caring for the people in a nearby community is seen as sustainability. When even an oil company can argue that they are sustainable, this has consequences for what futures we bring about and consider as desirable. To understand the politics of sustainability we need to turn to the practice of making sustainability where the consequences of these choices and actions become visible. This study is therefore done with an ethnographic approach, which allows a study of the multiplicity of objects and the way they interact with one another (Law 2004). This thesis will, instead of providing yet another definition or an evaluation of sustainability, look to how sustainability is done in a medium-sized company in this thesis called HygieneTech that sells and delivers hygiene products to professional customers (e.g. restaurants and hotels).

The company was selected due its reputation as a role model as a medium-sized company working actively with sustainability. Following the practices of sustainability I show how actors engage in and do sustainability in their everyday work life and in various contexts within the company, and how they understand the consequences of making sustainability in different ways. In this thesis, instead of turning to economics, philosophy or ethics to understand what sustainability should be about, I turn to Bosse, Wilma and other employees at HygieneTech in order to understand what sustainability is to them.

It's damn self-preservation! 
Those are the words of the owner of HygieneTech, Bosse, when he talks about why they work with sustainability. According to Bosse, the company's care for the environment, his employees and the surrounding society as well as its economic concerns are a part of being and living as HygieneTech. This thesis is about how this company cares for its business, but also for other values and in this thesis I will use care as a theoretical concept in order to study the enactments of sustainability. Through the pages of this book, you will get to know many of the important employees who care for sustainability. I will show different ways of doing sustainability beyond statistics and glossy business conference talks. Instead, the stories of sustainability can show how, in their everyday work, HygieneTech care for a variety of matters, which include not only profit making but also employee welfare and the environmental impact made by their customers. Caring for sustainability is done in practice, just like caring for a person:

Care, after all, is not necessarily verbal. It may involve putting a hand on an arm at just the right moment, or jointly drinking hot chocolate while chatting about nothing in particular. A noisy machine in the corner of the room may give care, and a computer can be good at it, too (Mol, Moser \& Pols 2010, p. 10).

Inspired by this approach, I will show how care can be done in many different ways. It is multifaceted; care can be gentle and loving, but it can also be brutal and may even involve killing; for example, sometimes we are required to kill a few sick animals in order to care for the herd (Law 2010). Likewise, care can be done by different actors, humans as well as non-humans. ${ }^{2}$ I have deliberately chosen to write about care in relation to corporations even though it is a concept we usually only use to describe human beings. "Thinking with care" (an approach inspired by Maria Puig de Bellacasa (2012)) enables me to conduct my study with different tools than I would have chosen if I were using already established concepts within organization and management studies. Care comes with a different set of attachments than, for example, "organizational culture", and by thinking with care, I aim to think differently about how actors within a company are enacting sustainability.

There is always a balancing act, juggling between different matters that need care in the making of corporate sustainability. HygieneTech cannot always care for all parts of sustainability while neglecting all other matters; if they did, the company would not survive for long. The company sells chemical products and thus generates chemical waste; the only way to avoid that would be to stop making the most important products

\footnotetext{
${ }^{2}$ My symmetrical approach to actors that treats humans and non-humans equally is inspired by actor network theory (ANT). ANT is introduced in Chapter 2.
} 
in its product line. Care is, just like sustainability, multiple, and sometimes care for the survival of the company is more important than care for environmental concerns. In this thesis, I tend to this negotiation between care for different matters that are connected to, or stand in contrast to, sustainability.

With curiosity, I wonder about sustainability to further understand how this concept is performed in practice and its consequences. To understand their versions of sustainability by twisting and turning a concept without a publicly recognized single definition, I will evoke a theoretical approach to science inspired by science and technology studies (STS). I study sustainability by focusing on how sustainability is done, through actions and in talk and texts, as well as through its materiality. I follow how sustainability is being made and approach sustainability as something that is enacted. By using "enact" instead of "construct", I imply that things are made by actors in a network rather than socially constructed (Gad \& Jensen 2010). Thus, I emphasize that sustainability is done in practice by recognizing it as an object that is enacted in different ways. I consider reality as done though practice and as locally and historically located (c.f. Latour \& Woolgar 1986; Mol 1997; Law \& Urry 2004). When the reality as we know it is enacted through different sets of practices, this means that reality itself is multiple (Mol 1997; 2002). The different realities are not just different perspectives; there is more to it than the different experiences of one world. These multiple realities will be considered as entangled enactments of different worlds from different actors. Within the different realities, an object can be enacted in several ways, and thus objects are also multiple. The realities are not easily constructed, and in their making we can study how concepts or objects become made through a set of messy practices (Law 2004). Thus, there is more than one version of sustainability, and these different versions are sometimes easy to combine while they clash in other situations. Viewing sustainability as multiple by rendering different versions visible can untangle some of the messiness of enacting sustainability.

How does one study the realities where sustainability is done? In this thesis, I explore these worlds by studying practice, writing stories and letting you get to know the actors I have met. Doing science through telling stories is a way to care for the multiplicity of the worlds we study, and a way to tend to place in knowledge making (Watts 2007). Our knowledge is not produced in a location, ready for us to collect it; instead, it is done by weaving together different worlds. This thesis is a multilayered story of the enactments of sustainability, and in the following chapters I have written short stories from my experiences at HygieneTech. I have chosen to talk about them not as excerpts of empirical material since this might imply that there is an empirical field that is untouched by me as an impartial observer. Instead, I am a part of the worlds that I study and thus I choose to tell the stories of the making of the different worlds in which sustainability is important. In these worlds, not everything can be 
brought into presence and this means that presence is dependent on absence. There are realities that are necessarily absent when an object is present (Law \& Singleton 2005). A version of sustainability enacted by a sustainable oil company cannot be brought into existence without clashing with a version of sustainability as only including renewable energy. What is made absent is thus interesting to study since its absence is sometimes required to make other versions of sustainability present. This approach makes it apparent when other values are turned into matters of care instead of sustainability and when one version of sustainability renders other versions absent. These clashes will tell about these messy practices of enacting sustainability in the different realities.

\section{Aim and research questions}

In this thesis, I show the different versions of sustainability HygieneTech use in their business. This knowledge will show how sustainability is done in practice and give insights into the challenges facing employees in medium-sized companies when they try to achieve sustainable development. I tell stories of studying HygieneTech, and by studying the everyday life at the company, I can show what matters of care the employees create in their sustainability work. What is seen as sustainability in one setting does not need to be sustainable in another context. Different versions of sustainability exist side by side at HygieneTech, and the employees need to work constantly to make sustainability into practices that make sense in their worlds. Different versions of sustainability can sometimes coexist while in other situations they clash since some enactments of sustainability cannot be made present at the same time.

The aim of this thesis is to study, with the notion of thinking with care, how sustainability is enacted in practice in a medium-sized company. To address this aim, I pose the following research questions:

- How are different versions of sustainability enacted in HygieneTech?

- How do versions of sustainability coexist side by side?

- When and why do different versions of sustainability clash?

- How do other matters of care stand in contrast with sustainability, and when is sustainability made absent in relation to these?

- How is sustainability with its many versions kept together at HygieneTech?

These questions and the aim of the study guide this text throughout the remainder of this book. The research questions, the aim and my care for sustainability have changed over the five years of writing this book. The curiosity that led to these guiding 
questions sprang from a wider interest in corporate sustainability and a wish to one day make a difference. This thesis is an act of care - that is, a way to do ontological politics (Mol 1999). I care, and hope, for a future in which companies take greater responsibility for their impact on society. This ought not to be a problem, at least if we all agree to the principle that sustainability will arise from the market economy, offered by the ecological modernists. However, as this thesis shows, sustainability is not always easy to bring into existence. It will become apparent that it sometimes takes extensive work to make things sustainable.

Following Donna Haraway, I proclaim that "Nothing comes without its world, so trying to get to know those worlds is crucial" (Haraway 1997, p. 37). This means that the worlds that I study are central to understanding the concept that I am interested in, since everything is done in relation to its worlds. Thus, I will get to know the worlds of sustainability through the practices that make sustainability and the matters of care that it evokes. This methodology will contribute to the field of science and technology studies by telling new stories about the relations, challenges and different versions of sustainability that govern organizations through studying the practice of enacting sustainability as care. This novel empirical field can furthermore contribute to deepening our understanding of care practices.

Furthermore, the theoretical approach in this thesis enables me to write stories about how sustainability is enacted in practice in HygieneTech by emphasizing the struggles and care involved. Few studies are done on corporate sustainability with an ethnographic approach, even though there are exceptions (e.g. Ernstson 2006; Lippert 2013), and thus the stories in this thesis will bring attention to the often neglected tinkering between matters in practice that is needed to bring about sustainability. The stories show how the flexibility in the concept sustainability is handled by the employees and thus tell how its boundaries are negotiated. Moreover, following the enactment of different versions of sustainability describes how sustainability practices can vary from one situation to another. The methodology thus facilitates a complex analysis of entangled matters, highlighting passion for sustainability as well as selfcare that sometimes stands in opposition to sustainability, while it in other settings can be combined with caring for sustainability. The combination of the symmetrical ANT analysis and the concept of thinking with care inspires a caring study in which both human and non-human actors have voices which can bring about new sensitivities and questions concerning corporate sustainability. Through the stories in this book, I show how actors struggle with sustainability and how much effort is needed in order to make sustainability profitable and doable. This knowledge can bring new insights in the making of corporate sustainability and how we need to (perhaps critically) wonder about how corporate sustainability will be a part of creating a better tomorrow. 


\section{Sustainability - the making of wor(I)ds}

There have been few critical debates over whether all companies should work with sustainability. The adoption of a sustainability approach is hard to question since it is profitable, socially responsible and environmentally friendly. Some claim that companies have not yet understood how profitable sustainability can be (Grankvist 2012). This useful concept is nevertheless hard to put into practice. When Ivey Business Journal asked 15 companies why they were not working with sustainability, the most important factor was that they got confused by the many metrics which claimed to be measuring sustainability (Laughland \& Bansal 2011). This also shows the weakness of a stretchable concept - it becomes hard to translate into real-life practices for companies.

The diversity in the nature of sustainability makes it a very interesting object of study, but even so, as must be done in every text that concerns sustainability, I need to contextualize my own use of the word. To do this I travel back in time to the birth of the concept as we know it today. Historically, the term "sustainable development" was first coined in Our Common Future, a report published by the World Commission on Environment and Development (WCED) in 1987. The report is also known as the Brundtland Report and included the foundational definition of sustainable development:

...development which meets the needs of the present without compromising the ability of future generations to meet their own needs.

$[\ldots]$

[It includes] ...the concept of "needs," in particular the essential needs of the world's poor, to which overriding priority should be given; and the idea of limitations imposed by the state of technology and social organization on the environment's ability to meet present and future needs (WCED 1987, p. 43).

The concept of sustainable development got acceptance by the United Nations (UN) General Assembly, which gave the term political salience. In 1992, leaders set out the principles of sustainable development at the UN Conference on Environment and Development (UNCED) in Rio de Janeiro, Brazil, also known as the Rio Summit and the Earth Summit. At the 2005 World Summit on Social Development it was noted that sustainable development requires the reconciliation of environmental, social equity and economic demands - the "three pillars" of sustainability (United Nations 2005). Today there are many different definitions and uses of the concepts of sustainable development and sustainability (e.g. United Nations 2005; The World 
Bank Group 2001). Ever since the Brundtland Report in 1987, this concept has been interpreted, translated and used in more or less well-accepted ways.

One way to avoid the constant struggle to define sustainability, that is, to simplify the messiness of the practices (Law 2004), has been to develop and follow standards. Sustainability comes in many different shapes, and the need for interpretations of how to approach sustainability has led to an increasing number of ways to standardize it. Following the thoughts of ecological modernization, numerous standards, measurements and indexes have been developed to measure sustainability in accordance with the market economy (Boström 2003). Standardizing sustainability is not an easy task, but some standards have been more widely accepted than others. Through the regulations within these standards, sustainability is enacted. One wellused standard is the Dow Jones index, which has the largest sustainability index with 2500 companies listed (Dow Jones Sustainability Indices 2015). This index puts numbers on how well each company fulfils a set of criteria that is enacted as sustainability. By measuring the intangibles of these companies, one company (SAM) claims to help shareholders:

Sustainability trends such as resource scarcity, climate change or an aging population continuously reshape a company's competitive environment. SAM is convinced that companies that can adapt to such challenges through innovation, quality and productivity enhance their ability to generate long-term shareholder value (SAM 2012).

Following this interpretation of sustainability we need to understand what lies in "shareholder value", and according to SAM, this can be measured in numbers. In their terms, sustainability is not about caring for the needs of the poor or fair use of resources; it is about making (primarily market) value for the company's owners and thus achieving economic growth. In their efforts to make sustainability into a measurable entity, standards often limit what can be regarded as sustainable. By enacting sustainability as shareholder values, other matters that are hard to translate into numbers are lost, or at least seen as uninteresting.

Measuring requires a scale, something that is hard to make based on sustainability since there are many different ways to define the concept. Even so, measurements are a popular way to evaluate the existence or presence of sustainability since it can be put into numbers and thus made more "real". As we find in this thesis, numbers are sometimes used to show how sustainability is made present, but most often this comes with a great deal of discussion due to the work needed to create a scale. Even though it is enacted in different ways, sustainability cannot be anything and everything. The concept has shapes; it has borders and a commonality through its enactments that 
(most often) have some connection to at least parts of its history. I follow the versions of sustainability made by the employees at HygieneTech. Sometimes they include social issues and economic balancing while at other times they only consider sustainability in terms of environmental issues.

In order to look for the practices of sustainability I have looked for problems, challenges or discussions that have connections to the reconciliation of environmental, social equity and economic demands - the "three pillars" of sustainability (United Nations 2005), since these are brought up when the employees are asked to define sustainability. Furthermore, sustainability touches upon many other "buzzwords" in the business world today, and any attempt to make a distinction between all these concepts and sustainability would require another thesis. The employees at HygieneTech focus on sustainability and rarely differentiate it from other related concepts such as corporate social responsibility (CSR). Consequently, I only focus on the enactment of sustainability since this is the concept the employees at HygieneTech use the most.

Sustainability is an interesting object of study as an already multifaceted concept that is well used in society today. If its use continues to grow at the current rate, according to the comic strip at the beginning of this chapter, within 22 years the word "sustainable" will be used once on every page published (already in this book, sustainability is mentioned on average over six time per page!). The unsustainable rate of the use of the word is of course just a comical way to display the tendency to label almost everything as sustainable. Eager efforts to label phenomena as "green", sustainable or as part of a company's CSR work have been investigated in many ways within research and in public debate. Greenwashing (when a company tries to make itself appear more environmentally friendly than it actually is) as well as whitewashing (when a company covers up immoral, dishonest or illegal acts or situations (Merriam Webster 2015)) is linked to the eagerness to expand the use of the concept of sustainability. Based on the understanding of companies as at risk for greenwashing, several studies have aimed to develop new models for avoiding this phenomenon (c.f. Lyon \& Maxwell 2011; Kirchoff 2000; Gamper-Rabindran \& Finger 2013). In this thesis, I will not judge the efforts at HygieneTech as greenwashing or whitewashing; instead, I aim to understand their practices and to study how they manage the many expectations from customers, the surrounding society and media. I study sustainability as a care practice not to unveil unfair practices, but to take a different perspective than thinking of corporations' sustainability work as potential greenwash. Even so, the diverse use of "sustainability" does spark thoughts about the usefulness and the slipperiness of this concept. At the end of this book, I come back to this issue and discuss how the different versions of sustainability can instead be thought of as strengths. 


\section{A research landscape: Situating and relating the thesis}

Writing a thesis with a theme that touches upon several different research fields comes with the challenge of narrowing down whom you want to invite to the conversation. Research on sustainability is a large and growing topic while a search for "organizational studies" in Google Scholar provides the eager reader with more than 3.5 million articles. This study belongs in some ways to both sustainability studies and to organizational studies, but it does not participate with ease in all conversations where corporate sustainability is discussed. The empirical work could probably be inspiring for organizational theorists or researchers in sustainability studies, but one must eventually choose an audience. Even though my empirical field is corporate sustainability, this thesis aims first and foremost to contribute to conversations within science and technology studies using sustainability at a SME as my empirical field. Even so, this research takes place in a setting where other research fields play a part in our understanding of the research subject. Therefore, I aim to situate my study in relation to other research fields in order to invite some, and at the same time exclude other, conversations in relation to this text.

In order to give the reader some understanding of the study of corporate sustainability, in this section I introduce some of the ideas that are discussed in this field of research. This is not a review of previous related research; instead, I aim to take the reader by the hand and take a short stroll in the landscape that my study is related to or situated in. The purpose with this text is to provide insight into how this topic has been studied within organizational and management studies in order to show how my study is different. I will also relate to some studies made within the discipline of STS to introduce the studies of organizations within this field. Many STS researchers have looked at organizations in different ways, and by highlighting some important and related studies I present some background to the theories that will be further explained in the methodology chapter. The most important contribution, however, will be to the discussion about care practices in relation to corporate organizations. I will discuss this further in the methodology chapter and in the conclusions. By the end of this chapter, the reader will have been familiarized with thoughts from organizational studies about corporate sustainability and organizational studies within STS. This is the setting in which this study is situated.

Since the Brundtland Report was published, numerous studies have investigated how companies can contribute to sustainable development. Small and medium-sized companies (SMEs) are argued to be important to investigate when it comes to sustainability (Santos 2011), and new policies at the EU level stress the importance of SMEs with respect to environmental and social questions (European Commission 2011). SMEs constitute the dominant form of business organization worldwide and 
account for at least 95\% of the business population (OECD 2005). In Sweden, 99.4\% of all companies have 49 or fewer employees while $0.5 \%$ have between 50 and 200 employees (SCB 2012). About $60 \%$ of employees in Sweden work in SMEs (Ekonomifakta 2010). Furthermore, estimates show that SMEs collectively account for up to about $70-80 \%$ of industrial pollution internationally (Hillary 2000; Cassells \& Lewis 2011). SMEs are important study objects from several perspectives and the societal relevance of this thesis is supported by research that states that SMEs are seen as a group that is hard to reach and lagging behind in terms of "green businesses" and sustainability work (Cassells \& Lewis 2011; Battisti \& Perry 2011).

Moreover, a range of different issues has been investigated in relation to sustainability in SMEs. I will bring one such issue to the table in order to show how this study is related to some research agendas within management studies. One issue is the motivations for SMEs to work with sustainability or environmental questions (e.g. Patton \& Worthington 2003; Vernon et al. 2003; Williamson, Lynch-Wood \& Ramsay 2006; Dewhurst \& Thomas 2003; Tzschentke, Kirk \& Lynch 2008). Studies suggest that SMEs only respond to regulation regarding environmental issues (Tilley 2000; Williamson, Lynch-Wood \& Ramsay 2006) and that this is inevitable, given the market-based decision-making frame that dominates the industry in which manufacturing SMEs operate (Williamson, Lynch-Wood \& Ramsay 2006). Some researchers have found a gap between what is seen as managers' values (such as perceiving environmental issues as important) and their actions (Rutherfoord, Blackburn \& Spence 2000; Schaper 2002). This "value-action gap" (Revell \& Rutherfoord 2003) has been explained by pointing out that attitudes are a poor predictor of specific behaviours, and that there are constraints on SMEs which affect the actions of the owner-managers (Schulz \& Zelezny 1999).

I will not try to explain this "value-action gap"; instead of accepting that such a phenomenon exists, I will treat values as enactments through practices. In order to commit to this analytical starting point I will use an actor network theory (ANT) approach in which values are only enacted, in practice, not inherited or held, and there cannot be a gap between values and actions. In accordance with ANT, I view values as enacted practice instead of as an ethical stance. I do not aim to understand actors' intentions; instead, I focus on actions such as statements spoken, texts written and activities undertaken in practice. Thus, both the making of judgements and actions are analysed as practices. This ANT approach complicates the ability to relate to research within management studies while at the same time it brings new ideas and perspectives to the table.

Many STS researchers have, with great success, contributed to the field of management studies. The field of science and technology studies is not a newcomer to 
the study of organizations and corporations. John Law studied the organization of a chemical lab presented in his book Organizing Modernity (Law 1994) in which he established the concept of "modes of ordering" - that is, embodied and performed stories which tell of the nature of organizations. Modes of ordering are enacted through stories told by the employees, but also through materiality such as paperwork. Representation is always a part of ordering, Law tells us (Law 1994). Like Law, I view paperwork as a part of ordering organizations, or in other words, paperwork is part of enacting sustainability through representation. Inspired by these thoughts, some parts of this study will concentrate on the paperwork involved in making sustainability.

Furthermore, other researchers (e.g. Czarniawska \& Hernes 2005; Lee \& Hassard 1999) have taken an ANT approach in their study of organizations. Studying organizations with ANT has provided a way to analyse organizations with a curiosity about the way ordering, devices and different actors (human and non-human) are part of keeping an organization working. The emergence of power and the study of macro actors has been part of the research agenda (Czarniawska \& Hernes 2005). This approach to the study of organizations has been used in corporate settings as well as in other types of organizations, such as labs (Law 1994) and a neonatal intensive care unit (Brown and Middleton, 2005). In relation to the studies of companies, ANT researchers have taken an interest in subjects such as project management and the way devices, such as budgets, play a part in the ordering of the construction of a building (Georg \& Tryggestad 2009).

From research about organizations and ANT, new topics have sprung up within science and technology studies. One such subject is market studies, in which researchers take an interest in the organizing of markets. ANT has inspired new ways to think about organizing markets and the role of performativity in the making of markets (e.g. Kjellberg \& Helgesson 2006; Caliskan \& Callon 2009; Caliskan \& Callon 2010). In relation to the organization of markets, researchers have focused on "concerned markets" as a way to highlight the complex interdependency of the economic and the social writ (Geiger et al. 2014). In a similar way, this study centres around the intertwining of the social and the economic, but the focus will be on one company instead of the making of a market.

Furthermore, researchers within STS have taken an interest in the ordering in organization that is related to environmental issues. ANT has inspired research that focused on the dynamic signification of product qualities related to environmentally friendly products (Reijonen \& Tryggestad 2012). This study shows how producing an environmentally friendly product is a constant trial about qualities. Only when environmental friendliness is combined with other qualities is this product seen as successful. The existence of the environmentally friendly PVC-free bag is a fragile and 
contingent collective outcome of the work of both humans and non-humans. There is nothing inherently green about this product; it is the result of a process that takes different concerns into account. Tools, such as calculative devices, matter also in the production of such a mundane thing as a plastic bag (Reijonen \& Tryggestad 2012). Moreover, calculations and accounting within organizations have figured in other studies taking an ANT perspective. One such study was done by Kristin Asdal, who shows how the attempt to account for nature within the organization concerned with acid rain instead turned nature into an economic matter (Asdal 2008). Furthermore, Ingmar Lippert (2013) has used an ANT approach to study environmental management in large corporations. His research shows how carbon emission facts are produced and how they co-configure climate change realities. Moreover, he argues that the environment is made multiple and is enacted through accounting (Lippert 2013).

This thesis thus connects/relates to several different research fields, but its main contribution will be to science and technology studies. The literature about organization from an ANT approach is extensive and my aim in showing some examples of the way ANT has been appropriated is to inform the reader about the landscape in which this thesis is situated. Studying organization with ANT is not new, neither is it revolutionary to take an interest in sustainability. However, this study contributes to ongoing discussions within STS in several ways, foremost as involvement in the study of care in practice and studies within a corporate setting. A further introduction to actor network theory and the concept of care is presented in the methodology chapter (Chapter 2).

\section{Thesis outline}

In the following, I briefly present the different parts of the thesis in order to provide the reader with an understanding of the structure and ordering of this book.

The first chapter introduced the topic of the thesis, situated the thesis within an empirical and theoretical context, and explained the aim and research questions. In Chapter 2, I develop the methodology and theoretical standpoint in depth. This chapter describes the scientific approach on which the thesis is built and how ontological politics is part of this methodology. The theoretical foundation is inspired by actor network theory, and this chapter presents how I combine Annemarie Mol's ideas of multiplicity with ideas about looking at what is made absent. By analytically thinking with care (inspired by Maria Puig de la Bellacasa) I furthermore approach my case with a different set of tools and words than those commonly used in studies about 
corporate sustainability. In this second chapter, I present how I built my case study and how I care for the making of the thesis and the community I studied.

Chapter 3 is an introduction to HygieneTech; it presents the core process of the company and introduces some of the important actors that work within the company. This short chapter provides the reader with an insight into the processes of enacting HygieneTech and is to be read foremost as a background chapter for the empirical chapters that follow it.

Chapter 4 further describes how the chemical products become sustainable and discusses the importance of labels. This chapter explains how corrosive detergents are enacted as sustainable and how labels are a way to care for the environment while still producing cleanliness. By focusing on the core processes of making cleaning products I show how sustainability is closely connected to the labelling of products and thus to the identity of the company. This approach also makes visible the tensions between sustainability as saving resources and sustainability as environmental labels. In this section I introduce "care enabler" as a concept that can be used to describe devices that distribute care in an organization.

The next empirical chapter (Chapter 5) looks at the paperwork that is connected to HygieneTech's sustainability work. In this chapter I study environmental and sustainability reports in order to show how sustainability is enacted on paper. The practice of making sustainability as paperwork presents interesting tensions in that sustainability is sometimes enacted as marketing while at other times it is thought of as a conscious and idealistic choice. I discuss how different versions of sustainability can be enacted side by side in the pages of the reports while some clashing versions of sustainability are kept separate.

In Chapter 6, I show how sustainability is done through following standards. This chapter shows that working with standards often results in extensive paperwork. Standards are a way to enable care for sustainability since an "objective" partner provides a definition of how to move towards sustainability. By using standards, a small company with limited resources to put into sustainability can avoid spending time on legitimizing their efforts as sustainable; at the same time, standards benefit them by creating new relations to other actors interested in sustainability. The chapter allows for discussions on the importance of standards in the making of sustainability and shows how the standards are turned into practice in relation to local practices and other matters of care.

In Chapter 7, I study how HygieneTech works to sell sustainability to customers that are often not that interested in sustainability work. With reference to the concept of guerrilla marketing, I tell stories of how HygieneTech's employees handle customers 
that seem not to understand what is best for them. We get to know the "ignorant" and the "interested" customer. The former is assumed not to understand how sustainability is good for them and therefore needs to be educated, whereas the latter is often absent in the everyday work of the company but is evoked to support sustainability whenever it is questioned. Showing the relationship to the customer explains the world in which sustainability is being made and why it becomes a struggle to incorporate sustainability in the everyday lives of many of the employees.

Chapter 8 follows how water is connected to sustainability and how caring for water is a way to enact sustainability. Water, and especially clean water, is important at HygieneTech since they work with chemicals that are washed down drains, and if they are not biodegradable or else taken care of in a purifier, they might end up in streams and harm the wildlife there. The company's care for water arises from an awareness of how they are a part of society, but even so, care for water is sometimes set aside in favour or other matters. Placing the focus on water makes the materiality of sustainability in HygieneTech visible, and it shows the tensions between different versions of sustainability.

The final chapter of the thesis provide the concluding analysis. I discuss the research questions related to different versions of sustainability and I begin with introducing some of the important versions of sustainability that I have made visible in my study of HygieneTech. Furthermore, I discuss how different versions of sustainability sometimes clash while in other settings they can coexist. I analyse how standards can be important care enablers in the making of sustainability at HygieneTech, and how they can sometimes also bring new tensions into the decision making in the company. I present how economic profit sometimes is included and sometimes is made absent in relation to sustainability and discuss the controversies that arise when different matters of care, such as cleanliness and sustainability, clash. In order to develop theoretical thoughts on care, I contemplate on thinking with care in relation to studying a collective and discuss how different matters of care can be kept together in a messy reality of corporate sustainability. Lastly, I look ahead and suggest some future research topics which emerged during the writing of this thesis. Addressing these topics can further develop our understanding of sustainability and care. 



\section{Methodology}

Autumn 2013

I have been given an office for the day on the upper level at HygieneTech's headquarters. The small room has no windows other than the large glass wall that looks into the open space between the offices. I sit a bit nervously with my computer on my desk and try to figure out how to study the practices of HygieneTech's office employees. Every now and then an employee passes through the open space and I follow them with curiosity, looking for traces of sustainability in their questions to their colleagues, or just in the way they are going about their everyday tasks. Bosse, the owner of the company, suddenly appears in front of my glass door and strides by on his way to his office a bit further down the corridor. He looks into my office and nods and smiles when he sees me, but in his rush to get to his office, he does not seem to have time for small talk. I barely recognized him since our interview was a few months ago, but I manage a short smile back. I go back to my computer, but a few minutes later Bosse reappears, this time standing in my doorway. After a very brief bit of small talk, he asks me if I can explain a research report on why young people are less involved in sports today.

Bosse You're a researcher, there are some things that I can't figure out about this. Can you help me? 
I respond that, sure, I can try - but I am certainly not an expert on the subject of the study. We go out into the open space and take a seat on the leather sofa group that has certainly seen better days, and Bosse talks animatedly about how important sports are for young people.

Bosse You know, I have read this whole report but there are no figures or numbers anywhere! Why would you do a report without numbers?

Due to Bosse's very energetic manner, I struggle to find the right words to defend pretty much the whole of social sciences as well as my own study.

Maria Well, there are many different ways to do research...

I feel uncomfortable with the situation, wondering how to explain the science wars in a few simple sentences.

Bosse Yes, yes. But if you don't present any numbers in it, it's pretty meaningless, isn't it?

Maria Ehm... I wouldn't say that it is meaningless; numbers don't tell you everything. Sometimes you can get better information from talking to people, or like I do, from observations.

The conversation continued for a short while, and in the end I was convinced that I could have put up a better fight for qualitative methods as well as my own study.

Throughout my study I have had conversations with employees at HygieneTech, their customers, other researchers and my own family members concerning the meaning of my study as well as my methods. Many concerns about my study touched upon issues similar to those that Bosse brought up about the research report on kids' sports habits: Where are the numbers? Another early suggestion came repeatedly from my interdisciplinary collaborations: Can you present it in a table instead? In line with Bosse, one might wonder whether, if it cannot be presented in numbers or within a square box, is it really still science?

As I said to Bosse, science can be done in many ways. This thesis studies enactments of corporate sustainability, and in this chapter I present my choices in doing science. I want to understand the life of sustainability: What is sustainability for employees at a medium-sized company? In order to tell new stories of doing sustainability, I need an approach to science that can help me find categories beyond the traditional 
organizational science setting. The theoretical approach I have chosen will help me experience how sustainability is done in practice and understand how the employees categorize things as sustainable or unsustainable. The practices of sustainability happen in the company and I will follow the actors (Latour 2005) and let them show me how practices, actors and relationships are entangled. Likewise, in accordance with my ontological and epistemological understanding of science, theory and method are entangled, and one cannot be explained without the other (c.f. Law 2004). This is not a chapter about theory, nor is it a method chapter. Instead, I have chosen to write a chapter about methodology. Methodology will help me explain how my choice of methods is a result of my choice of theory and an ontological standpoint. I therefore introduce the reader to the methodology in this thesis, starting with theory. Theory not only helps me in my analysis, it guide me in the rather a long chain of decisions made throughout the thesis. Thus, my method was designed in accordance with theoretical positioning and is an outcome of ontological and epistemological considerations. During the five years that I conducted this study, countless choices have led up to this finished text. My choice of theory, methods and company as well as Wilma's consent to let me study their company have created texts that want to tell us something about society. In this chapter, I introduce you to the choices and theoretical standpoints that have guided my thesis.

The foundation for my research lies foremost in actor network theory (ANT) and its later developments, post-ANT. ANT is not so much a theory as a repertoire and a way of turning questions inside out and upside down (Mol 2010a). I understand ANT not only as an analytical tool but also as a "take" on science (Latour 2005). The reason for choosing an ANT approach in this study is the intriguing way ANT focuses on the networks of the study object and its ontological positioning. The ANT researcher follows the actors that are important in the making of the study object and looks into the practices which are connected to this object. In this way, I will be able to study sustainability in practices and understand the different ways it is made by focusing on the relations that make up the web in which sustainability is enacted.

ANT is my approach to science, and in my study, I also use a few of its concepts, that is, ways to categorize or analyse my empirical material. I think of sustainability as an object that comes in different versions, and thus is multiple. When a versions of an object is being enacted, some things are made present while others are made absent. Since I am interested in how borders are drawn to delineate what counts as sustainability, I also study what is made invisible when sustainability is enacted. Moreover, I use the notion of care as a thinking tool to be able to see how care is used to enact sustainability. Care adds sensitivity to what is made important to the actors and provides a way to analyse my empirical findings with care for sustainability. What 
I mean by these concepts and how they will be used in this study will be explained later on in this chapter.

Firstly, I introduce actor network theory. Through ANT I touch upon the ontological questions of studying enactments of corporate sustainability and how this starting point connects to the theoretical concepts. In the last parts of the theory section in this chapter, I explain my theoretical concepts and how they will be used to study sustainability practices in HygieneTech. I also provide background information explaining why I chose HygieneTech as my case and how I have conducted my study using the methods chosen. However, in order to explain the motivation behind my choice of method, I need to tell you more about my theoretical foundation. Therefore, I would like to introduce some important women and men who have inspired me since the very start of my Ph.D. education.

\section{Introducing actor network theory}

Actor network theory is a way to approach science, and it intrigued me with the way it incorporated everything in one level, leaving all my previous building blocks (such as organizational culture, management strategies etc.) as equal parts of a network instead of using them as explanations. Theory is not something that is applied to reality; instead, the ANT researcher studies how objects become real. In the early years of science and technology studies (STS), Bruno Latour and Steve Woolgar studied how scientific knowledge was produced in a laboratory (Latour \& Woolgar 1986). They concluded that facts were not a result of an unbiased experiment in which nature was discovered; instead, facts were a result of social processes intertwined with technological artefacts. Scientific knowledge came to be through a set of practical contingencies and practices. In these practices, science also produces its realities. This means that the scientists in the laboratory did not just try to describe the world "out there"; at the same time, they created the reality they described with help from inscriptions and tools. They created "facts" by writing papers about their results and by interpreting their tools. Until the controversies concerning nature's properties have settled, the possible realities are endless. When the controversies of the research results are resolved, only a single reality remains. In this way Latour and Woolgar (1986) argue that by establishing these facts they created the reality they studied. Facts, natural objects and social structures are made real in the same way through materially heterogeneous practices in networks (Law 2009). In this thesis, this means that sustainability and facts are made real in the same way in the practices that make up reality. Natural objects, as well as organizational structures and sustainability, are all enacted (Mol 2002). Using "enact" rather than "construct" implies that reality is 
performed rather than observed (Gad \& Jensen 2010). An object can be enacted in several ways; it can be talked about, or actions can be taken that are connected to it. Studying the enactments of sustainability will include studying conversations about sustainability, the tools used to do sustainability and the actions that are seen as, or connected to, sustainability. Instead of thinking of sustainability as constructed, I will approach it as enacted through practice.

Within ANT, anything that acts can be an actor. Non-human actors can be seen as working in assemblages together with human actors and create new actors (Latour 2005). By committing to this view, the researcher can learn which actor has the most influence, whether that actor is an organization, a person or a machine. Within organizational studies, it is common to refer to an "organizational culture" to explain why people act in certain ways. This can be seen as black boxing elements, which means that certain practices are made invisible by their own success. In the case of making science, this is shown when a matter of fact is settled, and then the focus is placed only on its input and output, not on its internal complexity (Latour 1999). Likewise, structural explanations are used to black box the ordering of an organization and, consequently, the more successful a theory about organizational structure becomes, the more opaque and obscure it turns out to be. In order to open this black box, the ANT researcher would use a different approach. For this study, it means that I consider an organization to consist of many different parts and realities. The "organizational culture" that is often said to be important in the making of sustainability could be dissected instead of taken for granted since "as soon as structures are investigated, they do not seem to hold" (Latour \& Woolgar 1986, p. 178). Organizational culture should be seen as an actor only if it actually affects the situation rather than be used as an explanation in itself.

With a theoretical perspective inspired by actor network theory, I treat everything in the social and natural world as an effect generated by the web of relations where they are located (Law 2009). Accordingly, actors are not quite the same from situation to situation. Rather, they are transformed in their movement between situations. Actors are found in different yet related versions, and networks develop through actors' transformational interactions (Gad \& Jensen 2010). Outside these relations, nothing has any form or reality; therefore, it is the network and the enactments of its relations that can be said to be the object of study. The studied network includes a series of translations, which simultaneously produce knowledge and construct a network of relations. Translation is both about making equivalent and about shifting. The study of translations will help us understand how an actor can gain the power to represent others. A translation happens when an actor creates a stronger network through displacements of other actors or by making an actor into a spokesperson for other 
actors. To be able to gain this power the actor enrols other actors and disassociates others' black boxes in order to enlist their elements (Latour 2005). Both enacting an object and translating it are processes, but they are different processes. The translation of an object changes what the object is, and this is done through different enactments of that object. In my study, I focus on enactments of sustainability, how sustainability is translated and the consequences of these enactments. I follow different actors within HygieneTech that enact sustainability, such as documents, biogas trucks and environmental labelled detergents, in order to understand how these translate in different settings. Moreover, I study what actors are enrolled in the making of different versions of sustainability.

\section{Multiple versions of sustainability}

Accepting the ANT approach comes with new challenges and possibilities. If reality is done by different sets of practices, this means that there are many different realities in the making at the same time. In different situations actors can create new realities through their practices and relations. Reality is not single, but multiple! In these realities, objects travel and take diverse forms. Like realities, these objects are enacted in different ways and come in different versions. As Mol says about the body in her study of atherosclerosis: the body is more than one but fewer than many (Mol 2002). Even though objects come in different versions, they still seem to cohere. The question is how these versions of an object can exist at the same time and how their outcomes differ.

Mol (2002) explains the different versions of the body in her study of the enactment of atherosclerosis. Likewise, I argue that sustainability comes in several versions and is translated in different realities. In this study, I make visible different enactments of sustainability, and thus study different versions of sustainability. In Mol's study, she found that the versions of an object sometimes coincide and can be added together to bring about a coherent, composite object (Mol 2002). Two versions of an object can coexist and overlap in one reality. For sustainability, we can find this when more than one version of sustainability can be brought into presence at the same time. Sustainability as saving resources can coexist in some realities with a version of sustainability that includes caring for the environment. By studying how versions of sustainability can be added together I show how sustainability is often enacted as a coherent object despite its many faces. Adding together versions of sustainability can also be a way to enrol other actors and justify sustainability efforts. 
Not all versions of an object can be easily added together. This happens when versions of sustainability include contradictory content that is impossible to enact in the same situation. When there is a clash between the versions of sustainability, a greater effort is needed to enact sustainability. This can be done by privileging one version over the other (Mol 2002), thus enacting one version as more important. In this thesis I show how versions of sustainability clash and when this becomes a problem for the employees at HygieneTech. By looking at the clashes between different versions of sustainability we can learn about the challenges a company has to deal with in their efforts to become more sustainable.

In addition, practices can be mutually excluding and these different versions of an object cannot be enacted in the same situation. As in Mol's book The body multiple (Mol 2002), a cross-section of an artery cannot be done on a live patient; it can only be done during an autopsy. The practice of doing a cross-section of an artery is therefore excluded when the patient is alive. Practices can do more than just create conflicting versions of objects; they also create different objects. Mol (2002) shows how atherosclerosis was done differently in two settings, in walking therapy and in studies of blood pressure measurements. These practices created two separate objects when a patient suffered from both symptoms: the patient was said to have both "pressure atherosclerosis" and "walking atherosclerosis". Instead of two conflicting versions, the object is split into two separate objects. This can be shown also in the enactment of sustainability; one example of this is when there is a split in ecological sustainability and economic sustainability. These different objects are created when the different versions of sustainability become mutually excluding.

Sometimes the different practices of an object do not cause any problems since they are located in different places. This can happen if the practices are separated through some sort of distribution, such as when they are spread out over time or among different actors. It can also occur as mutual recognition, for example, the distribution of atherosclerosis as a gradual process of deterioration and its reality as a painful condition for the patient. Separation may also occur through acknowledging the differences in the conditions of possibility, for example, the understanding that surgery is necessary at present, but that in the future this might not be needed. In this thesis, I show several different versions of sustainability, some that are separated by time and location and therefore do not clash. With this in mind, I study these versions' enactments in the separate locations by following sustainability through the organization. Sustainability comes in different versions for the seller standing beside the dishwasher and for Therese in front of her ISO 26000 binders. By focusing on these different enactments of versions of sustainability, I will learn more about the ordering of sustainability within HygieneTech. 


\section{What is made absent?}

When we view the world as enacted, objects have to be brought into presence to be a part of our reality. To study these "bringing-into-presence practices" we need to think in terms of method assemblages, says John Law (2004).

[A method assemblage] ...is the crafting, bundling, or gathering of relations in three parts: (a) whatever is in-here or present (for instance a representation or an object); (b) whatever is absent but also manifests (it can be seen, is described, is manifestly relevant to presence); and (c) whatever is absent but is Other because, while necessary to presence, it is also hidden, repressed or uninteresting (Law 2004, p. 144).

In order to make something present, we also have to make other things absent. Not everything can be brought into presence and this means that presence is dependent on absence. There are realities that are necessarily absent when an object is present (Law \& Singleton 2005).

Law and Singleton (2005) take as an example the construction of a British aircraft. The wings of the aircraft were designed with the help from some fixed conditions, such as the demands of lift to be placed on them. These were designed to require more lift than the typical civil aircraft by a set standard. This is because the wing came from a warplane meant to be used in a European war against the Russians. They assumed that the Russians would try to destroy conventional airways and therefore the planes were created to be able to take off on short airstrips. Even though there was no room for the Russians on the technical drawings detailing the design of the aircraft, they were present in the design. If we take into consideration that objects are generated through realities that are necessarily absent, we need to think of objects as transformative. The transformation is not gentle.

In this way of thinking, constant objects are energetic, entities or processes that juxtapose, distinguish, make and transform absence and presence. They are made in disjunction (Law \& Singleton 2005, p. 343-344).

Thus objects, like sustainability, are energetic and depend upon difference and otherness. In another case, about alcoholic liver disease, the object (the disease) creates absence in many different ways (Law and Singleton 2005). When patients undergo treatment, they are required to sign a contract stating that they will abstain from alcohol. Thus, alcohol is absent from the treatment of the disease but at the same time it is necessary to and present in it. In the same way, organizations that work with 
alcohol-related issues, such as Alcoholics Anonymous, are other to the hospital but at the same time included in its version of the alcohol in the liver disease.

In relation to sustainability, I thus search for whatever is absent but manifest, which could mean that I would look for actors that are described as important, but that are not present in the situations. This can be an actor that initiates sustainability efforts but is not present in an enactment of the efforts to implement them. The notion of absent but manifest actors highlights the actors that are rather silent but still affect the situation. Following these examples, I believe that what is made absent is another very important relationship to study if I am to understand sustainability. In some situations, different versions of sustainability are made absent since they cannot be enacted in the same situation. Furthermore, sustainability can be made absent in relation to other matters, such as the economic well-being of the company. The objects that are absent are necessary but made invisible when talking about sustainability and through them borders on sustainability are drawn.

\section{Thinking with care}

We are sometimes hesitant about thinking of corporations as aiming for more than profit, and companies that openly work with environmental issues are often accused of greenwashing (e.g. Furlow 2010; Delmas 2011). However, I believe this approach to companies and their employees leaves us with a very limited view of their capabilities and concerns. Instead, I choose to think with the concept of care and study how actors in HygieneTech care through practice. By thinking with care, I let the actors have a broader repertoire of behaviours than those typically attributed to the rational actor that is always trying to make the most economic utility of every situation. Care has been an increasingly popular concept within feminist studies in a range of different fields. Hywel Bishop (2012) argues that there is an important conceptual distinction in the way care has been used through much feminist analyses: care as doings (a set of practices involved in the material provisioning of care) and care as an ethical disposition. In moral philosophy, feminist ethics has explored care as an ethical disposition in relation to responsibilities and relations (c.f. Held 1993; Tronto 1993; Bowden 1997). Care as practice has been studied as bodily work in care work (Twigg 2000) and in social policy, care has been central in the study of paid work (Williams 2001) Furthermore, ecofeminism evoked care in the study of the relationship between nature and humans (c.f. Mies \& Shiva 1993; Curtin 1991).

A classical feminist definition tells us that care is about everything we do to maintain, continue and repair our world so we can live in it as well as possible (Tronto 1993). Even though this definition is well acknowledged within academia, it has been 
criticized for being too broad and thus failing to focus on the situation and relationships involved in caring practices (Bowden 1997). Following the writings of STS researcher Maria Puig de la Bellacasa (2012), caring is not (only) about normative ethics or an affective state. Caring is vital to creating relations since care and relations share conceptual and ontological resonance. To care about something, or for somebody, is inevitably to create relations (Puig de la Bellacasa 2012), and inspired by these thoughts, I study the relationships in which care for sustainability is done. Since caring is relational, it therefore creates multiplicity. Caring relationships are vital; they hold together the technoscientific world we live in today.

Caring is more about transformative ethos than an ethical application. We need to ask 'how to care' in each situation. This is attuned to STS's way of knowing on the ground. It allows approaching the ethicality involved in sociotechnical assemblages in an ordinary and pragmatic way (Puig de la Bellacasa 2011, p. 100).

The way we, as well as companies, care has implications for our worlds. With this in mind, I can study what is needed to generate more caring relationships.

In studying worlds, the notion of "matters of care" can be a proposition to think with (Puig de la Bellacasa 2011). Maria Puig de la Bellacasa starts from Latour's notion of matters of concern, where he turns away from matters of fact and develops another understanding of knowledge politics. Latour (Latour 2004; Latour 2005) aims to highlight that agencies (both human and non-human) are presented not only as matters of fact but always also as matters of concern. This move embraces objects such as politics (as a part of doing things that matter) and connects representation to more than interests since feelings, care and vulnerability also are included. However, this turn is not enough if we, as I do, agree with Puig de la Bellacasa. Instead of thinking about matters of concern, there is value in thinking about matters of care. Using the concept of matters of care in a study can make caring visible and can generate care. Matters of care connect us to the object of study and challenge the critical distance so typical of scholarly work (Puig de la Bellacasa 2011). By re-affecting objects, thinking about matters of care instead of matters of fact or matters of concern, I study what is cared for when it comes to the enactment of sustainability while also caring for the objects of study. This makes it possible for me as researcher to think with different tools, to focus on care and emotions in addition to being aware of my responsibilities for the outcomes of the study.

However, care does not always imply something positive; sometimes we have to care by killing (c.f Law 2010), and, furthermore, caring for the self can be as important as caring for others (c.f. Foucault 1988; Law 2010; Singleton 2012). Law explains how 
veterinarians during the outbreak of foot and mouth disease in 2001 cared for several aspects/objects: animals, farmers and themselves (Law 2010). It was important for the veterinarians to be able to care for the animals and the farmers, while not caring too much, since that could leave them immobilized by pain.

Care, here, is about responding, but not responding too much. It is about being there, about sensitivity, and yet it is also about distance. It is precisely about self-protection (Law 2010, p. 64).

Related to my case, I am interested in how HygieneTech care for sustainability without losing their self-protection. By thinking with care, I study how HygieneTech care - for their customers, the environment and the employees. In relation to matters of care I study how the employees at HygieneTech care for the self as well as many different matters, and in some situations, sustainability is important. By using the notion of care and matters of care, I can understand how the actors value actions and consequences in relation to sustainability. In thinking of matters of care, I can find the matters that are brought up as important and also find those that are made absent. This helps me to understand how sustainability is enacted through care and how borders are drawn to delineate what is sustainable and what not is sustainable.

Furthermore, several researchers within STS have studied care practices in different ways, and often, but not always, the empirical field has been within health care (e.g. Mol 2002; Mol, Moser \& Pols 2010). An example of a study outside of health care is Frank Heuts and Annemarie Mol's use of care in a study investigating how good tomatoes are valued (Heuts \& Mol 2013). For them, care is a way to understand the ambition to create the good tomato through respectful tinkering for improvements.

The term "care" suggests enduring work that seeks improvement but does not necessarily succeed. It also implies that the object of improvement should not be overpowered, but respected. Respect does not depend on leaving things and situations as they are. Hence we called the work that our informants invest in achieving "good tomatoes" care (Heuts \& Mol 2013 p. 141).

"Tinkering" is about adaptation, about improving the current state and being flexible regarding others' concerns. Tinkering can also include concrete advice or norms and the trials and errors to include them in our daily life (Asdal 2014). In my study, I analyse tinkering in situations when different matters of care clash, such as when a standard urges the employees to work with issues that they do not find important. In these situations, employees need to tinker with the practices to care for the standard on a more general level while still caring for the matters that are important in their local practices. 
Thinking with care comes with possibilities of new ways of approaching corporate sustainability, but it also comes with challenges. As I have pointed out, care is not only about affection, it is about practice. Michael Fine (Fine 2007) argues that care is deeply philosophical and at the same time experienced as a basic everyday activity and as a common attitude concerning all manner of things that people value, and this makes care hard to define. However, I will not attempt to define care beyond providing the reader with this framing of care as it applies in this thesis, where it is considered as practice, both affective and corporeal. Critics of Mol et al.'s work in the book Care in Practice (2010) argue that if care can be found anywhere and is not defined, care can appear more as a style than a practice (Mol, Moser et al. 2011). However, in line with Mol, Moser and Pols (2010), I do not think that a definition of care will be helpful in understanding care practices; instead, Mol, Moser and Pols ask for curiosity. "We would have killed our curiosity if we had defined it [care] before going out in our various fields" (Mol, Moser et al. 2011, p. 85). I do not aim to define care; instead, I show what I have learned about care through my study. By studying sustainability as care practice, we learn about care as situated action and how sustainability as care for different matters is enacted.

\section{Studying sustainability as care practices: The theoretical approach}

Following actor network theory, I look for the actors that have a voice in the network of making sustainability. By doing this I can understand who has power over decisions and what matters are considered to be important in HygieneTech's sustainability work. Thinking with different versions of sustainability will help me distinguish how sustainability is done differently in different situations and how these versions are connected to practices. This approach tells stories of the things that are done and of the matters and actors that are made present. However, I do not believe that this is sufficient in order to give the reader a reflective analysis of what is at stake in these situations. Consequently, I add the concept of care to my analysis and in addition I study what is made absent. Not everything that has an impact on a situation can be made present at every point in time since everything is made in a web of relations. Following the actors will show what is made present, but in addition I also show what is made absent. What is made absent can be just as interesting as what has a voice in the socio-material network of HygieneTech's sustainability work.

Studying practices of sustainability will, in accordance with my theoretical standpoint, also include studying what is being cared for - what matters of care (Puig de la Bellacasa 2011) are made important. In sustainability work there is a lot of caring going on; Bosse cares for his employees, Therese cares for following the ISO standard 
and Wilma, the CEO, cares about water. Like Mol, Moser and Pols (2010), I believe that care practices need to be highlighted more, otherwise they risk being squeezed out. But how does one study care practices?

Following the theoretical standpoints argued in this chapter, care is done through practice. Caring practices are done rather than known and they are not always made explicit (Singleton 2012). I therefore need to study the practices where something is cared for, made important, both verbally and in actions. Following the symmetrical approach to actors advised by ANT, both humans and non-humans can enact care. Humans, cars, dishwashers and other actors can enact the care for different versions of sustainability. There are many ways to do care, such as tinkering for the perfect tomato or tending to the sick. Enacting care can be done by talking about something as valuable or acting to enhance, protect, cherish or improve a certain matter; care is actions done to improve the world. We can never fully know the intentions behind actions or statements, and in this study the intentions are not in focus. Even if we do not know the intention, caring can be done in practice and be analysed as care in different ways.

I do not want to say that everything can be interpreted as care, nor am I trying to define care as a finite concept. Instead, I argue that there is a lot of care going on all the time, but I am only interested in care connected to practices that enact sustainability. This care might look very different in different situations. I have looked for enactments that I have interpreted as care for sustainability by studying how things are made present and absent when the employees enact sustainability. Matters that are made present in a positive way are cared for, while the issues that are excluded receive less care. I study how versions of sustainability enact different matters of care, how these versions can coexist and when they clash and thus discuss how different matters of care are prioritized. One such practice has to do with privileging some versions of sustainability over other versions or over other matters of care. Different matters of care are sometimes in opposition with each other, which makes it hard to care for the matters at same time. The employees at HygieneTech cannot care for the most efficient logistics for the sellers' workday and at the same time encourage the sellers to meet for social gatherings during lunch. The social value of a group lunch is not compatible with the most efficient logistics for all the sellers, which means that matters of care collide, and there is a cost involved in caring for the environment (through logistics) and caring for the social gathering during lunch. By analysing care in this way, I do not define or draw borders to what care is, but I can study when there is a struggle between matters of care, when there are different care actions wanting to take place at the same time. 
In other situations, such as when labelling products, care is done quite easily since this care fits nicely with the matters that are important in the organization of HygieneTech. I also study care practices by investigating how objects are made present or absent (Law 2004). I thus look at what is made present, tinkered with, and therefore cared for, in meetings and training sessions. In these situations, certain matters are made more important than others are. In seeking to understand what versions of sustainability are privileged, I want to understand how choices are made regarding which matter of care is made most important in enactments of sustainability and which matters are made absent.

\section{Methodological choices to study practice}

To be able to study versions of sustainability, a researcher needs to understand the set of practices that are connected to these version since when trying to understand how realities are enacted, practices are the key (Law 2004). Mol suggests that the best ways to study practices are through what she calls praxiography (Mol 2002). The praxiologist searches for thick descriptions and tries to find out how objects are enacted through practices. For this study, it means that I write about the worlds of sustainability and thus let you get to know my informants. It is important to understand the research object in its local setting, and through the tools and bodies that are connected to it. The praxiologist believes that to study what an object is means to look for how the object is situated and related.

To be is to be related. [italics in original] The new talk about what is, does not bracket the practicalities involved in enacting reality. It keeps them present (Mol 2002 p. 54).

To study practices inspired by Mol's praxiography thus means that I will study relations of sustainability and focus on the materialities and localities that are connected to sustainability. Some of these practices take place in meetings while other practices are done in cars or in restaurants.

Practices of sustainability are claimed by HygieneTech to be everywhere in the organization, and I have tried to follow the traits of sustainability whenever I found them. I have chosen to study the practices of sustainability through participant observations and interviews and by studying documents. In 2012 I started doing interviews with the members of the sustainability group and other employees. I also observed sustainability meetings and other types of meetings and followed a few sellers through some of their workdays during 2012 and 2013. The meetings and training sessions I attended were chosen for their potential to contribute to my 
understanding of the structure of HygieneTech and where decisions on sustainability were taken. I tried to follow sustainability as it travelled in the organization while I also let recommendations from the employees guide my choices of observation sites at some times.

\section{Participant observation}

Participant observation entails active observing, listening and talking and is often understood as including all method practices called qualitative (Ely \& Anzyl 1993). However, in this first section I will discuss the part of my method that focuses on my presence in the field while observing people at work, during meetings and also outside meetings. In this thesis, I broaden the understanding of the concept sustainability and show how it is done in practice. Due to its richness and grounded approach, observations are a useful method in achieving empirical material that can be used to challenge conventional knowledge (Alvesson \& Kärreman 2011). By turning to practice, we can avoid assuming that there is a grounding order and instead view orders as generated by practice (Law \& Lien 2013). Studying practices through observations made it possible to understand what the actors enact as sustainability in the course of a typical workday. Being an observer while still participating in the conversations to some degree is a method called participant observation. As a researcher, I do not aim to fully participate in the events, nor do I become a member of the studied collective; instead, I take the role of an observer, systematically studying and keeping records to that end (Spradley \& Baker 1980). Through observing meetings and the sellers' workdays, I have studied employees' everyday habits and activities. I have observed what issues are seen as important and acted upon and also which questions are silenced and made absent. During observations I have tried to keep a notebook close by, and whenever I had an opportunity I took notes of our doings and the places we went to.

I attended five sustainability meetings (they had about four each year), two management team meetings and several smaller meetings revolving around issues such as sustainability reporting, inventory problems and lean production. Furthermore, I attended a product development meeting and took part in three all-day training sessions for sellers - one of the days concerned cleaning products and the other two focused on sales techniques. In 2014 I also had a meeting with the new sustainability manager who succeeded Therese to present my study and discuss how to handle HygieneTech's engagement in the last parts of this study.

Some of the meetings were short, spontaneous meetings between two employees, while the management team meetings were six hours long and involved up to 10 employees. During these meetings I mostly remained quiet but participated when I was asked questions, and I was always introduced to the new employees as a student 
looking at HygieneTech's sustainability work. I have studied how the employees talk about sustainability by looking at what issues were brought up in conversations connected to sustainability. I brought my laptop with me to all meetings and wrote down the conversations and events as fast as I could. After the meetings I ran spell checks and added supplementary notes if there were things that I did not have time to write down during the meetings. These could include such things as tension between two of the participants or people constantly checking their smartphones and thus not showing interest in the discussed issues. Even though I did not have time to write down every word and statement during the meetings, I soon got an understanding of the participants and their ways of talking. I focused on learning their ways of talking and identifying their languages (Spradley \& Baker 1980). I tried to catch the important discussions, and when I got used to the way the respondents talked I tried to use their vocabulary when I did not have time to write down everything verbatim.

The practices studied at meetings have granted me information about how sustainability is enacted through discussions and decision-making. By following meetings, I have, among other things, learned what issues employees at HygieneTech talk about, who gets to be spokesperson for different agendas, what issues are seen as important and how decisions are made. By attending meetings, I understood what they counted as sustainability issues and I could follow up on the consequences and on discussions about work that was done by employees between the meetings. In HygieneTech, many of the activities that were named sustainability first took place at meetings and were then implemented in other parts of the organization. For example, the issue of whether or not the company was to sell imported products which they could not label with environmental labels was first raised in a product development meeting. This issue was then taken care of by the sustainability manager and a product manager, who developed a test for when a product needed to be taken up for discussion at board meetings.

Besides studying meetings, I have followed four sellers during a normal workday and spend a lot of time at the head office. Studying the practices outside meetings has provided me with empirical material covering how sustainability is enacted in the daily work of the employees at the head office and in the sellers' work outside the office. When I accompanied the sellers, I helped with carrying boxes when I could, but mostly I followed in the sellers' footsteps and tried to understand what they were doing. I was able to witness what practices were labelled as sustainable and what ones were seen as unsustainable. I asked the sellers about their practices in order to understand their workdays and how sustainability was enacted during them. Through these observations I have been able to understand how certain practices are connected to sustainability and how they are cared for by different actors. This has given me 
insight into what actors are enrolled in the enactment of different versions of sustainability.

Even though the company had a friendly and welcoming environment, there were many situations, especially in the beginning, when I felt out of place or in the way. To overcome this sensation of being an outsider, I tried to make time to just be around the company and get to know the company's environment. At every visit to HygieneTech, I made time to sit in the waiting lounge, the coffee room or an office in order to get to know the company better and for them to get to know me. I made sure to have plenty of time to be around and talk to people during lunch breaks or when I was waiting for my train. I have also kept a research diary on my thoughts about everything that has to do with my study. After all my visits to HygieneTech, I have taken time to write down a summary of the activities I had been a part of.

All in all, I have spent approximately 150 hours talking to employees at HygieneTech. Spending a long time in the field is a way to gain a better understanding of the studied phenomena and thus validate the data (Creswell \& Miller 2000). After visiting HygieneTech on and off for two years, I started to feel at home. People recognized me and I no longer had to report at reception when I came to visit the company. Some employees also believed that I was employed by the company since I seemed to be around quite often. At this point, I felt that I had an understanding of the work done at HygieneTech and that the studied themes repeated themselves during my visits. The feelings of completion and redundancy can be used as indicators that it is time to leave the field (Ely \& Anzyl 1993). I felt that I now could tell HygieneTech's story of sustainability and, supported by feedback from my midway seminar, I instead turned to writing.

\section{Interviews}

In addition to observing meetings and everyday practices, I have chosen to also work with interviews in order to get access to the way the employees talk about sustainability outside their usual setting. Interviews is a good complement to observations since it adds comments, fantasy and clues as to what is not being directly manifested in actions (Alvesson \& Kärreman 2011). The distinctive character of the interview situation can bring about new discussions that would not have occurred otherwise, thus insights from such specific situation can instead be seen as an asset (Hammersley \& Atkinson 2007). Interviews have not been a way for me to get access to the employees' thoughts or hidden values; instead, I am interested in the enactments that take place during the interviews. I view an interview situation as a way for two people to, together, seek knowledge in a common conversational endeavour (Czarniawska 2004). Interviews will show how the employees enact sustainability through talking about sustainability with me, but I will also discuss the practices they 
describe during the interviews, such as decisions taken in different meetings. Thus, "An interview is not a window on social reality but it is a part, a sample of that reality" (Czarniawska 2004, p. 49). Interviews can tell about the practices of labelling actions with sustainability and how employees care for versions of sustainability in this situation. The interview can show how they enact sustainability and invite us to take part in the making of their realities.

I did 14 interviews with employees at HygieneTech during my years in the field. The interview subjects were chosen from their engagement in the company's sustainability work. I interviewed all the participants in the sustainability meeting (10 interviews) and other employees that repeatedly came up in discussions about sustainability. The interviewed employees outside the sustainability group were the owner of HygieneTech, a region manager, the manager for Spotless Production, and the manager for the international part of Clean Hygiene. I have also asked the sellers similar questions during my observations but due to the unstructured nature of those conversations I have treated them as observations rather than interviews. I also asked the employees after the interview if they had any suggestions on who I should talk to next. Most of the interviews took place at the very beginning of my stay at HygieneTech, providing me with an overview of the way the employees talked about sustainability and providing information about what places and practices they connected to sustainability. From this information together with information gathered from the early observations, I chose new field sites for my observations.

The interviews were semi-structured, which means that, beforehand, I decided on the themes to be discussed but then I asked follow-up questions during the interview based on how the situation developed. I followed different interview guides for all the different employees. Even though I let the questions on paper guide the interviews, I made room for follow-up questions and for development in different directions. This method allows for elaboration from both the perspective of the interviewee and the interviewer and aims to facilitate conversation (Aspers 2007; Hammersley \& Atkinson 2007). During the interviews, I allowed for silences when I felt that a subject had not been emptied and thus allowed the interviewee to think and add more information (Kvale 1997). This proved to be a productive way of providing the interviewee with room to expand on the subject.

During the interviews, I started with introductory questions about the interviewee's role at the company, how long ago they had been hired and what their responsibilities are. The next questions mostly centred on their everyday practices, but I also included more open and visionary questions, for example, about what sustainability means to them, how they see their own role in the making of sustainability and how and why HygieneTech are so active in working with sustainability. The questions were mostly 
about practices of doing sustainability in relation to the respondents as members of the sustainability group or in relation to their professional role. I adapted the interview guides to suit the different roles of the employees, thus asking the CEO more about decisions on meetings and visions and asking the region manager more questions about his role in working with sustainability in relation to his appointed sellers. The understanding sustainability as enacted though different sets of practices and devices (cf. Mol 2002) is the reason for changing the interview guide. By tweaking the guide to focus on the employee's work tasks and responsibilities in relation to sustainability, I could understand how dishwashers, standards as well as other entities or processes took part in enacting sustainability.

All the interviewees have been informed about the aim of the study and that their names are anonymized in the thesis. All interviews but one were audio recorded; during the interview with the CFO the dictaphone stopped recording. The interviews have been transcribed approximately word for word, and since I took notes from all interviews, I was also able to recover the most important information from the interview that was not recorded. Some interviews took almost two hours, while most lasted around an hour and a half.

\section{Studying documents}

Documents are often central in the making of "facts" or "rules" (Hammersley \& Atkinson 2007) and studying how sustainability is enacted in text is important as a complement to observations and interviews. By showing in a report how much is done in the name of sustainability, HygieneTech establishes themselves as a sustainable company. The paperwork tells different stories of what sustainability is all about and what ought to be done. By following how paperwork is translated in HygieneTech I show important versions of sustainability that come to life in reports and ISO 26000 documents. In the case of ISO 26000 , I study the translations of the standard, from its general format to its translation into practices. This is done by following the standard from the first evaluation reports conducted by a consultant firm to the implementation of the action plan.

Texts and documents are not representations of an objective reality, they are more than that (Lynch \& Woolgar 1990)! They are important in showing us the story of the situations and networks in which they are inscribed. For sustainability at HygieneTech, documents are central in annual sustainability reporting and policy development processes. Documents can show the practices of marketing HygieneTech as a sustainable company and they can tell us about how standards are used to enact sustainability. STS have a background in ethnography and observations and have focused on both human and non-human actors. The non-human actors have traditionally been technological artefacts, but documents have also been an important 
part of the history of STS. Latour and Woolgar's study of a laboratory is often seen as the start of STS, and this study included documents (articles) that played an important part in making scientific facts (Latour \& Woolgar 1986). Furthermore, STS researchers have had an interest in how representations such as images, texts and tables create science (Lynch and Woolgar 1990):

Even for "highly realistic" diagrams and photographs, it does not do justice to the pragmatic and conventional features of these representational devices simply to describe the things that they depict or the meanings they reflect. Such a naturalistic reading contravenes the basic policy of "anthropological strangeness" which informs our understanding of scientific representations. This policy requires us to put aside the view of representation as transparent images of objects and ideas, and to pay extraordinary attention to the distinctive surfaces upon which representations are inscribed and the translations they undergo when transferred from one activity to another (Lynch and Woolgar 1990, p. viii).

The paperwork was gathered during my visits at HygieneTech. The gathering of material was done without selection; every potentially relevant piece of paper that crossed my path found a new home on my desk. However, not all documents were all that concerned with sustainability. Price lists, educational information and product catalogues cared more for information about the products and services that HygieneTech offered. In these documents sustainability was just mentioned as information about the vision of HygieneTech - to be the best hygiene and environmental partner for the customer. Other documents, such as the sustainability report and the action plan following ISO 26000, were more focused on what HygieneTech did in the name of sustainability. Many of the documents produced in an organization are entangled in each other. In HygieneTech, the policies are created to live up to the demands of the ISO standard, and the ISO standard is included in annual reports.

In this thesis, I include the individual annual reports for Clean Hygiene, HygieneTech and Spotless Production, the environmental report and the sustainability report for Clean Hygiene, the first GAP report on ISO 26000, the follow-up GAP report on ISO 26000 and the action plan for sustainability. These documents are interesting since they show how sustainability is enacted in the writings in HygieneTech. There are of course many more documents that would have been interesting to examine, but I have restricted myself to covering a few documents to be able to give the reader a few of the enactments of sustainability as paperwork. I have not chosen to look specifically at marketing, for example the company's home page, since some of the analysed material 
is also used in marketing. The chosen documents are presentations of how sustainability is done in documents, and by following them we can understand translations of sustainability in text.

\section{Building a case}

In order to study the corporate practices of sustainability I searched for a company where these practices existed and were easily located. The decision to look for a medium-sized company was guided by the facts that large companies are better studied (Hillary 2004) and that smaller companies face interesting challenges due to its very limited resources to work with sustainability. The medium-sized company is often expected to act somewhat like larger companies when it comes to sustainability issues. This is seen, for example, in the European Commission's attempts to encourage SMEs to engage in their corporate responsibility in the same way as larger companies do (European Commission 2011). Since all employees are more familiar with each other in a smaller company than in large companies, I hoped that the smaller company might be more open to letting researchers take part in more activities and that the employees would learn to trust the researcher. I thus chose a medium-sized company for this study since it would most likely give me opportunities to study sustainability activities while still being able, as a researcher, to build up trust with the employees.

Finding a suitable company for my study was not as easy as I expected. A subject for a case study should be chosen chosen with the research questions in mind (Yin 2003). Thus, I started looking for companies that actively worked with sustainability in order to study the enactment of sustainability. I asked everyone I could think of who might be able to suggest medium-sized companies they thought worked well with sustainable development issues. I talked to local business organizations and management consultants that I met through my contacts within energy research, I sent emails to people who wrote opinion articles about corporate sustainability, and I asked people at a corporate sustainability meeting for suitable companies. In a different project, I interviewed employees at companies that worked with energy efficiency issues and tried to find companies that had environmental and sustainability issues high on their agenda. I ended up with two companies that were mentioned several times and I contacted them for initial interviews. The first company was indeed working with sustainability and they seemed to have a CEO who was passionate about environmental concerns and who was very important for the sustainability work at the company. However, I wanted to study an organization where the interest in sustainability was not so tightly connected to a single person, and after my first interview with HygieneTech, I chose to make them my object of study. Employees at HygieneTech seemed to be open to letting me take part in their workdays and the fact 
that their sustainability work seemed very ambitious and distributed though out the organization affected the choice positively.

Most of the time, access to my field did not pose any problems. Initially, Wilma (CEO) and Therese (sustainability manager) were positive about my being at HygieneTech, taking part in their everyday life and observing their meetings. Their attitudes opened doors, and Therese in particular was a "gatekeeper" (Hammersley \& Atkinson 2007) who had access to key resources and helped me throughout the process. Therese helped me get in contact with possible respondents and talk to people that she believed I should interview. This most likely made them more open to being interviewed or observed. The fact that I chose HygieneTech due to their successful sustainability reputation probably also contributed to their openness. Additionally, in referring to its sustainability work HygieneTech state that they are a transparent company, and this might explain why I was so readily allowed access to study the company. However, sometimes I had trouble getting in contact with some employees for interviews or to grant me access to certain sites. The main reasons people did not answer my mails or were hesitant to agree to an interview seemed to be shortage of time and that they felt confused about how they could contribute to my study. Even though employees at HygieneTech were always positive about my presence, there were times when I felt that they would have preferred that I was not listening. After observing and interviewing them for 10 months, I visited a management meeting, and in the middle of this meeting they took a break and asked me to sign a confidentiality agreement. The questions that they felt were sensitive at this and two other meetings did not have relevance for my thesis subject and will not be part of this text.

All respondents were informed that I was studying their sustainability work and I was always introduced as a researcher at meetings and training sessions. However, the employees at HygieneTech were not personally asked to consent to take part in my study. Since Wilma, the CEO, permitted me to study HygieneTech, the employees accepted my presence at meetings and observations. Since I will not use their real names and made all citations anonymous, I hope that none of my respondents will feel that they have been treated unfairly in my study. The first plan was for Therese, the sustainability manager, to read and give input to the text in the final stages of writing. However, in early autumn 2014, she told me that she was leaving HygieneTech and therefore we arranged that I would present my preliminary results at a breakfast meeting for all interested employees at the head office. After the open meeting, I had a shorter meeting with Therese in which we discussed some of my findings and she told me that the next sustainability manager would be responsible for reading the thesis later on. However, I met with the sustainability manager replacing Therese, but after less than a year, she also left HygieneTech. Instead, Markus, the marketing manager, was my new appointed contact. After my final seminar in November 2014, I sent my 
manuscript to Markus and ask him for comments. He responded in a positive way and encouraged me to continue finalizing the thesis.

\section{Handling the material and creating caring text}

The text in this chapter is shaped in different ways with several matters of care in mind. It ought to be a scientific text that is easily understood and that takes seriously the concerns of the community that I have studied. The work behind the finished text is a messy process of turning and twisting questions and matters inside out. To make this process more structured I have used a computer program called NVivo. All my written notes from observations and transcripts from interviews were imported into this coding program. In this program I coded all material according to certain principles. At first I used initial coding principles (Saldana 2009), which means that I tried to find themes in my material while still staying open to different interpretations of the data. The most important part for me at this stage was to find different themes and try to understand the processes of HygieneTech. I looked for processes that mattered in my data, where the participants' actions created consequences connected to sustainability. During this process, I also found concepts that created connections between different settings. I focused on the network in which sustainability was done in order to understand who the important actors were. Furthermore, I kept my ANT approach alive during the coding, making sure that material actors were given an equal place in the coding practices.

After coding my empirical material, I had 117 themes, or nodes as they are called in NVivo, which I turned into broader themes in a second cycle of coding. After the first cycle of coding, I used simultaneous coding, coding both more general themes and small subthemes simultaneously. This type of coding is most effectively used when a segment is both descriptively and inferentially meaningful (Saldana 2009). This way of coding makes it possible for a researcher to make different connections to several overall themes in a less structured way than other more hierarchal coding styles. Differentiation and merging of codes is important in structuring the material (Aspers 2007), and after several cycles of thematizations, I found some broader themes that could be traced throughout my material. The themes that were often made present when sustainability was discussed came to be important for the structure of the analysis. I took note of the different ways sustainability was enacted in my fieldwork texts in NVivo, and through the nodes I tried to find similarities and differences in the different enactments of sustainability. Any analytical ideas that came up during coding were written down in analytical memos in NVivo and then coded in the same way as the other material. Writing analytical memos during coding is a way to reflect on the ethnographic material and start the writing process (Saldana 2009). The broader themes were selected through the stories that I found surprising or absurd, that spoke 
of some tension between the employees or situations where they expressed that they were talking about (or doing) sustainability. Some of the broader concepts came to be influential in guiding my empirical chapters while others will appear later on in the analysis.

Since all observations, interviews and documents were in Swedish, I have translated all quotes in this thesis to English. I have tried to translate the meaning of the statements from the fieldwork and have added explanatory text and corrected some grammar in order to make the texts more readable. I have always kept the speaker in my mind when writing their words, trying to create the right tone of voice. This has been especially important where I wrote down conversations that took place during meetings or other observations that were not recorded. Even though I have not been able to use the exact words spoken, I have had a sense of the person and thus been able to choose a voice that both presents the speaker and brings forward the message of the statement.

Furthermore, I have written my empirical chapters as layers of doing sustainability, telling stories of how sustainability is enacted in different situations and places. Watts (2007) looks at technoscientific knowledge as weaving while wandering through places. In our wandering through these different stories, and by storytelling, we can weave together worlds and create new futures. Consequently, knowledge making is more storytelling than stories themselves (Watts 2007). Viewing storytelling as knowledge making comes with responsibilities for the futures we write about. Ethnographic stories re-represent worlds and thus the researcher has to make stories in ways that are generative for the people and practices the stories are about (Winthereik and Verran 2012). Stories are agential since they make and work relations and can thus be tools for writing futures we care for. Storytelling is always about choices, foregrounding some things while make others invisible.

As a unified text, a narrative, it exemplifies and enacts a particular time and place (condensing it as a here-now). As indexes they foreground, background, and render some things out of the frame (Winthereik \& Verran 2012, p. 40).

Storytelling is thus about making relations and it is a way to care for some futures more than others. Thinking with care through storytelling will give me the opportunity to care for my study object. For me, corporate sustainability is an important matter of care. Caring for this matter is what made me choose to do this study in the first place. Acknowledging that any actor can be written in or out of the stories in different ways provides an opportunity for researchers to take responsibility for their stories 
(Winthereik and Verran 2012). Writing different stories and making different futures (Watts 2007) is my way to enact care for a matter, a better common future.

Law advocates that everything Mol says about the multiplicity of the body also applies to organizations (Law 2004). Organizations consist of multiple patterning, multiple versions of repetitions and ordering. Organizations are a gathering of different realities and Law sees managers in organizations as consummate allegorists. Law also plays with the thought that organizations in themselves are about holding things together that are not strongly consistent. He argues that good organizational science is:

... studies in allegories that depict and manifest realities that achieve allegorical gathering rather than a single-version discursive consistency. Fractionally (Law 2004, p. 113).

In this thesis, I paint pictures, tell allegories, of how the employees at HygieneTech together with me as a researcher are creating realities and enacting sustainability. In order to achieve this I have chosen to start all empirical chapters with a vignette, a telling picture or a citation, and I aim to give the reader a description of the studied situations. Many chapters are built on short abstracts of conversations, and by letting the actors in my field speak I aim to let you get to know them and let them tell the stories. These texts are not fiction, nor are they the truth. I use these short narratives to show the fractionality of the organization and invite you to get to know some of the realities of the employees of HygieneTech the way that I experienced and analyzed them.

The stories that I tell in this thesis are structured with several purposes in mind. The ANT approach made me interested in artefacts and some of these could tell stories that showed how sustainability was cared for. Water was a recurring theme in HygieneTech's sustainability work and by following the connection between water and sustainability, several care practices became visible. Likewise, the two GAP reports and the action plan was highly visible in the work done in the sustainability group, and they could therefore serve as storylines for a chapter. Even though paperwork and water could tell interesting stories of sustainability practices, the chemical products are in the centre at HygieneTech. Therefore, the first empirical chapter discusses the relationship between chemical products and enactments of sustainability. Some of the stories in this thesis were easy to tell, others have been harder to put in words and plenty are the tales that never made it to the table of contents. The stories left out were discarded for different reasons, some for their lack of connection to the study object, others due to overlap with stories already told and a few due to concern for the employees at HygieneTech. I have avoided describing events that could put 
individuals in problematic situations or make their identity apparent for a wider audience.

\section{Concluding methodology: Creating stories, telling science}

“So why aren't you eating meat?" Erik asked me during a business lunch at a rather fancy restaurant by the sea.

"Well, for several reasons..." I responded and hesitated over whether or not I should let this conversation take this direction. Then continued, "I don't like the way we treat animals as products, goods that just need to be produced as efficiently as possible and not caring about what a natural life would look like for them. But more importantly, I avoid meat for environmental reasons. I actually recently read a study that showed that meat production produces more carbon emissions than all the transport in the world."

This story did not end with just making conversation over lunch. Erik asked me to send him the study I referred to, and so I did. We came to discuss carbon emissions over email and I think these conversations did affect his view on carbon emissions and meat production in some way. I believe this to be a good example of how this study was made, but also what it created, and that is why I have taken some time to tell you about our lunch table discussions. The making of this study and the enactment of HygieneTech go hand in hand, and even if I can only speculate on the outcome of my being at HygieneTech, walking their corridors, making small talk with employees beside the coffee machine, and telling their stories, I consider it as an important part of this chapter. I am aware of my own presence in my thesis and I believe the researcher influences the empirical data no matter which method is chosen. Instead of trying to find the result "out there" we as researchers have to take responsibility for our interpretations of the practices that we study, since we too make realities. To approach my study with this awareness I have chosen to turn to actor network theory for guidance. ANT is not a theory that can be applied to empirical material; instead, ANT explains how the different actors, both human and non-human, make up the network that creates the reality we experience. In this thesis, I cannot give you the whole story about HygieneTech, as there is none, but I will present one version which explores sustainability in manifold ways. By doing this, I can tell stories of HygieneTech that I think the employees at the company will agree upon.

This chapter has explained the methodology behind this thesis. By starting with theory, I have introduced the ontological and epistemological standpoints from which choices regarding data collection and empirical approaches were made. Theory is not only an 
analytical tool; it is about making choices and creating science (c.f. Law 2004; Mol 1999). With actor network theory as a starting point, I have explained my view on ontology and how this guided my choice of methods as well as my presentation style. In order to study the different versions of sustainability I have studied the practices associated with sustainability and what is made absent in sustainability work at HygieneTech. I have also chosen to study matters of care since this can show what is important to the actors in enacting sustainability and how this affects their actions.

I have approached my case by studying documents concerning sustainability in order to understand how sustainability is made on paper. I have also done interviews with employees and asked them about what sustainability is and whether and how HygieneTech is a sustainable company. However, most of my empirical material comes from observations of meetings, training sessions and the employees' everyday lives. I followed four sellers during their workday and got to meet some of their customers. The combination of interviews, observations and document studies have been a fruitful method in understanding the enactment of sustainability at HygieneTech. It has allowed for knowledge about the most important settings where sustainability is enacted and provided me with different types of empiric material. The materials has told slightly different stories and given voice to a number of actors in the network where sustainability is done. By interviewing employees at the head office and observing their meetings and other practices, I have been able to study what they enact as sustainability and understand the many regulated processes of standards and labels. Following sellers has generated understandings of how sustainability is (or is not) part of their workday, thus showing other sides of doing sustainability. In addition, studying documents has told yet another story of how sustainability is done, both as part of internal processes as well as a way to profile HygieneTech. The empirical material has been transcribed and coded using coding software, NVivo. I have thematized the findings in several cycles and used my theoretical concepts to analyse the material in accordance with my research questions.

In this thesis, I present my findings using quotes and storytelling in order to show multifold ways of enacting sustainability at HygieneTech. The choices in presentation are made with care, since it not only creates relationships but also fosters isolation. We cannot possibly care for everything and therefore we make cuts.

However, thinking with care compels us to look at thinking and knowing from the perspective of how our cuts foster relationships, more than how they isolate figures. [...] That is, we can draw attention to how "new" patterns inherit from a web of relationalities that contributed to make them possible (Puig de Bellacasa 2012, p. 204). 
Relations have consequences since beings do not exist before their relations. Through thinking with care, I aim to make a difference in worlds I care about. This is done by studying sustainability, a matter of care for me, and by telling stories that I believe will contribute to a better common future. With the stories I aim to contribute to our understanding of sustainability and through thinking with care I can do ontological politics (Mol 1999) in this thesis. Mol argues that since realities are done through practices and conditions of possibility, they are not fixed but can be changed. Consequently, I can change the realities I touch upon with my writing, participant observations and the outcome of this thesis. I am therefore responsible for the consequences that my texts might have on the world, both for the people that I have studied and for the society. Doing this thesis has thus entailed thinking with care, both for the society and for the people at HygieneTech.

Care for the surrounding society is done in several ways in this thesis. For one, if we do not study care, it risks being made invisible (Mol, Moser \& Pols 2010). In this study I highlight this important notion/concept which I believe makes care more present in both academic and corporate settings. Furthermore, it is my hope that the knowledge in this thesis will contribute to creating a better world and more caring relationships. This brings me to the issue of generalizability of the study. Just as Barbara Czarniawska (Czarniawska 2004) argues that the interview is not a window to a social reality, but a part of one, I believe this study brings about a range of different realities. The realities in which we take part in this book cannot be considered representative for all companies, regardless of size, location or business idea. They can, however, tell about these studied realities and inspire to new questions.

Good case studies inspire theory, shape ideas and shift conceptions. They do not lead to conclusions that are universally valid, but neither do they claim to do so. Instead, the lessons learned are quite specific. If one immerses oneself long enough in a case, one might get a sense of what is acceptable, desirable or called for in a particular setting. [...] It [the case study] offers points of contrast, comparison or reference for other sites and situations. It does not tell us what to expect - or to do - anywhere else, but it does suggest pertinent questions. Case studies increase our sensitivity (Mol 2008, p. 10-11).

This study is a case of caring for sustainability, and even though the study cannot be generalized for other companies, we can learn about the practices of caring for corporate sustainability through this window. Furthermore, this study tells caring stories and thus brings about new issues and points of reference. 


\section{3}

\section{The hinterland of sustainability at HygieneTech}

Following the methodology in this thesis, realities don't just exist - they are always in the making. Some classes of reality are easily produced while others are harder to cobble together. A hinterland is a geography to think within; it determines what possibilities are made thinkable and real (Law 2004). The hinterland of sustainability at HygieneTech comprises the paths that make certain things possible in the making of the sustainable company. In this chapter, I introduce you to the people and materialities that I have studied in HygieneTech. I present some of the employees and their working groups as well as the structure of the company. In order for you to get to know them, I also show you the process by which HygieneTech provides services, and cleanliness, to their customers. The core activity of HygieneTech is producing and delivering products to their customers, and I explain how they do so. The hinterland of sustainability at HygieneTech is much more than an organizational map, it is the bundle of realities that create an ontological logic. Bear with me for a while; the sustainability of HygieneTech will soon become visible in our journey through the processes of producing, packaging and delivering cleanliness. Let's start from the beginning!

It all started with Bosse, a man brought up in the deep forests of Småland in Sweden. His father worked with milk hygiene and, according to Bosse, his family lived by sustainable principles. To be sustainable in this setting was "to use as few resources as possible”, and this mindset later came to characterize Bosse's business approach as well. Early in his career Bosse worked at a company that produced hygiene products, and the extensive use of harmful chemicals worried him. Eventually he started making his own mixture, with less polluting detergents, in his own garage. This resulted in a business that produced environmentally friendly detergents, which were delivered directly to the customers. Today, Bosse's company is seen as a success, an example of 
how to combine entrepreneurship with environmental concerns. I will let Bosse tell his story of how his concern for sustainability created this company.

Bosse and I are seated at the long table in one of the conference rooms on the ground floor at the head office. After my first interviews with Therese and Wilma, they suggested that I talk to Bosse since it is because of him that the company works with sustainability. His vision of sustainability as resource management became a guiding principle at the company and continues to be, even though he is long retired from the position as Chief Executive Officer (CEO). Bosse is a very energetic person, and during our conversation he jumps from one subject to the other, which makes it challenging to interview him.

Maria Tell me about the history of the company!

Bosse You know, I belong to the generation that lived when we had few resources, when it was real sustainability. I was born in 1940 and I remember well, I lived on a farm and we walked and collected milk in milk pails that we cleaned. My father's job on the side was milk hygiene. You know, our mattresses were made with straw, and we gathered everything we could - nothing was to be wasted! We had an outhouse as well. My parents were... sustainable. [...] Another perspective on this with environmental work, as we called some years ago, I mean that was not strange for me. I could see that we saved money with it. A lot of people wanted to be environmentally friendly and wanted to buy things that were environmentally friendly. When I started the company it was called environmental friendliness; when I was growing up it was called saving. And now we are back after 60 years and it is called sustainability. And our sustainability work turned out to be very good marketing. It became crucial for our brand - it built our brand.

Maria So the environmental friendliness was already in place when the company was started?

Bosse But it was pure bloody self-preservation! To save, that is environmental work. I haven't been CEO in the last 15 years, but I'm the one who decided that we would develop this way. And a lot of people have been here and thought that it was cool. 
Ever since Bosse started HygieneTech he worked with sustainability, in the sense of "saving". Coming from a poor background, saving resources comes naturally to Bosse. This approach to sustainability and environmental questions has stayed in the company long after Bosse left as CEO. His son Nils took the position after him and worked as CEO at HygieneTech for five years. Nils was the one who started talking about how they could highlight their sustainability work in their marketing. It was during the early years of the 2000s that the environmental questions started to interest him as a strategic tool, Nils told me. HygieneTech were at the forefront of environmental work at that time, and this gave them a competitive advantage over competitors who were adapting more slowly. HygieneTech started using environmental issues as a way to distinguish themselves from their competitors, and they argued that there was more value to their products due to the environmental labels on them. HygieneTech was one of the first companies to produce environmental labelled detergents for professional customers, and they proudly showcased their environmental work in their marketing materials. Moreover, their environmental focus was reflected in the company's green and blue logotype. Due to their early efforts Nils was nominated as "environmental leader of the year" by an influential Swedish environmental paper.

A story similar to this always came up when I asked the employees why HygieneTech worked with sustainability issues. "It goes back to Bosse," they often told me. Even though Bosse is now over 70 years old, he still is active in the company. Today, the hygiene products are no longer manufactured in Bosse's garage, and HygieneTech is no longer a one-man operation but instead a company with more than 200 employees. Most of HygieneTech's customers are small restaurants that buy detergents and desiccants for about 14200 SEK (1650 EUR) per year. Their customers also include large conference facilities and environmental labelled hotels which buy products for more than 100000 SEK (16 600 EUR) per year. The diversity of the clientele presents some challenges, both in strategic terms for the main office and in practical terms for the sellers. HygieneTech's product range is also very diverse. The company's product catalogue presents 60 pages of different products for cleaning, washing, food hygiene and service equipment for large kitchens. They produce most of the chemical products themselves while they supply their customers with a variety of brands of cleaning supplies and equipment, such as garbage bags and dishwashing machines. Most of their chemical products have an environmental label, and so does some cleaning equipment, although there is far less labelled equipment than labelled chemical products.

Today most of the work that is explicitly described as sustainability work is done in the sustainability work group led by Therese, the sustainability manager. This group consists of members from different parts of the organization, including the CEO, Chief Financial Officer (CFO), product managers and sales managers. As a part of their 
sustainability work, they have committed to operating according to ISO 26000 - a standard for organizational responsibility. To understand the core process of HygieneTech I think that we need to understand how the detergents physically travel in the company. And if we want to follow the detergents' path in HygieneTech we first have to travel to another area of dark woods similar to Bosse's birthplace of Småland, that of a small remote village somewhere in the middle of Sweden. The village is, like many other Swedish small towns, in a downward spiral. Many jobs have moved to the larger towns, and several shops and houses are just empty shells, nostalgic memories from more prosperous times. This is a typical Swedish small town: it has one grocery shop with an overwhelmingly large parking lot, one café with decent lunch but terrible coffee, and many houses that desperately need repairs but whose owners would never benefit financially from investing in them. For the sake of the story, let us call this village Viby.

This village provides very few promises of a positive future but it has a strong artery, its own chemical factory. In fact, it is one of Sweden's largest chemical factories for cleaning products. The factory was founded in 1980 by a local entrepreneur but was bought by HygieneTech in the year 2000. Today, 24 people work in the factory, which makes it one of the largest employers in the village. The factory produces most of HygieneTech's chemical products and manufactures consumer products for other partners as well. This is also where the lab for developing new types of products is located. When Bosse bought the factory, the business was renamed Spotless Production and became a part of the Clean Hygiene corporate group, of which HygieneTech is also a subsidiary. Since HygieneTech was the first company and the largest employer, the employees mostly talk about HygieneTech, even when they are referring to Spotless Production. Clean Hygiene is mostly an organizational feature to connect HygieneTech and Spotless Production.

\section{Spotless Production: The factory}

The factory is located two kilometres from the grocery store (the village centre), and right beside the nondescript white factory building sits a yellow-brick house. When the retired couple who lived in the house wanted to sell it, HygieneTech bought it for 200000 SEK (24 000 EUR) and renovated it for 2 million SEK (240 000 EUR). Such a large investment in renovating a house is very unusual in this area. Today this house is the place for team-building activities and also provides lodging for visiting international customers. Investing such a large amount of money in a house in Viby might seem a bit strange, but this is an example of the spirit of HygieneTech. Because they invested in this worn-down house they now have their own conference rooms and 
can save money in the long term. Long-term investments are an important part of Bosse's engagement in his business and an explicit part of his vision of sustainability. In fact, the whole purchase of the factory has to be seen as a long-term investment since it has struggled financially from the beginning. This year the factory manager believes they will produce a zero result, which is a huge success considering the factory's history. Johan, who manages the factory, seems proud to show me around and introduce me to all the different machines. Since 2006 HygieneTech have invested 6 million SEK (660 000 EUR) in automating the factory; this has led to several dismissals. "At that time, I was glad that I wasn't living in Viby but in Fredriksdal!" Johan explains. Fredriksdal is the closest larger city in the area, and only a few of the staff travel from Fredriksdal to the factory every day.

The everyday activities in the factory revolve around different types of chemicals. Certified companies transport the chemicals to the factory at Viby. The certification means that the companies have been licensed to transport chemicals that might be dangerous to the public. The chemicals are loaded into large silos close to the packaging machines. The silos are placed on scales, which allow the employees to program the distributor according to the recipe for each product. The recipe specifies down to the gram what ingredients the product should contain. The liquid mixtures are transported in long metal tubes to the packaging machines. The large packaging machines are the hard workers of the factory; they take in a pallet of cans and fill them with the liquid mixture, put labels on them and neatly load them onto a new pallet. A few employees supervise the processes while others pack smaller deliveries. During my visit there is a power outage and everything goes dead quiet. "This is what it is like, having a factory at a place like Viby" Johan explains. "Power outages are common and they disturb our schedule and there is really nothing we can do without these machines." Luckily, the power soon returns and the production goes back to normal.

The factory produces products both for the consumer market and the professional market. Johan tells me that HygieneTech is the largest customer on the professional side. Even though they are a part of the same enterprise, the factory seems to be different in many respects. Their location and their approach to customers are two aspects that seem to accentuate the geographical distance from the main office. Johan tells me that HygieneTech is used to producing whatever they need with a very short time frame, whereas at Spotless Production they need more time to prepare a change in the production due to the large volumes. The detergents for HygieneTech are manufactured and packaged in Viby and loaded onto a trailer to be taken to the head office, which is located in a suburb of one of Sweden's largest cities. After the detergents are shipped by HygieneTech's trucks the 300 kilometres to the head office, they are unloaded into the crowded warehouse. Now the "guys in the warehouse" have 
to load the detergents and other products onto pallets according to order forms from the sellers. These pallets are then shipped out to the different parts of Sweden where the sellers are located, from Malmö in the south to Piteå in the north. All sellers outside Stockholm have their own storage rooms to which the pallets are delivered.

\section{Distributing cleanliness}

The next step for the detergents is their delivery to the various sellers. From there, the sellers deliver the products to the customer's shelves; they pick up new orders, conduct maintenance service on the dishwashers, educate the customers in hygiene and try to find new customers. They have quite a varied workday and they handle many technical devices. The sellers have their own trucks to carry the products to the customers, and these are important allies with which they spend a large part of their workdays. The seller's relationship with his or her truck is an important part of being a seller at HygieneTech; it matters what kind of truck you have and, most importantly, what fuel it uses. As a part of HygieneTech's environmental objective, the company tries to run as many trucks as possible on biogas. This is not very popular among the sellers since these trucks are slower and have to be refuelled more often than diesel trucks. I will get back to this subject in Chapter 7 .

Being a seller at HygieneTech requires certain qualifications and comes with a large amount of responsibility. The sellers are free to choose how to plan their workweek, and in the remote areas their communication with their manager is limited to phone conversations a few times a week. They are also responsible for their inventory; each month they do an inventory check to make sure no products have been lost. Being a seller at HygieneTech involves more than knowing about the products that the company sells. Sellers take several courses during their first years on the sales force and they are also trained by more experienced sellers. Sellers need to know how to help their customers improve their companies' hygiene practices and they also need to know which chemicals are the best for specific purposes. "You are cleaning chemists," as one trainer told us during a course in hotel cleaning. Finding the right products for the customers entails not only knowing the products but also knowing how cleanliness works. Sara explains at the hotel cleaning course:

Sara There are four factors that you have to take into consideration, which is called the Sinner's circle. These are: chemicals, mechanics, time and temperature. At HygieneTech we can lower the time factor by enhancing the mechanics. In cleaning can we rarely ever use stronger chemicals; instead, we have to use more mechanics. 
Knowledge is important - knowing how long it takes and which product to use.

The sellers' job is to make sure the customers use the right products and to know how to help their customers improve their cleaning practices. Even so, most of the time the sellers' job consists of packaging, loading and shipping the products the customers have always used. When a customer insists that the only way to get his floors clean is by using a more expensive oven cleaner product, then there is really no need to discuss it further since both HygieneTech and the seller will profit from it, a seller told me at a training meeting.

HygieneTech is known for their care for sustainability, and some customers have chosen them specifically for their work with environmental labels. However, not all of HygieneTech's environmental initiatives have been viewed positively by customers. An example concerns the company's recycling programme. For some years HygieneTech had recycled the five-litre containers its detergents came in. The sellers took the containers back with them after delivering new supplies to their customers. This is a service that the customers appreciated, and it was an important part of HygieneTech's sustainability profile. However, after some calculations, Therese discovered that the recycling of containers was neither good for the environment nor profitable. It was taking up too many resources and too much time to clean the containers, and after a short discussion at a management team meeting, they decided to stop the recycling. Several customers have complained that they miss the service of the sellers taking the containers back with them, and they have the impression that HygieneTech's sustainability work has deteriorated However, the company does still recycle where the employees thinks it makes sense to do so. For instance, it continues to recycle the smaller detergent containers that are used in dispensers. These containers are brought back to HygieneTech's head office, where they are cleaned and filled with new detergents. In this way the product circle is closed.

When I asked the employees about how sustainability is a part of their everyday work, they often answered that it is in their approach towards their business. In this thesis I aim to unpack what lies in this statement and try to understand how it is done in practice. This story of the hinterland of sustainability at HygieneTech serves as an illustrative introduction to the organizing of the company. Through this story you have also become acquainted with some of the most important actors in this study: Therese, the sellers, Bosse, Johan and the detergents, to mention just a few. In the coming chapters, we are going to spend some time getting to know them even better in order to understand how they are a part of enacting sustainability at HygieneTech. 


\section{4}

\section{Corrosive sustainability: Chemicals, labels and sustainability}

Once again, we are back at the factory site at Viby. The manufacturing process is running at its regular speed and the fully automated machines produce an impressive number of "ready to ship" pallets per day. Johan, the manager of the factory, gives me a tour of the factory and the laboratory. The noise of the machines on the production floor forces us to raise our voices, but it is still easy to have a conversation in the modern factory. Johan talks proudly about the new machine that can produce fully loaded pallets all by itself. The large mechanical device is loaded with empty bottles, and it fills, labels and packs them in an effective and ordered way. Only very small orders need human interaction; for those, a worker has to load the bottles into the 10metre long machine by hand. Next to the machines there is a floor drain with a steel grating that catches my eye. About a foot beneath the floor floats a liquid of the brightest blue colour. The colour makes the liquid seems highly toxic, and I ask Johan about the amount of dangerous chemicals they use.

Johan None of the chemicals that we handle are dangerous.

Maria Oh. [I probably sound a bit surprised.] I've seen all these warning signs on the packaging everywhere, so I figured they were toxic or something.

Johan Well, I guess that depends on what you consider dangerous. There are a few that we have to handle with gloves and masks, and many chemicals are of course corrosive. But 
not really dangerous. It's not like we would make a large hole in Viby if something went wrong!

Maria I see.

I may not sound very convinced while I stay focused on not getting in the way of the workers and the truck moving the ready-to-go pallets stacked with cleaning products. Johan moves with ease through the factory and introduces me to all the employees we meet. Corrosive chemicals are rather normal at the factory in Viby and no one I see during my visit seems to be wearing safety equipment. Even so, there are a number of procedures and regulations to ensure that no employees are at risk, Johan tells me. Instead of manually loading the large packing machines, there are other machines that take care of the supply of different components. Large silos with chemical compounds are clustered on one side of the factory. The silos are placed on scales that are connected to a computer that knows the exact amounts of the chemicals needed for the product currently being produced. The corrosive chemicals are not dangerous, since the regulations and the technical devices prevent contact between them and human skin.

In this chapter, I turn to the detergents with the intention of seeing what their story can tell us about sustainability. The products, and especially the detergents and desiccants, play an important part in HygieneTech's sustainability work. In HygieneTech, a sustainable product is a product that is labelled, and thus 95\% of HygieneTech's selfproduced products are sustainable. But even with the label, the products and their substances can be corrosive and somewhat harmful to nature and to people. This tension between the harmfulness of a product and its sustainability gives voice to interesting valuations where important matters of care are turned against each other. The level of dangerousness of a product is set in relation to even worse scenarios, and this makes the less harmful chemicals seem almost innocent. In this chapter, I discuss the tensions that arise between different versions of sustainability and how sustainability is enacted through labels.

In HygieneTech's identity as a sustainable company the labelled products have a central place. The process of labelling a product starts at the product development group meeting. At this meeting the group produces a specification of the product's characteristics, and an important characteristic can be that the product must meet environmental labelling requirements. This specification is sent to Viby, where a recipe for the product is developed. The product is then tested by the environmental label organization. In most cases HygieneTech use the Swedish Svanen (Swan) label, since this organization is known to have stringent requirements, and HygieneTech can 
get a discount for putting several products under the same label. HygieneTech pay an initial cost for the new product and later they report on how much of the product has sold and pay a percentage of their sales to Svanen. Some of HygieneTech's products are labelled through another organization, "Bra miljöval" (Good Environmental Choice), but since they do not test the products' quality, Therese says that they prefer Svanen. Besides, she adds, Svanen is better known to the customers.

Being able to use the environmental label is the main criterion for a sustainable product at HygieneTech, and to understand how the sustainable product is enacted I will begin by showing how the labelling is a part of the company's identity. The practice of labelling products has consequences, not only for the identity of the employees but also for the labelled products. I will therefore introduce the most commonly used label in HygieneTech, Svanen, in order to understand what is being cared for when the label is used as a sustainability practice. Furthermore, we will revisit the factory at Viby where it all starts. This is where the products are produced and labelled with a swan that tells us that the product is environmentally friendly. By then following the chemicals through the processes in HygieneTech we find out how labelling enacts sustainability and how care for the environment sometimes clashes with care for other matters.

\section{The importance of labels}

The reasons HygieneTech works with environmental labels are manifold. In my first interview with Wilma, the CEO, she explains why and how HygieneTech work with sustainability. She first tells me about how the owners worked on saving resources and how that also connects to environmental issues. Then she explains further:

Wilma And we want to work with labelled products... When we work in this kind of business it is important to be as environmentally aware as possible. We take pride in the fact that $95 \%$ of our chemical products have an environmental label; it is something that we are proud of and can talk about in the company in order to create a corporate culture.

I believe that the enactment of being a company that put environmental labels on their products strongly influences the way a lot of the employees and their customers view HygieneTech. Svanen is always mentioned when any employee talks about HygieneTech as an environmentally friendly company. When I ask the sellers if they think that HygieneTech is a sustainable company they all have an answer that related 
to the high number of labelled products. One of the sellers tells me that it feels nice to know that their products are good for the environment. At a training session for sellers on hotel cleaning, the enthusiastic teacher talks about HygieneTech's products and adds:

Sara And it is fun to sell environmental labelled products!

The environmental labels are important for the identity of being a part of HygieneTech. It is fun and feels nice to work with environmental labelled products. The label adds a positive value to the product, and through the product and its label the employees can care for the environment. The care for the environment is made into pride of being a part of a company that cares for environmental concerns. The label enables care through the mundane practice of selling hygiene products.

The care for environmental issues is not always shared by the customers. Most of the smaller restaurants are more interested in prices and do not care about labels. A seller, Tobias, tells me that he usually doesn't talk about environmental issues or labels with the smaller customers. It is only during visits to prospective customers that he mentions HygieneTech's sustainability work and environmental labels. He does have some customers that care about labels - mostly hotels that have their own Svanen label and need to use Svanen-labelled products in order to keep their certification. The hotels with the Svanen label are often brought up in different conversations as a reason for HygieneTech to work with labels. Sara tells the sellers at a product training session how the environmental label is important when talking to some hotels that may be more demanding about environmental issues. Therese also explained it to me during our first interview:

Therese If we look at the hotel side, several of our customers are environmental labelled and their demands are more clearly expressed than those from the restaurant side, I would say. They place greater demands on us as suppliers of environmental labelled products and dosage systems so that they will be able to keep their environmental label.

The customers who care about labels are another reason why HygieneTech work with environmental labels. The labels make them proud of their work and their company, and this pride is reinforced when their customers care about the labels too. An extended discussion on the customers' role in the making of sustainability at HygieneTech will be found in Chapter 5. For the scope of this chapter, I conclude that the customers who care for environmental labels have an important role; even so, I believe the labelled products are used more as the identity marker of a sustainable company than as a result of demands from certain customers. The employees often 
refer to the environmental labelled hotels when asked why HygieneTech work with environmental labels, but only as an addition to the conscious and idealistic choice made by the company. The $95 \%$ labelled products represent one of the practices of making HygieneTech sustainable. Thus, the ontology of being HygieneTech is entwined with a green swan on a white background. The identity of the corporation is connected to a feeling of care for the environment that goes back to the day Bosse started the company. If the ontology of HygieneTech is so entwined with this label, the practice of labelling is a matter of care that needs to be studied more closely. In the next section, I analyse what is cared for in the certification process in order to understand what is enacted as sustainability through the labels.

\section{The Swan: Certified sustainability in a bottle}

The Nordic Council of Ministers started the label organization "The Swan" in 1989 and it was Sweden's first official environmental label (see the logo in figure 1). The aim was to help Nordic customers easily identify environmentally friendly alternatives in the market. The organization is now a company that, since 2012, has been fully owned by the Swedish government. Today, 1000 companies promote about 9000 products (in Sweden, over 20000 in the Nordic countries) that are labelled with the environmental friendly Swan (Svanen 2015).

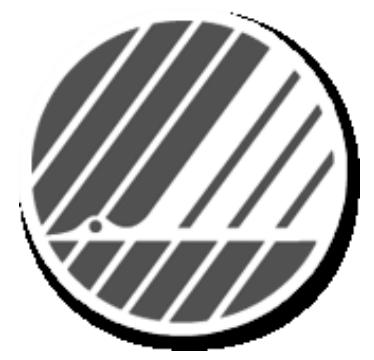

Figure 1. The four white bars representing the wings of the Swan in the logo represent the four Nordic countries that started the label:

Norway, Sweden, Iceland and Finland. Denmark joined the collaboration in 1992 but was not given an additional wing.

The company behind the Swan, Svensk Miljömärkning AB, has high ambitions for the label:

The aim with Svanen is to help customers choose the best products on the market from an environmentally friendly perspective. Our vision is a sustainable society and, through our environmental labels, we contribute to sustainable consumption. For companies Svanen is proof 
that they work actively for sustainable production and that their products have met our high environmental demands. Everyone can contribute to a better environment, consumers by choosing environmentally friendly products and services, and companies by labelling their products with an environmental label (Svanen 2015).

Sustainability is achieved by buying the right products and producing products in an environmentally friendly way. However, not all products can be labelled with the Swan; today, over 200 types of products and services from a broad range of fields have met Svanen's criteria. The product groups and services for which Svanen has developed criteria are chosen based on their environmental impact, whether there can be a relevant environmental difference between a Swan-labelled product and a nonlabelled product, and an assessment of how much the label will affect the development of the product or service in the long run. The criteria focus on the products' environmental effects, function and quality. Companies have to pay a starting fee for labelling their products in addition to a fee per sold product that the companies report to the labelling organization each year. The label is one of the best known in Sweden; in a survey in $2015,96 \%$ of respondents replied that they recognized the Svanen label (Svanen 2015).

The criteria for different products are developed together with companies, NGOs and authorities. They are revised every four years in order to encourage companies to develop their products to become even more environmentally friendly. I will briefly introduce the criteria for dishwasher detergents to provide an overview of what is made important in the making of the environmental friendly detergent. The criteria for detergents are available on a public web page and the document is 30 pages long. The document sets out numerous obligatory requirements regarding chemicals, usage and environmental effects. Furthermore, seven sections are presented with different possible scores: CDV (critical dilution volume), phosphorous content, fragrance content, dosage, controlled dosage, fill ratio, and performance. In order to be approved a product needs to comply with the obligatory requirements and receive at least five points out of the total of twelve in the seven sections. The obligatory requirements state that the product cannot contain certain harmful chemicals, allergenic substances or environmentally hazardous substances. An important measurement to rate the harmfulness of the detergent is the CDV limit - that is, the amount of water that is needed to neutralize the product. A high score is given to products that have a limit lower than 25000 litres per wash. The degradation of the product is another measurement of its environmental friendliness. The criteria also state which colorants, fragrances and preservatives may be used in the products. A fragrance-free product is given one point extra in the protocol (Nordic Ecolabelling 2010). 
The dosage is also controlled; the maximum allowed dosage is 18 grams of detergent per wash. A low dosage gives an additional point, and so does a controlled dosage (where a technical device takes care of the dosage for the user). The packaging must be environmentally friendly and fulfil a certain weight ratio in relation to the efficiency of the detergent. This means that the detergent must be highly concentrated (or extremely efficient!) to live up to the demands of the label. Another controlled aspect is how the product is packaged and how information is given to the consumer. Good performance of the detergent is stated as an obligatory requirement, and if the product performs well even at low temperatures, it is rewarded with bonus points. In the last section, on quality and regulatory requirements, we are told that the product needs to fulfil all laws and regulations of the sites where it is used. The company is responsible for reporting all changes in the product's recipe and must document all data that is attached to the application. The company also has to have a plan for their marketing of the labelled product that is in accordance with the label organization's policy and meets the requirements for recycling within their sector (Nordic Ecolabelling 2010).

When these requirements are met and the product is approved by the labelling organization, it can carry the well-known Swan label. The detergent is then not only a cleaning product, it is a piece of the puzzle that makes up the sustainable society. An approved product is friendly to the environment and to humans, performs well and fulfils all relevant regulations. Not all other labels focus on how well the product does the job; instead, they are interested in what the product contains and its effects on the environment. Svanen cares for the environment through the requirements regarding CDV limits, forbidden chemicals and packaging. However, just like Bosse at HygieneTech, Svanen believe that saving resources is important in the sustainable society. Svanen states that a good performance is required to make sustainability, and a high concentration is preferred since it saves water and lowers logistical costs. Some things are required for a product to be approved as sustainable, such as guaranteeing that the product does not contain any of the long lists of forbidden harmful chemicals, while other things can be negotiated. A product without fragrance is given bonus points, but it is still possible to label a product that has a hint of mint. This shows how some things are more important than others in the sustainable detergent. For the label organization, I believe chemicals are their first matter of care since these are presented first and most extensively in their information materials. Other things also matter, such as performance and marketing, but they are given less emphasis. The requirements on detergents have consequences for how sustainability is done in HygieneTech. Since the label is a part of their sustainability identity, the care requested by Svanen becomes practices of sustainability. The demands from the labelling organization have consequences for how sustainability is enacted in HygieneTech. The matters that are 
important for Svanen are made into matters of care at HygieneTech. By following the chemicals from the product development meeting to their production in Viby, we can study how the labelling process enacts care as sustainability in practice.

HygieneTech and Svanen also collaborate on advertisements, and HygieneTech is a referral organization for new standards from Svanen. They have collaborated in other settings as well; HygieneTech's sellers can help restaurants and hotels become Svanen-labelled since HygieneTech have a special certification for this. As we can see, their collaboration goes well beyond just putting environmental labels on products. Some insights into Svanen's organization might also lead to advantages in other areas. At a product development meeting Sara (product developer) explains:

Sara We have just bought in new candles and we think they will work fine. We think that Svanen will change their environmental demands [on candles] and then we will sell plenty of these candles!

Their close cooperation with Svanen gives HygieneTech an advantage since they can change their products to fit the criteria from Svanen before their competitors. Therese tells me that it is always easy for HygieneTech to work with Svanen since they know them and are familiar with their routines and forms. Even so, HygieneTech have also worked with other organizations; for example, they helped the large food chain Coop to develop new products for their environmentally friendly product line "Änglamark".

\section{Production of the sustainable detergent}

The factory in Viby is not the heart of the company; rather, it is an extension of an already functioning company. The production in Viby takes place far away from the bustling head office, both in terms of kilometres and in mindset. "We do it our own way here, and they [the employees at the head office] are starting to learn how things have to be done now," Johan says. He tells me how, sometimes, the head office should have better planning procedures to make life easier for the production staff at Viby. HygieneTech is the factory's largest customer, but they also produce products for many different types of customers who want to sell their own brand of cleaning products. The detergents that HygieneTech sell to their customers are labelled highly corrosive, just like many other products produced at the factory. By using machines to do most of the handling of chemicals, some of the possible negative social effects are reduced. Unfortunately, this way of (not) handling the corrosive chemicals cannot be translated to all other settings. When the detergents are manufactured and packaged in Viby, they are loaded onto a trailer that will take them to the head office, or in some 
cases directly to the sellers. Since the load contains certain chemicals that are considered dangerous, it has to be handled by a person with special training, and the trailer has to be labelled (Figure 2).

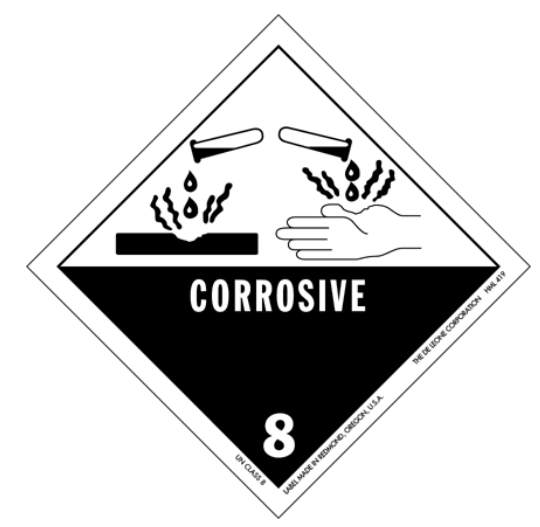

Figure 2.Warning sign on corrosive chemical products.

The products that arrive at the head office are then distributed to the sellers' storerooms. Since there are special regulations on shipping corrosive products, the sellers need to think twice when they load the products into their own trucks. They need to have a safety sheet on all products that they have in their trucks, and if they have not yet completed a special safety training course they can only load a smaller amount of the products. The same applies when they travel with visitors (such as me); if the visitor has not completed safety training, the sellers have to load fewer products. The regulations around these products do seem to imply that the chemicals are dangerous, and they can sometimes do real damage as well. When I accompanied one of the sellers, Karin, on her customer visits, I could see how the detergents can also pose a problem for the sellers.

Karin and I are visiting a customer that has a machine that is not working properly. Karin starts the dishwasher and after a minute she opens the machine to check the water. After testing the water sample, she concludes that there is too little detergent in the water. After she looks for awhile, she finds the containers with detergents under the sink and tells me: "The detergents have got stuck in the hose that leads to the machine; that happens sometimes. Now I just have to rinse it and it will work fine again." She starts to rinse the hose and in the process some of the detergent spills out and Karin gets some on her hands. Almost immediately she turns the water on in the sink and washes her hands. "I always bring gloves with me, but today I forgot. It burns if you don't get it off right away." Back in the truck she brings 
out some hand lotion and offers it to me. She tells me that in some seasons she uses hand lotion after almost every customer visit, partly due to the corrosiveness of the detergents and partly because she works a lot with water.

For Karin the detergents are a part of her workday and the strong chemicals help her do her job: delivering clean dishes. At the same time, it results in dry hands and if she is not careful, burns on the skin. One of the sellers I followed had recently had some leakage from a container of detergents that had made burns on the back of his truck (see picture 1).

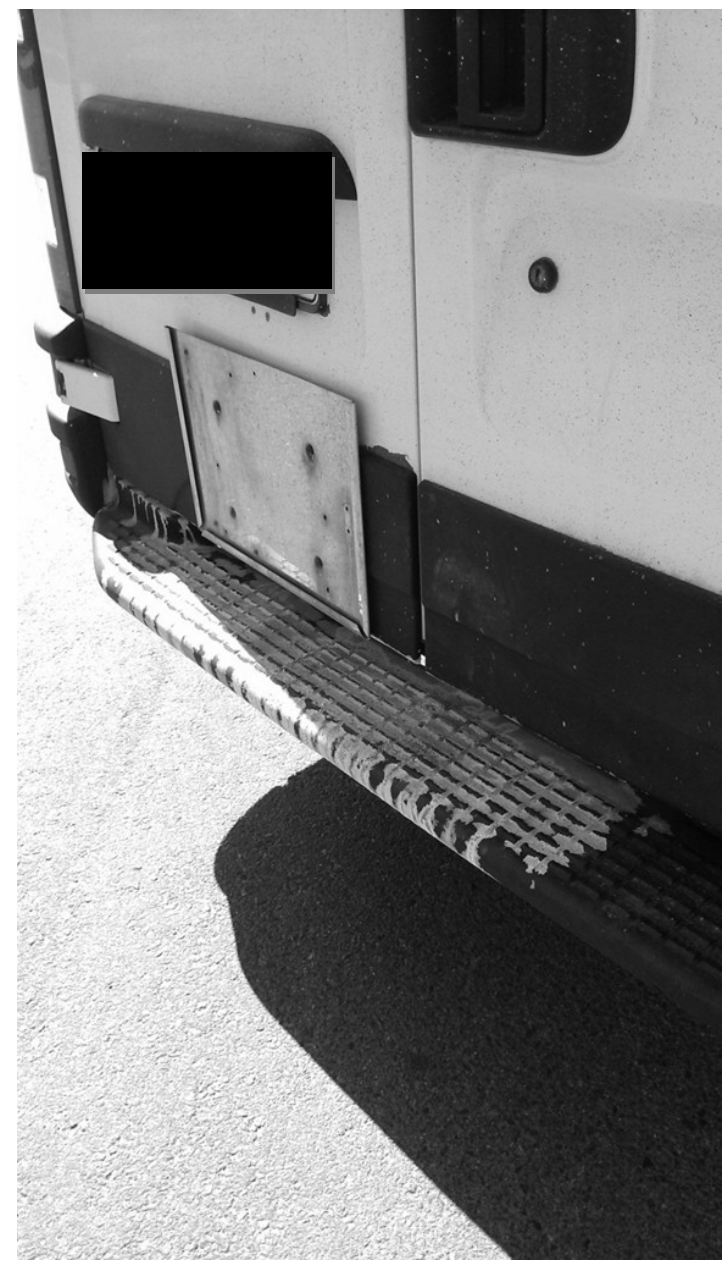

Picture 1.Damange due to leaking detergents.

The corrosiveness of the detergents is partly due to the high concentration of chemicals. Since the detergents contain a minimum amount of water, it is possible to 
use less packaging and reduce the use of fuels since the smaller containers are easier to transport. The absence of water is one of the reasons this product is perceived as sustainable; the second reason is its environmental label. As we have seen earlier in this chapter, several criteria have to be met in order to receive an environmental label. The recipe of the detergents is verified to make sure that no chemicals that are regarded as dangerous to the environment are used. The permitted chemicals are less polluting and thus seen as a good environmental choice. Furthermore, the efficiency of the detergents is compared to the weight to make sure that no unnecessary water is shipped around. The employees at HygieneTech enact sustainability by translating it to the practice of using less dangerous chemicals and less water, as required by the environmental label. The corrosiveness of the detergents is not seen as a sustainability issue; instead, it is labelled as a health and safety problem. The social side of the detergents' sustainability does not fit within the sustainability that HygieneTech enact and thus boundaries are drawn to define what sustainability is. This enactment of sustainable detergents includes labels and resource management, but the dimension of the detergents in use is in this case left out of the discussion. The labelling process enacts sustainability as caring for saving resources within a regulation of what are permitted as acceptable harmful chemicals. Reduced water content also saves money since logistical costs are lowered, as are the costs for packaging. Sustainability in this case is seen as both an economic and environmental concern, while social aspects of the product's corrosiveness are absent. The product has to be handled to be an effective detergent, thus the fact that it is not too dangerous to touch is a part of enacting the detergent in practice. Even so, the negative effects the detergent has in this process are not part of the making of the sustainable detergent. Different versions of sustainability are clashing and thus the handling of the detergent is made absent.

After I had finished gathering my empirical data, I was invited to HygieneTech to talk about my findings, even though I had not yet completed my study. When I talked about the problems with the corrosive product, one of the sellers raised his hand and said: "I don't agree! In the past we worked with much more corrosive stuff. Nowadays it's much better; the chemicals we use today are a lot less damaging." This shows that the development in the chemicals that are used in cleaning products has moved forward. Care has been put into working with the danger of corrosiveness. I do not argue that HygieneTech do not care for their employees' welfare by not making their products less corrosive. Instead, I believe that what we can analyse from the findings presented above is that, by working with labels and meeting Svanen's requirements, certain factors of the chemical products are made more important than others. There is a lower limit that is presented by the labelling organization; some chemicals are just not allowed due to their harmful effects on humans and the environment. When these limits are reached, the product is considered sustainable. Care has been put into the 
product through the work with the labelling process, and the corrosiveness that remains is accepted as a normal effect of a chemical product. Even so, the problem is still present and is evident in the need for strict regulations and sometimes a liberal use of soap and hand lotion.

\section{The limitations of the sustainable product}

HygieneTech's product catalogue is 60 pages long and includes an impressive array of products, including products for cleaning, washing, food hygiene and service equipment for large kitchens. In each category, there are almost always multiple options to choose from; if you need garbage bags, the selection of 13 different products ensures that you will get something to satisfy your needs. To manage and develop its many products, HygieneTech has a product development group. This group meets every month to discuss possible new products, make decisions on the product range and evaluate new and old products. The meetings are chaired by Therese, who, in addition to her role as sustainability manager, also has some product responsibilities and is the quality manager. HygieneTech has appointed product managers for different segments of products due to the large product range. It is at the product development meeting where new products are proposed and evaluated and decisions are made on which products HygieneTech should produce and which should be bought from other suppliers. This is where the first steps in the making of the sustainable product are taken. New products are presented with a budget, evaluations from test users, information on whether it can be labelled and about other properties. The participants at the product development meetings include all product managers (Therese, Sara, Fredrik and Erika), region managers (Jens and Anders) and representatives from the sellers. At the meeting we will visit, however, there was no seller present, due to sick leave.

In the conference room at the main office at HygieneTech Therese uses PowerPoint to show an evaluation document of a product. The proposed product is a foam spray that is intended to be used as a window cleaner. This product already exists with the environmental label, but here it is tried with a foam nozzle instead of a liquid spray pump. A survey from a few test consumers shows that they were not very satisfied with new foam product.

Fredrik I don't wash windows very often but I think that I would like it.

Therese Yes, ok. But we have to focus on the evaluation now.

Sara Is there any demand from the customers for this product? 
Therese I think it was an internal idea from the beginning.

Sara Foam can be really great when you clean window joints; sometimes it's the only thing that works.

Anders But if the customers don't ask for it, it can't be that important.

Erika Do you have to use more of it when it's foam?

Anders Karin tested it and she found that she had to use more since you had to do more wiping than usual. It is supposed to give the same dose, but if you use it more frequently it runs out faster, and that's good.

Jens But is that really sustainable? [He clears his throat, looks at me and smiles.]

Erika It's economic sustainability!

[The group laughs]

Therese Yeah... And it has the environmental label, but since the evaluation showed that they didn't like it we will wait with this product and move on to the next point on the agenda.

It is interesting in this discussion how the sustainability aspect is related to the economics of the product. Since the product can have the environmental label it is considered to have sustainable qualities. Even so, when one member asks if it really is sustainable to produce a product which will lead to an increased use of chemicals, this is seen more as a joke than a real conflict. I believe this shows how important the labelling of the product is to HygieneTech. If a product is labelled, it is seen as sustainable enough. What is cared for in this context is the product's ability to live up to expectations from the user and the label, and its profitability. Sustainability as saving resources is not present in this meeting. Instead, the economics side of using more chemicals is brought up as both sustainable and not sustainable. Letting both economic profit and saving resources exist as sustainability creates tension. The common version of sustainability as saving resources is mostly absent in this room. Even when the tension is made visible it is handled with a joke. Hence, sustainability has to be reduced to labels; otherwise it would clash with the clearly stated aim to sell higher quantities of chemicals. The different versions of sustainability cannot coexist, and in this room sustainability as labels makes the task at hand possible. If the overall goal at the product development meeting were to reduce resource use, most likely only a very narrow selection of products would live up to the demands. The most sustainable action in that case would be not to produce new products but only to improve the existing range of products. The aim of the product development meeting is to select the most promising products that will be appreciated by the customers, and in addition, it is nice if the product is sustainable. This aim does not work well with the 
version of sustainability as saving resources but fits rather nicely with products that can be labelled. In this way sustainability as labels is present in this discussion while other versions are made absent.

A cleaning product has several purposes; one of these is to reduce dirt and another is to make a convincing argument for the cleanliness of the treated surface. This is done by adding a fragrance to the product to make sure that anyone who walks through the door will know that the floor has been recently cleaned. However, the label puts restrictions on what chemicals may be used in the labelled products, and this includes what fragrances are permitted. At a product development meeting a new version of the product "Clean off" with a new fragrance is discussed. The members of the group have had a sample of the version to use at home and evaluate in a survey. A small bottle of the new mixture of Clean off is sent around the table. The bottle contains a light blue liquid with a sweet smell.

Anders I thought that it was ok, but my wife and children thought that it smelled like a Greek supermarket. It smelled cheap and chemical. That is not a good association.

Sara Yes, I think it smells good but a bit cheap. It does smell like something, but the question is whether it is better than the existing one.

Anders Aren't we allowed to still manufacture the old version?

Therese We can't put an environmental label on the old one. And it's a good opportunity to change now since we have run out of product labels.

Erika Can we change fragrance or make it smell less? I don't link this scent with cleanliness.

Sara Most often we connect citrus scents with cleanliness, but they are hard to label with the environmental label.

Therese Yes, there are few fragrances that have an environmental label.

Sara Yeah, almost no perfumes are labelled.

Jens I'll go and get the old version so that we can compare.

[...]

Jens returns with another bottle, which is passed around the table.

Sara This smells more like a real cleaning product!

Jens I actually think it smells of citrus and chemicals.

Sara Can we label the new version with "Bra miljöval" instead?

Therese It doesn't matter; for economic purposes we have to gather all products under the same label. 
Fredrik I think the new one smells better but it doesn't smell like a cleaning product.

This discussion shows us that the scent of citrus is connected to the concept of cleanliness. Even if the new scent is considered to smell better, it does not smell clean! In this conversation, the perception of cleanliness clashes with the desire to put the environmental label on their products. They have to negotiate on whether their products can smell "like a Greek supermarket" or if they can have products that are not labelled. This is a practice that has consequences for their sustainability work. The scents that smell "clean" - like citrus, are harder to put environmental labels on. They have to negotiate on whether to make this product sustainable or more connected to cleanliness. In this practice, they have problems including the properties of cleanliness and sustainability in the same product due to the regulations on what chemicals can be included in a labelled product. The different versions of the product, the sustainable (labelled) product and cleaner-smelling product, cannot be added together. The group members end up deciding to do some more tests in order to find out how some of their customers perceive the products before making any final decisions on adjusting the recipe.

The first step to making a new, sustainable product starts at these meetings. What sustainability is and what is cared for are negotiated at the product development meeting. When products are discussed the question of whether they are "labelable" is always present. In addition to high demands on performance, other qualities that are important for the product concern the way it presents itself - the colour, liquidity and the fragrance. The most prominent matters of care when it comes to evaluation of a product are cleanliness - through performance and experience, expected economic results and eligibility to display the Swan on its packaging. The perfect product can combine all these aspects; however, some products cannot live up to all of these demands. When cleanliness stands in opposition to sustainability (as environmental labels), the tension between the clashing matters of care becomes visible and has to be addressed. Therese has realized that the process they use to assess products sometimes fails when different values clash.

During a product development meeting, Therese raises this issue:

Therese While we are talking about products, Erika and I have talked about "Spotless". Among other things it contains chlorine, and we thought about whether we should sell it or not and how environmentally harmful it is. Shouldn't we have clearer guidelines around this? When we discuss products in the product development group we value 
certain things: price, quality and sustainability. I think it is difficult to find a system to work with this. But we have an idea; we already have an environmental and health specification that the suppliers fill in. There are good questions about what kind of product it is, then it goes deeper on bio-accumulative chemicals, how environmentally dangerous the product is, if it contains nano particles, surfactants, if it has an allergy rating, if it has EDTA or phosphates. We have some products that have phosphates but we want to move away from that. And then there are questions on whether the product contains dissolvents, parabens, if it is possible to environmentallabel the product and what kind of packaging it has. Our thought is to convert this into a checklist to be used in our group. If it fulfils all requirements it gets a green mark; otherwise it is marked with red. The question is what we do if a product gets a red mark - should we say no immediately to the product then?

Markus That depends.

Sara Maybe the product should be assessed at a higher level then.

Erika Yes, then we do not automatically buy in the product.

Therese Ok, and what is the next level?

Sara That the product needs to be further assessed.

Markus How many products do we have that would get stuck?

Therese We have some products - for example Spotless. Some products we have had for a long time, it is easier to stop them on the way in. But if the product doesn't pass, who will make the decision? There are a lot of other values that have to be considered as well.

Erika Most products will pass. It's the person responsible for the product that has to raise the issue to the management meeting. Then they have to include the potential for the product as well.

Markus Yes, and then it is discussed together with a calculation.

Sara It is against our aim of working towards more environmental labelled products, but then that has to be considered.

Therese Yes, this is a simple way to do it. Then there is the issue of quality, how to assess the quality of the product without 
making it arbitrary. Another thing that is not included in this is social issues.

Markus Well that depends on how it is done. That could be included in the supplier assessment instead.

Erika Yes, that should be included in that process!

Therese Ok, good. Then we have agreed on a work process.

Erika Spotless will be an issue for the management meeting, in other words. ${ }^{3}$

The red-marked chemicals touch upon a valuation process that involves several important matters of care in HygieneTech. Spotless cannot be labelled with the environmental label; therefore it does not easily fit in as a product of a sustainable company. Even so, there is a place for products without the label if they contribute to other values instead. Spotless might have a potential that outweighs its lack of environmental friendliness. Therese would like to see some more explicit instructions about requirements for their new products. Three important aspects - price, quality and sustainability - are considered when they decide on taking in a new product. In this process Therese would also like the supplier to give them more information in order for them to understand how environmentally damaging the product is. She includes some known harmful chemicals, such as EDTA and phosphates, as part of making a product harmful, but also such things as whether it is allergenic, what packaging is used and whether it can be labelled. A product that can be labelled is a "green-marked" product and does not have to go through the process a "red-marked" product has to. The labelled product is more worthy and fits better with the idea of HygieneTech as a sustainable company. Even so, some products might have other values that outweigh their ineligibility for an environmental label. In this situation, labelling is set in relation to other qualities of the product (such as ability to clean heavily soiled surfaces) and the authority to decide whether this is an appropriate HygieneTech product is left to the management meeting. A narrow path is created for the unfitting, but maybe promising, products that are not labelable. These unlabelable products

\footnotetext{
${ }^{3}$ Therese brings up the "social sustainability side" of the products in this conversation, and how this is invisible in the suggested process. From a socio-technical perspective, a chemical product has a multitude of social aspects. How the product is used and what network it is part of are important parts of the socio-technical puzzle. From this view, the social sides of a product cannot be moved into separate contracts but are a part of the enactment of the product. The social issues Therese discusses are a more narrow understanding of the social side of the product. She is not concerned with the use or understanding of the product; instead, her social aspect of the product concerns mostly the working conditions at the supplier. This issue is moved to the supplier assessment that is conducted by the purchasing department as a part of their sustainability work. The "social aspects" are in this situation things that can be put into general contracts; they are not related directly to the product, but to the manufacturer.
} 
require special attention and the sustainability of the product can be negotiated away.

This conversation tells of a world where labels are one of the first trials a new product has to pass through. At the same time, other versions of labelling exist. Sometimes the statement "everyone is doing it nowadays" comes up when labels are discussed. Fredrik tries to turn the focus away from labels and instead he wants them to look at resource management:

Fredrik Having "birdie birds" on the products does not impress anyone anymore since everyone has them. We are more interested in how much it can save.

Everyone is already working with environmental labels and this is not a positive thing for HygieneTech. What used to be their competitive advantage is now considered "a hygiene factor" since everyone is doing it nowadays. In the same spirit, Lars, a region manager for the sellers, describes how everyone nowadays has to work with environmental issues, otherwise they will be left behind. There is a discussion going on at HygieneTech concerning their extensive use of environmental labels. Today, $95 \%$ of their products have an environmental label, but according to their action plan for ISO 26000 they ought to have the environmental label on all their products. This goal is a bit controversial since this would mean that they would have to change their product line somewhat. Furthermore, there are downsides to working with environmental labels.

Lars And then we work with environmental labelled products even if the result might have been better with another type of mixture, or if it were cheaper or something else, but we are very restrictive in this issue. If we have decided not to work with something we will not go back on that.

Environmental labels are more than just marketing, they are the face of a statement HygieneTech will work with environmentally friendly products as far as possible! Sometimes cleanliness and lower prices can (at least partly) take a back seat to environmental concerns. This is a way for HygieneTech to care for sustainability, by using standards even if they clash somewhat with cleanliness and profit making in the short run. Labels are tools for standardizing care, and by evoking this publicly recognized way of caring for the environment they justify prioritizing sustainability over cleanliness and profit. I believe it would be hard for the company's employees to enact sustainability that stood in contrast with profit and cleanliness without using environmental labels. Labelling enables a way to care for sustainability. 


\section{Caring for resources or labels?}

Labelling products may seem like a quite straightforward practice for a company that wants to work with sustainability. But as always, there are complications. There are rules about how environmental labelled products are to be developed, and certified recipes must not be changed. From the certification organization this seems to be a reasonable demand, but in reality it can be more controversial. In the example that we will analyse in this section, different matters of care are negotiated and clash within the frame of sustainability. The labels are important for HygieneTech's view of themselves as a sustainable company; likewise, they always talk about the practice of saving resources as an easy way to do sustainability. In most situations these versions of sustainability can coexist, either due to distance between the practices or because their aims go well together. However, this is not always the case. A situation where caring for saving resources clashes with caring for labels is impossible to resolve. Two important matters of care that are set against each other create a tension that needs to be handled in the open. This means that issues that are often not talked about are brought up, and matters of care are set against each other in a very straightforward and open discussion. Unpleasant and intolerable alternatives are considered because of an impossible choice: between saving resources and keeping their word towards customers and the labelling organization.

A few years ago Bosse decided that HygieneTech should change suppliers of certain hygiene products that they could not produce themselves. The products concerned were mostly cleaning equipment but also included some chemical cleaning products. The change needed to be done quickly and there was no time to sell all the products in the inventory before starting to sell the new brand. Some years have passed, and the employees are complaining that the storage area is too crowded and there are too many "shelf warmers" that never get sold. An inventory shows that there are at least five pallets of chemical cleaning products of the old brand left in stock. This product contains an environmentally dangerous chemical called NTA that needs to be declared on the packaging of the product. To just dispose of the old, functioning but not certified chemical products would be to waste resources. Even though the products contain NTA, it is allowable to use them and to sell them to professional customers. At a management meeting the question of what to do with the entire stock of old brand chemical products comes up.

Wilma Next point: We have old branded products in stock. What is the problem here?

Therese Well, Bosse wants us to mix in the old products with the new. But it is not okay with the labelling, we got a recipe approved - we are not allowed to change that. 
Erik Yeah, he says that we should just dilute the new products, it won't be noticed.

Wilma How much is there?

Therese Five pallets of powder products.

Wilma There has to be so little that it won't be noticeable. Or could we do it any other way, other than destroying the products?

Lars How large is the risk that we will get caught?

Wilma Well, you could think about it like that, but there is also a question of trustworthiness.

Markus Yes, but we need to remember that the quality of the product is the most important thing!

Lars If they made the judgement at the chemical department that it is ok, then it should be ok for us.

Wilma Yes, that would be the best.

Therese It is just a little mixture of the other chemical in each product, but the total amount of NTA is quite large. And they think that NTA is carcinogenic. Sara and Eva do not want to do it, but is Tobbe ok with it?

Erik Well... He will only do it because a certain person says that it is ok.

Wilma At the same time, our largest competitor has NTA in all their products.

Therese But they have been reported for it, so we might not want to do the same thing as them.

Wilma No, we do not want to damage our trademark, but we need to figure out how to handle this.

Erik We [Therese, Erik and Wilma] can put together some numbers on this and discuss it. Have we sent down the products for mixing to the inventory yet?

Therese No I stopped it. ${ }^{4}$

The discussion is difficult since important matters of care in the organization are put against each other. There is no decision about how they will handle the problem at this meeting. Later on in the meeting they talk about how they feel that the fast switch between the brands was not fully anchored in the organization in advance, and about

\footnotetext{
${ }^{4}$ Later on Therese told me how she felt very uncomfortable with the discussion and that the group decided to destroy all the old products since they did not want to risk their trademark and the commitment to the environmental label organization.
} 
how to make sure this will not happen again. There is no easy solution to this issue; either they throw away usable resources or they break the deal with the environmental organization. Either option will have a negative impact on their business, through wasting resources or risking getting caught changing the recipe. The discussion opens up questions about what is the most important matter of care for their company. Trustworthiness, quality and saving resources are all values that should not be compromised. NTA is a chemical that is not accepted in the new products HygieneTech sells, due to the certification from the labelling organization and also as a conscious choice made by the company to reduce the use of harmful chemicals. Their choice to become more sustainable puts them in a position that some of their competitors never have to face, since sustainability is not a matter of care for these competitors. Caring is not always affectionate and easy, as we find in this example; caring for sustainability is sometimes a test of what we are prepared to do in its name.

What we also learn from this example is how Bosse has an important, and very clear, role in the making of the sustainable company. For Bosse, as have shown throughout this thesis, sustainability is a way to care - for people, but most prominently for saving resources for the benefit of nature and economy. "Sustainability is saving!" Bosse tells me in interviews and sustainability reports (see Chapters 3 and 5). In this way of reasoning, the sustainable choice is to make sure that all products are used in the best way and that functional resources are not wasted. With this version of sustainability the choice should be to use all products in order to make the most rational use of the already produced goods. Bosse has an important role in the company; he is the founder of the company and of the sustainability work at HygieneTech. His words therefore carry significant weight for the employees and add another dimension to the dilemma. Even so, he does not control everything that happens in the company and has delegated a lot of responsibility to the employees. Therefore it is possible for the employees not to comply with Bosse's suggestion since they value other things more highly. The members of the management meeting believe that other matters of care have a higher priority in this case, and they care for trustworthiness and quality over saving resources.

\section{Certified sustainability as care enabler}

The sustainable product is a result of a great number of processes, including those related to criteria from Svanen, safety equipment, and negotiations over matters of care for nature and humans. The labelling process is a way for HygieneTech to show the customers that they care, and a way to structure their sustainability work. The work with environmental labels is very central to the sustainability work at HygieneTech. 
Furthermore, the extensive collaborations with Svanen have made it possible for them to predict and give feedback to the development in the labelling of hygiene products. Through this work, HygieneTech commit to an agenda set by Svanen, and consequently they accept the requirements set by the labelling organization as a way to do sustainability. This means that the company accept and enact sustainability as done through the areas the labelling organization states: forbidden (harmful) chemicals, packaging, performance and effects on nature and humans. This is how products are enacted as sustainable at HygieneTech, and the making of the sustainable product is the making of the certified product. It is not too harmful either to people or nature, even though it can cause damage. Instead of doing the valuation of what is a sustainable substance "in house", HygieneTech leaves the decision making to what they see as a neutral organization, Svanen. Through this organization, which is enacted as a neutral control organization, HygieneTech gain legitimacy for their sustainable products. Being in a small company, the employees at HygieneTech do not believe that their own claims about their products' sustainability carry enough weight to completely convince their customers, and so the Svanen label provides the necessary reassurance. Working with labels also gives them an opportunity to test their products through a ready-made process of regulation to help the employees improve the company's products.

HygieneTech lives in messy realities in which the sustainable product is very important, while not always easily enacted. This is due to the corrosive and environmentally harmful substances that are needed to fulfil their business idea: cleanliness. These substances are somewhat harmful, but since it could have been (and has been) worse, they are, in relation, made sustainable. The making of this reality is not always easy; it entails a struggle between several matters of care as we have seen in this chapter. The sustainable product is done in different versions, but what is interesting is how this is achieved and when the product becomes contested. When the demands on a labelled product clash with another version of sustainability, such as care for the health of employees or saving resources, some issues become absent. Care for people, the health of the employees, is already institutionalized in the organization though work health and safety regulations. In order to achieve sustainability as labelling and saving resources by not by diluting products for more efficient transport, the corrosiveness of the product is absent in this sustainability work. Sometimes the issue of heavy lifting is brought up, but the question never lasts long on the sustainability agenda. Social issues related to the product's properties are not seen as sustainability issues. This is partly because they are handled elsewhere and partly because they clash with other versions of sustainability that have stronger allies in the network. Caring for the sustainable product is thus dependent on separation in place 
and time (care for health and safety issues is handled elsewhere) and by making the matter of care "caring for people" absent in enacting the sustainable product.

Likewise, as I have shown in other situations in this chapter, it is not possible for the employees to care for all matters at the same time. Besides sustainability as labels, sustainability as saving resources is an important version of making sustainability in the company. As I have discussed, care for matters such as the quality of the product, avoiding the use of some chemicals (e.g. NTA), and the relationship with Svanen are more important than the version of sustainability as saving resources. The making of sustainability through labelled products is thus a collection of stories about care for different matters. Even though labelled products are contested in some settings, what is evident in this chapter is how important labels are for the identity of HygieneTech as a sustainable company and how strongly they care for the labelled products.

Furthermore, the labelled products are "green" products, they have a different bond with the employees than products without labels, which are given a red mark. Green products are enacted as the desired products; they pass more easily through processes than the red-marked products do, without having to show their qualities. The labels enact the "good" products and this changes the role products play in HygieneTech. The labelling process is thus very important for the ordering and enactment of sustainability in HygieneTech and has the power to shape and reshape relations and to create matters of care. Care for environmentally friendly products has always existed in the company, but the labels enable HygieneTech to care in a more structured and visible way. Bosse's aim to make less dangerous soap is a part of the foundation of the company, but still, the labels are enacted as the best material proof that HygieneTech's products are sustainable. In this thesis, labels will be called care enablers, since labels make it easier for smaller companies to care for sustainability through legitimizing what they do as care and providing both a structure for caring and a material mark on the products.

To be a care enabler is to facilitate an agent's ability to care; that is, to provide opportunities to carry out caring practices. The labelling process has the power to configure care through defining what sustainability is when it comes to cleaning products. Environmental labels are highly valued in HygieneTech and, as I showed in the case of the green- and red-marked products, the label protects the products from further investigation. A labelled product has a shortcut to the product catalogue, while the non-labelled product has to argue more in defence of its own existence. This is one way that the structure of labelling in the company shows how sustainability is done; the label is used as a marker of sustainability. In this process, sustainability is not only legitimized through the power of the labelling organization, it is also defined through the structure of making environmental labelled products. Smaller companies do not 
have the resources to market their sustainability work or to investigate the consequences of their choices in the development of products. Instead, the label organization takes responsibility for making regulations concerning what sustainability looks like and thus removes some of the accountability from the company.

The label organization facilitates care by legitimizing what sustainability is and providing the company with a structured way to care. Care enablers have the ability to distribute care in the organization. Instead of only having the environmental manager caring for the environmental friendliness of their products, the labels enable and engage other actors to care for this matter. The label organization uses regulations to state what care for the environment through products should look like; this care is then distributed to the different roles at the producing company. The chemist is responsible for caring for a mixture that does not contain forbidden chemicals, the market manager is responsible for making the packaging of the product in a sustainable way, and the environmental manager is responsible for caring for the overall labelling process. This process enables people to care, not only by stating what this care looks like but also by distributing care within the organization.

Another, different yet related, example of distribution of care is found in Winance's study of how technical aids for disabled persons can be a way to share care among the members of a collective (Winance 2010). The request for different technical aids (such as wheelchairs, adapted seats, etc.) just as often come from the disabled person as the caretaker, and these aids make it possible to change the relationship between the members of the collective. The request from the caretaker shows that the caretakers need help, too, at least in giving good care. Through this process, care is distributed to not only being about caring for the disabled person, but caring for others in the collective. Moreover, it provides new freedom to the disabled person and thus changes the relationship to the caretaker. In a similar way, the labels change the relationships between the employees as well as the employees' relations to their products. The process of labelling products involves employees that had not been as interested in environmental issues before. Even though care enablers is a way to enable the employees to care for sustainability, the labels require tinkering to be part of the everyday of HygieneTech. Some argue that the product might have been better without the label, even so, the employees view the label as a part of being HygieneTech. They therefore care for the environmental product through tinkering with their practices, marketing it and enacting pride in the choice of being an environmentally friendly company and selling labelled products. As I will show later on in this thesis, there are more care enablers active in HygieneTech, and of these, labels are enacted by the employees as the most important in their sustainability work. 


\section{5}

\section{Paperwork: The making of sustainability on paper}

Conserving the earth's resources has always been an obvious practice at Clean Hygiene. Not only important, it was a given. Long before words like "climate impact", "sustainability" and "climate compensation" became buzzwords, we worked with ways to save water, gas, oil and labour hours. It became public knowledge that the owner of the company, who was brought up in the deep forests of Sweden, makes sure that no resources go wasted. During the 90 s, he got the farmers in the company's area to grow canola, so that our vehicles could run with as little environmental impact as possible. As a nice side effect, you could tell from the smell when we were in town.

This is a short text from the introduction in HygieneTech's sustainability report from 2011. The text is an enactment of doing sustainability, since practices of sustainability are not done only by labelling products or discussing sustainability issues. In some ways, the material actors included in the sustainability work at HygieneTech are the foundation that guides what sustainability is and how it should be done. Paperwork is done everywhere in HygieneTech. Sometimes the paperwork requires real, material paper, and other times it is virtual paperwork. Some of the documents tell us the story that HygieneTech wants us to see, through sustainability accounting, marketing on the web page and information material. Other documents are used to spread information, and still others, such as inventories or checklists, are used by employees to structure their everyday work. In this chapter, I study a few documents that have a strong connection to sustainability in order to understand how care is done on paper. 
A starting point for this chapter is that text can be seen as a practice! There are practices in writing the documents and there are also practices in using, discussing and living by the documents. The produced documents can be seen as inscriptions, that is, representations of natural phenomena (Latour and Woolgar 1986), and they deserve attention since they will also tell us a story of doing sustainability at HygieneTech. I will unpack some of the work required to create this version of sustainability. This will provide an understanding of the documents' role in the networks where sustainability is enacted. Documents can be a way to create a story in which divergent opinions are suppressed in order to establish a shared and enforced common ground (Smith 2001). The texts are also a part of reaffirming the existence and identity of the organization through policies that tell the employees what it means to be a part of the organization (Cooren 2004). In this way documents are part of creating the sustainable company HygieneTech. By also analysing the non-human agents, in this case the documents, we can understand the "mode of being and doing organizational forms" (Cooren 2004, p. 380). Documents are a part of the soul of HygieneTech, therefore I find it important to listen to voices about the documents as well as to the documents themselves.

I will study how sustainability is translated through the work with documents, since texts can be used to discover and unravel the situations and actions in which they are embedded (Smith 2001). Documents can also have other purposes, such as obtaining power; by ascribing agency to documents, more power is directed to the owner of the documents (Cooren 2004). Furthermore, care practices are embedded in many of the documents produced at HygieneTech, as they tell stories of how the employees enact care for sustainability in different ways. Some care is made explicit, such as the care for the environment described in the sustainability report. Other care practices are not as explicit and sometimes not as well articulated. In the documents, I look for what is made present, but also what is made absent. The sustainability report shows what sustainability is for HygieneTech, but also what is not enacted as sustainability. I study what is cared for in the documents and in the making of sustainability through the documents. Care for a matter, in this case, is that what is brought forward as important in the texts and in discussions. Concerns that are given privilege over other matters in space and time are seen as cared for. That which is not required, but written in anyway, has a (caring) attachment to it. But also, the matters that are not there, that is, the matters that have been made absent, tells us about enactments of sustainability. Matters that are silenced in the documents may have a voice outside the pages of reports and analyses, and they will show how different versions of sustainability are made in documents, and they will also show when they clash.

I begin by analysing the annual reports, since these formal documents discuss sustainability in an economic setting and how economics is related to sustainability. 
Moreover, I study the environmental and sustainability reports and how environmental issues and sustainability are enacted in these types of documents. These reports are partly used as marketing tools and tell a slightly different story than the annual report. I have chosen these documents because they explicitly tell stories about sustainability and thus enact sustainability in (text) practice. There are of course mentions of sustainability in many other documents in HygieneTech, and some will be explored in the chapter about ISO 26000. The choice of looking at a standardized annual report and voluntary reports (environmental and sustainability reports) is grounded in a search for the stories that HygieneTech wants to tell to others. This chapter therefore takes an interest in the practices that are put forward as important in HygieneTech's sustainability work while still trying to understand what is made absent.

HygieneTech's annual report reflects the company's commitment to sustainability, but in limited ways. In the sustainability report on the other hand, sustainability is in focus, and this document shares a story of how sustainability is enacted officially by HygieneTech. The annual report is required by law and has a regulated structure. The report has to include a profit and loss account, a balance sheet and a directors' report. The profit and loss account shows details of income and expenditure for the financial year. The balance sheet is a summary of the company's wealth, assets, liabilities and equity at the balance sheet date. The annual report is a public document that is handed in to an authority, Bolagsverket (Bolagsverket 2014). There is little space for creativity in the annual report since it is closely regulated and may be read by anyone interested in the company. Since 1999, companies in Sweden have also had to include a disclosure on environmental issues in their reports (Kolk 2003). Previous research has had trouble showing a significant relationship between the annual reports that also include environmental disclosures and the firms' actual environmental performance (Cho and Patten 2007). Following the theoretical approach in this thesis, the "truth behind the text" is not an accessible entity that can or should be weighed against the promises in the report; instead, the report shows the information that HygieneTech wants us to know about their sustainability work, and thus it shows how sustainability is enacted in writing. The report is crafted for a certain purpose, and like the diagrams Lynch and Woolgar studied (Lynch \& Woolgar 1990), the report is not a representation of the "world out there". Instead, it contains an enactment of sustainability, presenting it as something to be proud of. The reports - annual, environmental, and sustainability - enact sustainability as it is done in paperwork and it is thus another practice in which sustainability is important at HygieneTech.

In contrast to the annual report, the sustainability report is more likely to be used for marketing purposes. The different purposes and different degree of regulation around the reporting practices for annual reports and sustainability reports frame what is 
possible to do within the documents. I will firstly study the annual accounting report with a focus on sustainability and then move on to the environmental and sustainability reports. At the end of the chapter I will study some of the practices behind the making of the stories in the sustainability report in order to unpack the work required to produce these stories.

\section{Annual financial report}

Annual financial reports might not sound very exciting, even to some economists. I still believe that there is a point that can be made with the help of these kinds of reports, and I will only show you (what for me were) the most thrilling parts of the report. Even if the environmental section of the annual report is instituted by law, the combination of economic accounting and environmental issues brings about interesting tensions. In this section I will show what parts of the sustainability work are enacted in the annual financial reports for 2010 in order to understand what stories are told through the report.

HygieneTech, together with the company that produces HygieneTech's chemical products, is a subsidiary to Clean Hygiene AB. HygieneTech was the original company that Bosse started. Later on he also bought Spotless Production AB and placed both companies under Clean Hygiene AB. The three companies have separate accounting and annual reporting processes. Even so, the documents are very similar except when it comes to the economic figures. I will mostly discuss Clean Hygiene's financial annual report, since most issues from HygieneTech's and Spotless Production's annual financial reports are also brought up in this document.

Clean Hygiene's annual financial report describes the companies' economic situation and also states that they are trustworthy hygiene partners who care for the environment. One example of their care is the different education programs they offer to help their customers become more environmentally friendly. Under the heading "Research and development", environmental concerns are again brought up as a part of their practices. As an example, the document mentions that in 2010 they replaced one of their well-known chemical cleaning products with a more environmentally friendly product. Clean Hygiene and its subsidiaries are certified according to ISO 14001, and their work with ISO 26000 is mentioned as a part of Clean Hygiene's quality and environmental commitment. Furthermore, the companies environmental impacts are presented and, in this section, they focus mostly on packaging and transports. Water pollution are mentioned as a negative result of the customers' use of the chemical products. Furthermore, one section describes HygieneTech's environmental efforts and how this work has mostly involved labelling, transports and 
packaging. HygieneTech's work together with Svanen is seen as important and a result of their early efforts in working with environmental issues. In contrast, the annual report says very little about Spotless Production's environmental work. HygieneTech is much more present throughout the document and Spotless Production is often invisible when it comes to non-economic issues.

HygieneTech and Spotless Production have their own annual financial report as well. These documents are similar to Clean Hygiene's annual financial report except on a few points. HygieneTech's annual financial report has more information about their environmental work, and three major environmental issues are put forward as important: transportation, chemicals in their products, and packaging. Moreover, the document tells us that the company's sellers have been trained in eco-driving and that emphasis has been put on logistics to ensure that sellers plan their customer visits in ways that minimize the distances travelled between customers. HygieneTech's numbers show that, in 2010, the company made a profit of 2.9 million SEK (316 000 EUR). This result was slightly lower than expected because some employees were moved from Clean Hygiene to HygieneTech. In contrast to the other companies, Spotless Production lost about 400000 SEK (44 000 EUR) in 2010. However, since the company has had worse results over the years, this result is seen as a success. In total, the companies had 33 million SEK (3.6 million EUR) in earnings, and no dividends were paid in that year to Bosse, the sole owner.

The financial reports tells a story in which the companies are interested in more than just economic success; other issues matter as well. This document was written at the beginning of 2011 and the focus is on environmental issues rather than sustainability. The document shows that the environmental issues are connected to, or at least not in conflict with, economic issues. What matters is not only the profit and the economic story, but also other matters such as quality and environmental concerns, which fit well with this version of how Clean Hygiene worked in 2010. Economic and environmental concerns can be presented together, but the subjects are treated differently. Economic concerns are presented in numbers and tables according to accounting traditions. Environmental concerns, on the other hand, are presented in words and without numbers. Money amounts can be measured and compared. Care for the environment is done differently, by describing practices connected to the core processes, together with text about ISO standards. Economics is made real through numbers, while care for other matters requires words.

The story told in the annual financial reports is of course just one story of what happened in the companies during 2010. The economic story is paired with concerns for the environment but not with concerns for fair business methods, care for the employees or other factors that HygieneTech otherwise sort under sustainability. Other 
matters of care, often referred to as social responsibility, are left outside this document. They are not mentioned in the economic story about HygieneTech. I argue that this is in line with the version of sustainability that HygieneTech often presents; sustainability is about saving resources - both economic and environmental. The environmental matters of care (and their practices) are connected to making more money through saving. However, the environmental issues presented in HygieneTech's annual report are not all easily organized directly as economic concerns. Packaging and caring for logistics are both economically and environmentally viable, but using less polluting chemicals is further away from saving money than the other practices. There is of course an (economic) risk in using polluting chemicals since these might be prohibited in the future. However, as the story is told, this is not the main reason HygieneTech tries to work with this issue. As we have seen in Chapter 4, working with environmental labelled products is seen as fun and engages employees in other ways than those concerning purely economic profit. The annual report shows that there is a pride in enacting the environmental work in writing, not only in relation to economics.

\section{Environmental report}

The environmental report (later, the sustainability report) is voluntary and there is no standard for how it should be presented. For some years HygieneTech reported their environmental work in an environmental report. The last environmental report was done for 2009. In 2010 Therese became the new sustainability manager at HygieneTech, and due to the shift in staff no environmental report was done for 2010. In 2011 they started working with sustainability reporting instead of producing an environmental report.

The first page in the environmental report from 2009 shows a picture of Wilma, and her words are the first to greet the reader. Her text informs the reader that HygieneTech has $95 \%$ environmental labelled products and as many as 28 green cars. She tells us that their environmental work is very important for the organization, and at the bottom of the page she provides us with her own environmental tips, such as: "I always try to stack the dishes so that the dishwasher is full." It is evident that Wilma is personally engaged in these issues, both at work and in her personal life. The following pages introduce us to several of the employees at HygieneTech, who advise us to change our old light bulbs to more energy-efficient ones, and to use public transportation more often. These small, individual steps are presented as caring for the environment and committing to change for the sake of the environment. The document enacts caring for the environment as an easy task! This report tells a story in which 
care for the environment is done through small gestures individuals can make in their everyday lives. The suggestions that are put forward all point to actions individuals can take on a regular day, at home or at work. Likewise, the environmental employee of the year (which happened to be Therese, who at that point worked as a chemist) is presented as a role model of what a responsible employee at HygieneTech should be like. Caring for the environment is easy and takes little effort, the report tells us. You can do it now! Just switch that computer off!

These tips are of course just a small part of the environmental report. HygieneTech's work with less-polluting chemicals, packaging, energy-efficient office machines and paper consumption are put forward as the most important topics during the year. The report contains many pictures of people and scenes from nature, but there are few numbers. Caring for the environment is fun and easy, it enacts, and any trouble the company might have in agreeing about what this care should look like is polished out. This is a common procedure in documents: creating a story in which divergent opinions are suppressed in order to establish a common ground (Smith 2001). Unlike policies or internal documents, this report is used to provide information on (and possibly inspiration) about HygieneTech's work with environmental issues. Taking into account the setting in which this highly polished document was created, it is evident that it was made to be easily digested and uncontroversial. Rather than telling us about problems and institutional responsibility, the report tells us about the fun and easy parts of caring for the environment. Other than numbers for the labelled products and green cars, few numbers are used to describe their work with environmental issues. The environmental stories are told in words, not numbers. They are told in words that empower the reader, that show that what we do matters. The report presents Wilma, Therese and a few other employees as representatives of the environmentally friendly employee, and it enacts individuals' choices as important. Environmental issues are personal. Interestingly, this approach returns in the sustainability report, which came after the environmental report.

\section{Sustainability report}

Since 2011, HygieneTech have produced a sustainability report each year. They changed the name from "environmental" to "sustainability" report because they felt the new concept better described what their organization was already doing. The decision to do a sustainability report instead of an environmental report therefore seemed like a natural step, according to Therese. The number of (large) companies that produce a sustainability report today is increasing (Simnett, Vanstraelen \& Wai Fong 2009). Among large companies, the chemical and pharmaceutical companies are 
among the most likely to publish sustainability reports, while the non-industrial companies are less likely to do so (Kolk 2003). HygieneTech is a part of a market that has a high degree of knowledge about the environmental effects of chemical use. They might therefore be more likely to think of doing a sustainability report to show how they respond to environmental concerns. I briefly introduce the overall content of their sustainability report and then focus on a few areas that I find most interesting in the way they tell the stories of how HygieneTech worked with sustainability in 2012.

The sustainability report is more comprehensive than the environmental report and it contains more metrics. The sustainability report pertains to all three companies and their relations to each other are described in the beginning. The layout and the content of the 2012 report differ slightly from the 2011 version. One obvious reason that the 2012 report was changed was that there was a change in CEO. Wilma resigned in late 2012, and Bosse took her place and also took charge of writing the introduction in the report. First comes an introduction to the operational policy of Clean Hygiene and Bosse's introduction; after this, the different companies and their internal relationships are described. The following two pages talk about HygieneTech in relation to the professional hygiene market and explain why customers should choose HygieneTech as their supplier of hygiene products. "The customer is at the centre" is the heading on an early page, and by highlighting the importance of the customer, the report wants to emphasize that the company cares not only for the environment but also for its customers.

Under the heading "The green thread" we are told about how HygieneTech takes a holistic approach towards environmental issues. The description starts in 1993, when the company introduced the first environmental labelled detergent for the professional market. Once again, the history of HygieneTech is put forward as an important part of the company's environmental friendliness. HygieneTech is a product of a long tradition of taking care of the environment, a care that Bosse brought into the company and which has lived on throughout the company. This care for the environment resulted in the use of biogas for some of the trucks and also in the company's becoming certified according to ISO 22716 (a certification for the production of cosmetic goods). The next sections include the headings "The sustainable transaction", "Social responsibility", "Openness and transparency" and "The future". Some of these sections will be studied in more detail, starting with the introduction by Bosse.

\section{Introducing sustainability as resource saving}

Bosse's text covers half a page and under the first topic, "resource saving", he takes us back to the farm in the small village where he was born: "I was born after the war and am the youngest of five; I was raised in a reality of saving resources" Bosse tells us about what it was like living in poor circumstances, with parents who took pride in 
making sure that all resources were used to the fullest. He almost never got new toys and was never allowed to throw away food. Bosse tells us that his upbringing has made him who he is today, and it made it easy for him to think in environmental terms as a company leader.

When I got the opportunity to start HygieneTech I had no problem with how I was going to go about it. I had my role models and impressions since my upbringing, I did as I had been taught, saving resources and talking to customers and later on to employees. The car was always considered one of the largest environmental villains, just as it is today. From the first day as a seller, I planned my travel routes and meetings with customers so that I never had to sit in traffic jams [...] HygieneTech's environmental work started with this - with efforts to make the best use of resources in every possible way! I drove my car as little as possible; in addition, I had the seller, products and the supplier on the same cost [sic!]. Nature cheered! But who profited the most? HygieneTech did, and so did I; I had time for two more customer visits each day! The environmental/nature saving was free!

This is Bosse's story of HygieneTech and their sustainability work. It is as easy as changing light bulbs. Sustainability is about saving the environment and this is done for free! In addition, Bosse makes more money through his version of sustainability. Moreover, he writes the future with the story of the past. In his world, few things have changed since he was growing up. Resources still need saving and HygieneTech will continue to save in the manner they always have! His story is the introduction to the sustainability report, and it tells us about the practice of sustainability through personal inspirational stories. The individual, in this case Bosse, is made important for sustainability. Unlike Wilma's section introducing the 2009 environmental report, Bosse's introduction takes a more historical and businesslike approach. He does not share any personal tips, we do not know the manner in which he loads his dishwasher. Instead, he talks about his upbringing and a way of thinking about resources that he takes with him everywhere he goes.

\section{The sustainable transaction}

The longest section in the report is "The sustainable business transaction" (en halllbar affär). This section shows us how sustainability is a part of HygieneTech's business transactions with their customers. We are presented with a graph in which the most important environmental and social aspects are highlighted. What is interesting under this heading is what they have chosen to present as a part of a sustainable transaction, what is mentioned but not explained, and, of course, what is missing altogether. The 
first subheading concerns the product's life cycle, and in a few sentences we are told about the production, use and destruction of HygieneTech's products. Under the next subheading, "Impact on sustainability", the environmental aspects of the production and use of the chemical products are briefly discussed, while the social aspects are just mentioned in this sentence: "Social aspects are assessed annually by the sustainability group at Spotless Production, consisting of representatives from the companies." The social aspects seem to be harder to put into words, not to mention numbers. The text in this section does not explicitly say what these social aspects are, and this is not brought forward as an important part of the subject. It does say that the company cares about social aspects, which are made present but not explained. Instead, the rest of the text describes the sustainable transaction and presents information and numbers about the following:

- The level of discarded products in the production process; it lies below $1 \%$, which is seen as extremely low.

- Carbon dioxide emissions from transport (the sellers' trucks use about 800000 kilos of carbon dioxide per year) and the number of green cars $(36 \%$ in HygieneTech). There is also a picture of Bosse looking very pleased while charging the company's first electric car.

- Waste and recycling of used packaging (25 tons of plastic packaging are reused during 2012 - a decrease from 2011 when 38 tons were reused).

- Water usage - and about HygieneTech's new cleaning process, which can release four times as much clean water than before 2007, when the process generated more wastewater.

- Percentage of environmental labelled products sold (95\%).

- HygieneTech's environmental cooperation with their customers and Svanen. In 2012 they did over 300 environmental statistical reports for their customers - an increase from 2011, when they only did about 260 reports.

The numbers in this section are an important part of the report, quantifying the practices of sustainability. They show that some practices of sustainability can be measured, and that it is important to relate to the measurements from previous years. Even though some of these numbers tell a story of not achieving constant improvement, they are still included in the report. Until this section, no issues have been raised concerning the work with sustainability. The problem with the lowered number of green vehicles is explained as resulting from the difficulties sellers were having finding suitable gas stations to refuel their biogas trucks, while the reduction in recycled plastic is explained with reference to the decision to stop recycling 10-litre containers. The report explains that the decision to stop recycling these containers was due to both environmental and economic considerations. Furthermore, the report 
acknowledges that this decision will of course affect the statistics, but it notes that the company will instead focus on lowering the environmental impact of its transports. If the intention was to use the report only to show a polished story of sustainability at HygieneTech, it is interesting that these numbers appear in a report at all. I will come back to this issue later in this chapter. It is also worth noting that the numbers showing the reductions in recycling are not unpacked more, but are instead balanced with an intention to reduce the environmental impact in a different part of the process, transportation.

This shows a view of environmental concerns as interchangeable. If some numbers are not satisfactory, they have to be countered with a positive effort in some other area. This can be seen as a way for the company to legitimize a failure to commit to an objective that was previously very important in their view of themselves as a sustainable company. Likewise, the failure to increase the number of green cars is explained by external factors, while all the positive developments are enacted as a product of internal processes.

\section{Social responsibility: A different story}

The next heading concerns social aspects and is labelled social responsibility. I find this divide between the sustainable transaction and social responsibility interesting. The sustainable transaction is all about efficiency and using the right materials: saving water, using the best fuel, labelling products and saving through logistics. It is about making good choices for economic and environmental reasons. In the sustainable transaction section, the social aspects are only very briefly mentioned as an annual assessment; even so, the social aspects are important since they are brought up later on. In this section about social responsibility, we are first told that the code of conduct guides everyday operations at the company, but there is nothing about what the policy says. The section also discusses taking responsibility for the right use of the company's products, the company's work with reviewing suppliers in accordance with ISO 26000, and the very positive results of their last survey on employee satisfaction, with $70 \%$ of employees indicating that they are "very satisfied" at work. Furthermore, we are told about their work with employee education; work health and security; and gender equality and diversity. A short section also explains the values that guide their actions:

In 2012 we worked to create a new business vision. At our annual conference, all employees contributed their own vision of what Clean Hygiene stands for, and these contributions were used to formulate our new business vision: "We will be Sweden's leading hygiene partner, recommended by all customers and employees." As we have worked to formulate what we stand for and what we want to 
communicate, we have changed one of our core values; the core values we now follow are Responsiveness - Engagement - Business focus - Respect - Creativity. All employees should live by these words from now on, and these words can be a basis for decisions on different issues.

This quote tells us a story about an organization in which everyone has a voice and in which all employees value the same things. How to live by the value of creativity and respect the text doesn't say, it just tells us that the core values, together with the operational policy and the code of conduct, are guiding the choices and the practices in the company. Social responsibility is not only towards the employees; the employees also have responsibilities towards the company. Social responsibility is thus both about care for people and care for the company, or the values of the company. The core values of the company are abstract notions about ways of doing things with care, through listening, showing respect and engagement while still being creative and thinking in terms of business. Having a business focus also means keeping economic considerations in mind. In this section, we are told about the infrastructure of handling employees and suppliers, but also about how employees should act. This displays care (for the company's employees and for employees of the suppliers) together with demands on care (on the employees and on the suppliers).

Caring for the employees entails costs, such as the cost of health care and time spent making sure that equal opportunities are provided. Likewise, there are costs involved in caring for suppliers' employees through spent time and maybe also negotiations with the suppliers. These costs are not mentioned, and the reasons behind the efforts are not discussed. This care is not problematized; it is seen as natural to commit to it. There is no need to rationalize a desire to care for people. No numbers show how much money is saved by having happy employees or making sure that everyone gets equal rights to education. What is taken for granted is that care for people is not done for economic reasons. Economic concerns, such as being businesslike, are only brought up in the section that discusses what HygieneTech requires of its employees, not under headings about how the company cares for them. In contrast to how care for the environment is usually defended as a way to save resources and thus save money, care for people is allowed to cost!

This section about social aspects of sustainability discusses the social side of doing sustainability, about caring for people. This is not part of the sustainable transaction since it has its own heading. Social responsibility is something that is done outside the core business; it is about providing care through health care, equal opportunities and caring for work conditions in HygieneTech and in the countries of their suppliers. The divide shows shows a disentangling of economic and social issues. The social aspect is 
added on to what is presented as the sustainable transaction. Since sustainability is enacted primarily as saving resources, it cannot easily include care for people since it not is legitimized as economical. The social aspect cannot coexist with a version of sustainability as saving resources. Therefore, a new object is created: social responsibility. This object is tightly connected to sustainability but is made present in different ways than a version of sustainability that is about saving resources. Sustainability as saving resources is legitimized and presented as an easy way to care for nature while making money. This rhetoric is not translatable to care for people since this care is mostly disconnected from economic profit. The new object "social responsibility" therefore holds a different position in the stories of sustainability than sustainability as saving resources.

\section{Making sustainability}

The next section is headed "Openness and transparency". Under this heading we are told about the work HygieneTech has done in cooperation with some of their stakeholders. Clean Hygiene sent out a survey to some of their employees and customers in order to identify the sustainability issues they view as the most important for the company to work with. The survey presented some categories of issues that the respondents had to prioritize in order of importance, according to their opinion. The categories were: environmental issues; working conditions and working environment; human rights; product responsibility; business ethics, and local development. In each category different actions were presented as well. The customers at HygieneTech prioritized them in this way:

1. Environmental issues

2. Product responsibility

3. Working conditions and working environment

The employees at HygieneTech made a slightly different list:

1. Environmental issues

2. Human rights

3. Working conditions and working environment

4. Business ethics

Environmental issues are the most important, according to the survey results. This fits nicely with the story that is told throughout the report, starting with Bosse's aim to make detergents with environmentally friendly ingredients. Although employees and customers agree on the most important aspect, thereafter, their lists diverge. The employees indicate that HygieneTech should work more with human rights, a subject that will be discussed more thoroughly later in this thesis (see the chapter about ISO 26000, Chapter 6). What I find most interesting in this section of the report is how the 
survey is done - in what is included in the company's version of sustainability. Here sustainability is framed as a few distinct areas while some subjects are made absent. Environmental issues are included while saving resources is not. Human rights are included, but not charity. Framed in this way, sustainability is not about making money nor about saving resources. Sustainability is about making good decisions! Sustainability is taken for granted and does not need to be legitimized in economic terms in this section. This text, just like the previous section about social responsibility, is different from the rest of the text in the report. This story is about caring for sustainability because it is important. Sustainability is important for the employees and for the customers, we are told. Asking whether economic sustainability, or having a business focus, is an important part of HygieneTech's sustainability work does not seem to have occurred to the creators of the survey.

\section{For the future}

The last heading in the report looks forward: "The future". In this section, we are told how important it is to look backwards in order to be able to look forward.

For the following years we set our goals higher - we will do at least four supplier valuations per year. Together with the suppliers we want to raise awareness about the sustainability issue.

Raising awareness, talking about and committing to improve accordingly are important to HygieneTech. In the following years Clean Hygiene will also work more with carbon emissions and reduce, or at least not increase, emissions per year. The second last section on the page describes how Clean Hygiene will work to save money by working with sustainability:

We at Clean Hygiene in Sweden will continue to fight for the customers' total dish cleaning budget and a sustainable future!

Once again we are brought back to the economy of doing sustainability! The choice of saying that they will fight for a sustainable future might contrast somewhat with the rest of the report, in which sustainability is enacted as easy and obvious throughout the development of the company.

At the end of the report, we are reminded of the foundation of the company: "Just as everything started with a focus on saving resources, we continue the work of creating a sustainable future for ourselves and our customers." To strengthen the presence of a "spirit of saving" we are presented with an image of an award Bosse was given for his efforts in the competition "The day of savings" in 1950 when he won 1 SEK (Picture 2). 


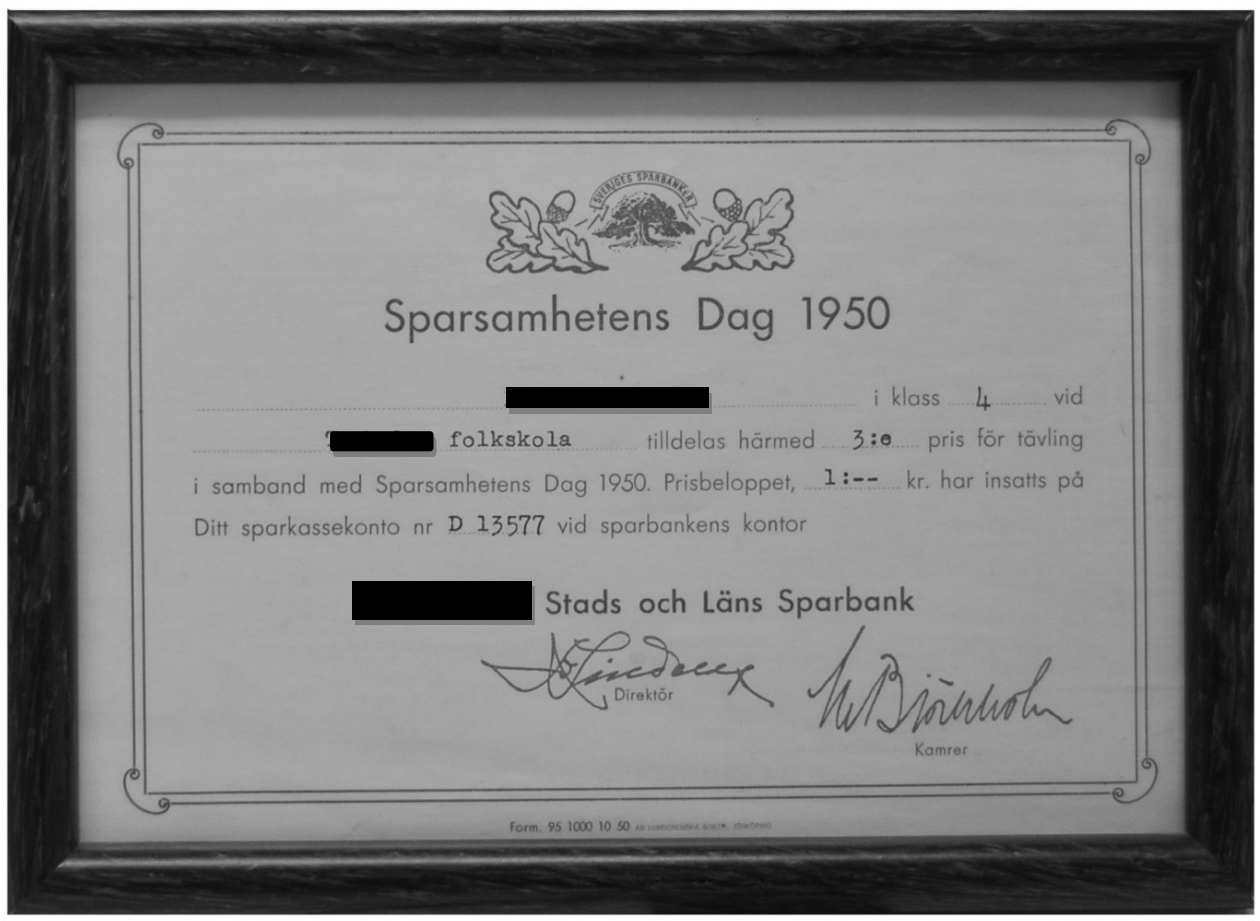

Picture 2. A picture from the sustainability report showing how Bosse won 1 SEK during a saving competition in his school in 1950.

This wonderful image not only illustrates how saving is built into the company's soul, it also tells the story of the great founder whose spirit still drives the company forward. Bosse is present in many of the pages of the sustainability report, constantly telling us how economical it is to work with sustainability. He is not present, however, in the sections where care for people or where sustainability as a principle appear. Bosse's presence is used to legitimize and explain why Clean Hygiene is so fond of working with sustainability. In one quote this becomes clear: "And today most people know what Bo Mollberg [Bosse] knew 40 years ago - that saving resources and sustainability work is pure profit!" Saving resources is a part of sustainability, but when it comes to Bosse's version, sustainability is saving resources. Therefore, this divide says something about the struggle of making a report on sustainability. The ecological modernization project has a natural place in this report, showing how easy it is to care for the environment while still expanding the economy. Even so, there is also a version of sustainability that sometimes comes with a cost, as in caring for employees and caring about local development and the working conditions at the suppliers. These efforts do not fit within the version of sustainability as a way to save resources and to make a profit. The reader of the report is therefore presented with two different versions of sustainability that are legitimized and presented in different ways. 
Even though these versions are different, they can still coexist within this report. The possible clashes between the versions are polished out and made absent in the text. In the next section I show the making of the report and describe how the employees deal with clashes in relation to making a sustainable report.

\section{Piecing together sustainability in reporting practices}

I have put in something about environmental issues and social aspects, but there are so many things we should include in the report. It is about being transparent and reporting on everything we have done and what we haven't done, however...

The silence lingers in the small office in which Markus (marketing manager) and Therese (sustainability manager) and I are seated for a meeting on sustainability reporting. Therese's statement and its open ending points to the problem of determining what to include in the sustainability report. As I previously mentioned, the sustainability report is voluntary and does not have a set structure as the annual report does. Common social aspects that appear in sustainability reports are (in priority order) community involvement, health and safety, equal rights, employee satisfaction, human rights, social aspects in supplier relations, child labour, freedom of association, fair trade, and corruption (Kolk 2003). When it comes to the economic aspect of sustainability, most companies highlight the economic benefits of sustainability in their reports (Kolk 2003). Research has shown that even though sustainability reporting has increased, the quality of the reports is still seen as poor (Comyns et al. 2013). In particular, indicators of greenhouse gas emissions are lacking from many reports (Guenther, Hoppe \& Poser 2006). It has been found that larger companies in polluting sectors are especially more likely to produce high quality sustainability reports (Comyns et al., 2013). Even though HygieneTech is not a large company, they have high ambitions in their sustainability work and therefore aim to be as thorough as the larger companies in their branch are.

There are several organizations that help companies to structure their reports; the largest one is Global Reporting Initiative (GRI). GRI has produced guidelines for sustainability reporting and states that the report should include the economic, social and environmental effects caused by the company's everyday activities (Global Reporting Initiative 2014). These guidelines have been developed to provide a standard way to show different performance indicators that can be used by all companies. These performance guidelines have been criticized for their inability to relate to performance, since a third of the indicators report on the existence of policies, procedures or documents (Kolk 2004). The guidelines are adapted for larger 
companies, and for our company the GRI reporting guidelines were never in question. Instead, Therese and the sustainability group looked at how other companies reported on their sustainability work and what they had previously published in their own environmental reports. Several different groups were involved in the creation of the report at different stages. Therese has the overall responsibility for the report, and in the first stage she talked to Markus about its content. In later stages she also consulted the sustainability group, and she asked Bosse to write the introduction.

Markus and Therese continue to discuss what to put in the report:

Therese It is environmental savings that are in focus in this report. Therefore, we could look at reduced water use for example.

Markus Right, but to be credible we can't work with ready-made standardized numbers.

Therese Maybe we shouldn't use as many numbers...

Markus Nor use percentages; only where we can be sure, I think, we should use numbers.

Therese This is something we can calculate, our use of plastic. When plastic is produced it require $\mathrm{X}$ kilos of oil.

Markus And we can connect that to our work with packaging, that's one thing we can write about.

Therese Yeah, but we haven't really done anything this year. Like our wire steel balls that come in a bag, in cardboard... From China. It is the same with the measuring tapes.

Markus But then we have to change that!

Therese Yes. But maybe we could do something else with packaging.

Markus We have the new packaging of detergents, the paste detergents. That saved packaging.

Therese That wasn't last year.

It is not only prioritizing the subjects that needs to be dealt with, as when they decide what to put in the report, some things do not qualify as suitable for different reasons. Therese and Markus feel uncomfortable about using numbers that they are not convinced can be validated properly. This relates to the absence of standardized and easy ways to calculate their sustainability efforts and is one of the reasons why the sustainability report contains fewer numbers than the annual financial report. They want to avoid using ready-made standardized numbers but do not feel that there are many options for including numbers on sustainability. Even though Markus and Therese were uncertain about what numbers they could use, the report gives us a few numbers on the sustainability work at HygieneTech. Carbon dioxide emissions are 
easy to report numerically, Therese told me, since they can get the information through the cost of gas. As we saw earlier, the report presented numbers from internal production processes (such as a low number on discarded products during production, reduced wastewater); also, numbers were used to report the carbon dioxide emissions from the sellers' trucks as well as size of the fleet of green cars. These numbers, as well as the percentage of labelled products and the number of environmental statistical reports, are collected from the internal processes of the company, and the risk of HygieneTech receiving criticism on these numbers is small. These are "safe" numbers that the company can be certain are correct, and thus they make it into the report.

Most numbers in the sustainability report tell a story of successful sustainability work at HygieneTech, but there are also numbers that show a slightly different version of the story. In an effort to include something that they can present in numbers, Markus brings up the company's work with packaging and plastic. Unfortunately, these efforts do not fit with a positive view of the company's work on sustainability, and show that there is still work to be done in order to become more sustainable. There is no pride in importing some products from China, especially since they come in several layers of (unnecessary) packaging. Even so, some numbers make it into the report. The number of kilos of recycled plastic is lower than the year before, and is explained by the decision to not recycle 10-litre containers (for both economic and environmental reasons). In addition, the number of green cars is lower than in the previous last year. When we are told about the decrease in recycled plastic packaging, this number is accompanied by an explanation of changes in the recycling process. The same goes for the number of green cars; even though it did not increase in the way Therese would have liked, the number appears in the report. These issues are explained with reference to simple facts, however. The reason they do not use more green vehicles is simply that it is not possible to refuel them in all cities. That this issue has arisen before is not mentioned, nor is it mentioned that it was an economic decision to reduce the number of biogas trucks since they broke down more often and took more time to refuel.

This small section in the report relates to a larger discussion in HygieneTech. The use of biogas trucks is not as easy a question as the report would suggest. Most of the sellers joke about the biogas trucks, saying that they are slow, take time to refuel and break down more easily than diesel trucks. "We did not commit to this, the company did," a seller said at a region meeting when the issue of biogas trucks came up. The seller added: "We are the ones who get stuck in the winter with a truck that won't start." The problem with refuelling the trucks is just one of the issues connected to biogas trucks. This discussion occurs in a different setting, mostly when the sellers are involved, and in other settings, the discussion sounds slightly different, telling a story about economic and environmental considerations. Wilma said in the very first interview that the decreased use of biogas trucks had to do with both economic and 
environmental consequences, however, this is not stated in the sustainability report. What is interesting in these different ways of enacting biogas trucks is how they are made different in different realities. In the report we are told about a sustainability effort limited by the inability to easily refuel in all cities; through the sellers, we are told about the fragile and slow trucks, while Wilma tells a story of economic and environmental considerations related to a sustainability effort. The green cars are made into actors that are invoked in different realities to strengthen their ontologies. The sustainability report is a reality in which sustainability is about the joy and profit of saving and caring for people and the environment. The problems of the fragile biogas trucks do not fit into this reality and are therefore made absent, and instead the responsibility for doing sustainability through green cars is limited by the cities' capacity for refuelling biogas vehicles. The story told in the report is about a company that has tried but failed (in some respects) due to factors outside its control. The economic reasoning in this case is not made present, but is stated as an unavoidable fact behind the argument.

In the case of plastic packaging, the choice was made to recycle less plastic since Therese's calculations showed that it was not profitable and probably not good for the environment either due to the need for hot water in the cleaning process. These practices and decisions are not visible in the report since the purpose of the report is not to show the difficulties that come with caring for the environment. The story that is in the report instead tells us that the environmental work at Clean Hygiene and HygieneTech is easy and profitable. It is not possible to problematize the sustainability work at HygieneTech in the report since the report is meant to show their good work.

During her discussion with Markus, Therese brings up transparency as an important matter of care to have in mind when writing the report. Still, some things, such as the over-packaged steel balls, do not fit into the report, while the lowered recycling numbers are acceptable. The polished surface is slightly stained by these numbers; even so, they have a place in the report. The reason some "dirty" numbers are allowed into the report can be explained by the continuation of Markus and Therese's conversation:

Markus: We are not listed on the stock exchange, so we are doing this more for our ISO 26000 standard, right?

Therese We don't have to report on this at all, really. But we are doing it to promote transparency, among other things.

Markus But if we talk about transparency, is there anything we should think about concerning the form of the report...?

Therese No, not really...

Markus But then we can think about who we do it for instead. 
Therese I think it could be useful when we talk to Hotel A, for example.

Markus But then it still is marketing material.

Therese Yeah... But if it is to be a report, it shouldn't be marketinglike.

Markus What is marketing-like then? Like Max [a hamburger company] won the gold cow for their report, isn't that marketing?

Therese True... We can look at some of the other sustainability reports that I gathered and see how they've done it.

It is a report, but still it is a marketing tool. It will be used to present what HygieneTech has done in their sustainability work and to show customers, suppliers and other interested parties why they should work with sustainability. At the same time, they want it to be similar to a financial report, presenting numbers and not trying to show off. They want it to be trustworthy, while at the same time not showing all the struggles that take place behind the scenes. The report is supposed to document all sustainability efforts made at HygieneTech during the year. These efforts are difficult to summarize and put into words, both due to the variety of the efforts and because some issues are not suitable for inclusion in a "marketing-like" report. I believe that the reason that this report tells us a mostly happy and easy-going story of doing sustainability is twofold: the report is used for marketing and the version of sustainability that is most dominant at HygieneTech is a version in which sustainability is talked about as easy and profitable. The complex struggles behind the scenes are other stories that rarely get told in reports.

Moreover, this conversation tells us something about why reports on sustainability and environmental issues have few numbers: it is too difficult and risky to try to quantify these efforts! To avoid being criticized for not being accurate enough, the company cannot use standardized numbers; instead, they need to find issues that can be quantified to put in the report. There are few publicly recognized ways to quantify sustainability, and therefore HygieneTech need to invent their own approach to determining what counts as a sustainability issue that they will be able to calculate accurately. The version of sustainability that is present in the report has to go through a narrow filter before earning its place in the document. The use of numbers, and the fear thereof, creates the version of sustainability that is enacted in this report. The care for sustainability that is practised in the report is partly limited by the inability to create legitimized numbers. The things that can be easily converted into numbers are more likely to turn up in the report, even if they are not as positive as the company would like them to be (such as in the case of recycled plastic packaging). This report is not enacted only as a marketing tool since it also displays what can be interpreted as 
failures. Instead, it is a tool to make the company transparent, at least to some extent. Balancing the need to be trustworthy with the need to promote the company is an important aspect in creating the care that we have seen in the sustainability report.

\section{Caring through paperwork}

In this chapter I have studied sustainability work that is done in paperwork, specifically in reporting practices. The care that is made present in the reports is multiple; the care for people and the environment in particular is made explicit. In the presentations it is more of a nice side effect, the company makes a profit from working with sustainability. This relationship between economic profit and the environment is interesting to follow through the annual financial report, the environmental report and, lastly, the sustainability report. In the annual financial report, the economics are in focus and environmental issues are given a few lines between the long lists of tables of numbers. Here, environmental concerns are not presented in numbers; instead, the report shares some of the issues that HygieneTech has struggled with as well as some of the measures they have taken in their efforts to deal with these issues. The annual report is regulated and the company has to include its environmental impact as well as its the efforts to address the issues and the results of its work in dealing with them. Because it is so highly regulated and therefore it has another set of practices attached to it, the material in this report differs from that in the other reports. The environmental concerns are not legitimized through economics, but are instead added onto the existing economic report. Environmental concerns are not as entangled with economic profit making than in the other reports.

Like the sustainability report, the environmental report contains few numbers, and its structure is very different from that of the annual report. In this report economics and environmental concerns are coproduced. The version of sustainability as saving resources is enacted as personal, easily done and important. There are voices from several people present in the report who provide the reader with small tips on how to be more environmentally friendly in their everyday lives. This report enacts care for the environment as a responsibility that is mostly focused on the individual, suggesting empowering actions to which everyone can commit. This individualized care is not present in the sustainability report; here the company is in focus and the only person present in the text is Bosse. It is also here where the focus on saving resources becomes present as a way to legitimize the work of caring for the environment.

In the reports, the entanglement of making profit and caring for the environment is a common way to enact sustainability as saving resources. This version exists in the annual financial report, the environmental report and the sustainability report. In the 
first page of the sustainability report, Bosse gives an example of the coproduction of care for economic and environmental matters. He describes his upbringing and we are invited into his childhood in order to understand how sustainability is good for us (and the environment). Caring for sustainability does not come with a price, only with benefits, according to this view. Bosse is central to this version of sustainability, featuring as a spokesperson in several of the pages of the environmental and sustainability reports. His background is enacted as important to explaining why he believes saving resources is essential. His disadvantaged childhood and the place where he was brought up are made present in relation to his view on sustainability. Highlighting these circumstances gives the reader the impression that cost efficiency is second nature to him.

There is another part of the sustainability report that cares for matters other than the environment and economics. Caring for employees is seen as separate from business transactions and caring for profit. As shown in the sustainability report, caring for people does not need to be legitimized; it is taken for granted that HygieneTech care for their employees and the surrounding society. In contrast to care for nature, which is repeatedly argued for as an investment, economics is not part of the social aspects of sustainability. These two versions are included in the same report but are presented differently and with different wording. Sustainability as saving resources is about caring for the environment and saving money at the same time; this care is often legitimized with reference to economic measurements. In contrast, sustainability as care for people is not legitimized - it holds a different position and needs no explanation. Caring for people is self-evident in the sustainability report. Sustainability as care for people is presented on its own, separate from economic concerns. Care for people becomes something else, since the enactment of sustainability as saving resources holds such a strong position in the report. Care for people is turned into a separate object, while still connected to sustainability. The new object is called "social responsibility" and can coexist with sustainability as saving resources in the report, as long as they are kept separate. Even though social responsibility is given several pages of the 20-page sustainability report, it is sustainability as saving resources that is in focus. It is made present in ways that make it clear to the reader how profitable and important sustainability as saving resources is. Both the introduction and the final part of the report bring us back to Bosse's childhood and the importance of care for (scarce) resources. The future is framed with stories from the past, thus enacting the concept of sustainability as part of the company's identity.

The stories in these reports tell of the many efforts that are made in caring for the environment and sustainability, while the struggles of shaping the texts are made absent. In the meeting between Therese and Markus we get a glimpse of the work required to polish the stories so that they will fit within the reporting context while still 
staying true to the idea of transparency. Reporting, environmental and sustainability reporting specifically, is hard work when it comes to making a suitable story of HygieneTech's sustainability work in 2012. Different matters of care clash when the employees view the reports as marketing tools and, at the same time, as an ethical engagement in transparency. The stories that appear in the sustainability report are mostly success stories, describing the good work done by the companies. However, some numbers that are deemed valuable for the report are allowed to be part of the text even though they show the company in a less positive light. The numbers reflecting negative aspects are explained with reference to factors outside of the company's control, or as the expected results of well-thought-through decisions. These numbers can be a way to show transparency, thereby strengthening the company's credibility as it demonstrates that it can be open about its mistakes as well as its achievements. The care for transparency is in this case negotiated in relation to the desire to create reports that can be used in marketing. Even though some dirt is uncovered, the stories behind the numbers are black-boxed as unproblematic. The making of the sustainability report consists of shaping realities where things make sense and in which HygieneTech care as well as they can for sustainability. The full stories would never fit within the report format and therefore some things are destined to be absent; the decision to make most but not all stories positive shows the tinkering that is required to practise sustainability in a corporate context. 
104 - Chapter 5 


\section{6}

\section{Caring standards: Working with ISO 26000}

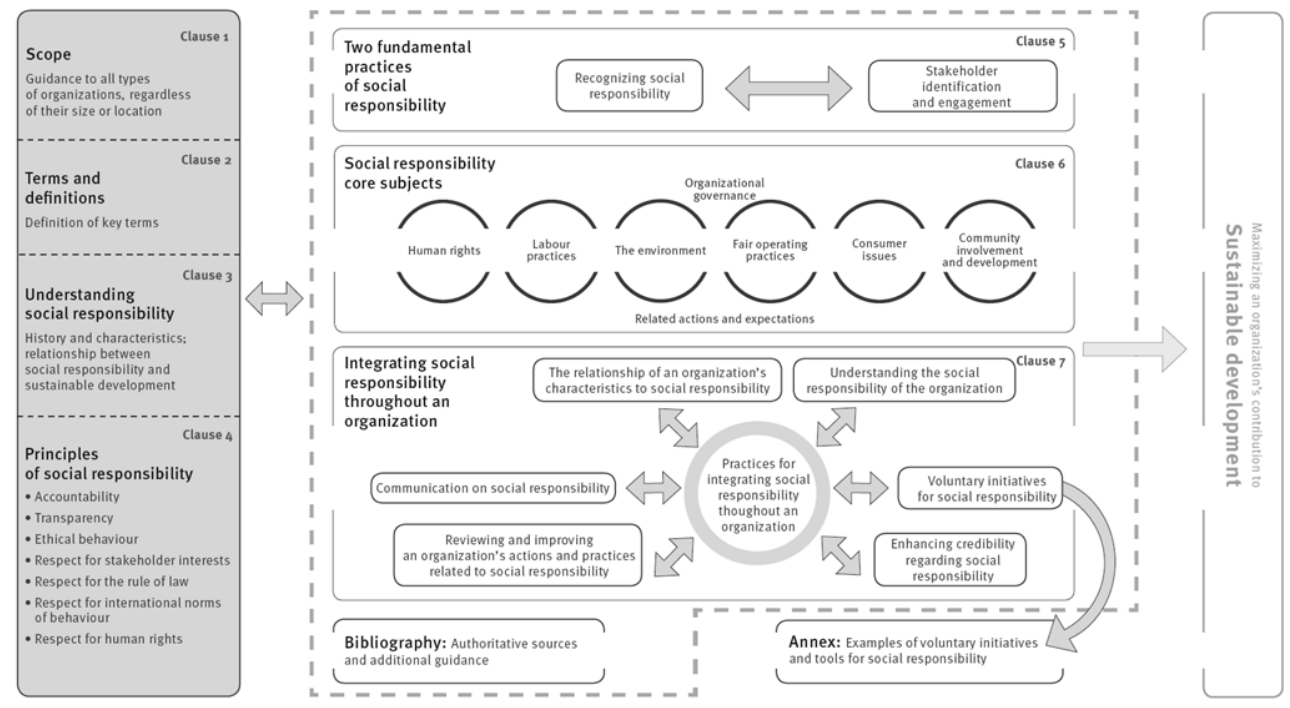

Figure 3. A picture from International Standardization Organization

(ISO) explaining the complexity of the ISO 26000 standard

(International Organization for Standardization 2010).

The making of social responsibility is not an easy task, even with the help of ISO 26000 - an international standard for social responsibility in organizations. The complexity of the many core subjects, principles and factors is evident in figure 3, which presents a schematic view of some of the challenges facing the socially responsible organization. However difficult social responsibility might seem, the goal of sustainable development is worth the effort, according to ISO, and in this quest a 
standard way of doing things can be a method to structure care for matters that might otherwise be neglected. However, these standards are often aimed at large companies, and they are not easy for SMEs (small and medium sized enterprises) to implement. In fact, studies have shown how environmental management systems (EMSs) and management tools are usually designed for large firms, which makes it harder for SMEs to implement them (Jenkins 2004; Hillary 2004). Even though environmental management systems are most often aimed at large companies, Hillary (2004) suggests that SMEs can make use of environmental standards and find ways to incorporate them into their organizations. One way to do this can be through cooperation with other companies (Ammenberg, Hjelm \& Quotes 2002). It is with this in mind that we need to understand the view of HygieneTech as a successful case of a sustainable company due to their choice to work with a brand new standard geared to large companies. Studying standards enables a move towards an understanding of the networks that shape much of modern life while exploring the ethical and political dimensions of classification theory (Bowker \& Star 2000). Standards, and the practice of making things accountable, do not have to be in opposition to caring (e.g. JerakZuiderent 2013), instead it can distribute care among actors. In this thesis I do not aim to explore the efficiency of the standard; instead, the focus will be on the consequences of enacting sustainability through it, as well as the entanglement of the standard and care.

HygieneTech has worked with this standard since it was first introduced to the Swedish market. "We were already doing a lot of the things in the standard, so when one of our customers asked if we worked with it, it seemed natural to start doing so," Wilma told me when I asked why they were among the early adopters of the standard. Also, Bosse told me that he thinks that the work with ISO 26000 is rewarding: "It has always had a special place in my heart," he answered when I asked why they work with the standard. ISO 26000 has an impact on how the employees at HygieneTech's office view their sustainability work. ${ }^{5}$ They often refer to the fact that they work according to ISO 26000 when asked how they handle sustainability issues. The ISO 26000 standard holds a special position in the company, and in this chapter I will look into how their work with the standard gets translated - as well as when it does not translate - from the ISO paperwork to the employees' everyday work practices. I will study the matters of care that the standard sets out for the company to follow, and I will also look at how the employees handle the complex standard in their work practices.

\footnotetext{
${ }^{5}$ Some readers might start thinking about how, in practice, social responsibility relates to sustainable development since this standard talks about both social responsibility and sustainability. This, however, is a different thesis and not something that ISO gives any answers to. For HygieneTech, the work with the standard is enacted as sustainability.
} 
Standards can be much more than frameworks developed by international organizations; they can be forms, traditions and sets of rules. A standard is a process of constructing uniformities across time and space by generating agreed-upon rules (Bowker \& Star 1999). Standards are everywhere in my study, but the most prominent ones are the environmental labels and ISO 26000. When it was being developed, ISO 26000 was meant to improve the world (Tamm Hallström 2008), but as previous research shows, standards rarely work as intended (Timmermans \& Epstein 2010). Since the standards are written in very general terms, they have to include some elements of local practice in order to be implemented (Timmermans \& Epstein 2010). This can be done by adjusting existing processes to fit the standards' requirements. Standards thus need to be tinkered with and interpreted to fit local environments, and different standards are always nested into each other (Lampland \& Star 2008). The entanglement in existing processes is evident in the way HygieneTech implements ISO 26000 in their everyday practices. When Wilma started looking into the standard, she found that HygieneTech already had a lot of the required processes in place. It seemed that it would be easy to comply with the standards without changing their existent processes too much.

At the same time, the board of HygieneTech started talking more about sustainability issues, and the company wanted to investigate what the next step should be in order to live according to ISO 26000. Since the standard was very new, they contacted a consulting firm to help them. Therese (and the sustainability manager before her) believes that the documents covering the standard are hard to interpret, and this is another reason the company hired a consulting firm to help them develop a sustainability action plan. The consulting firm (which I will call Consult AB) interviewed key people in the organization about how HygieneTech worked and about their processes. The results from the interviews were presented in a workshop in which possible future actions were discussed. This then resulted in a document called the GAP analysis report, which was finished late in 2009. Since this is one of the first ISO 26000 reviews undertaken by Consult $\mathrm{AB}$, the consultants saw the assignment more as a cooperative learning endeavor than as a regular consulting assignment. Once the process was completed, Consult $\mathrm{AB}$ and HygieneTech planned to market it together to potential customers. After two years, the consulting firm was hired to do a follow-up GAP report in order to follow how HygieneTech worked with improvements in accordance with the standard.

The two GAP reports tell stories about HygieneTech's internal work on sustainability from the perspective of the consulting firm. In the documents, matters of care are formulated in accordance with ISO 26000, and these reports have consequences for the practices of the sustainability group. The GAP reports are the foundation for most of the content in the action plan, the document that guides the work of the sustainability 
group. In the ISO 26000 documents, it is possible to follow the translations from a standard to different practices, both textual and practical action. These translations do not always come easily, and in this chapter I will look at how the standard leads to the creation of new documents and how some of these documents affect the everyday practices at HygieneTech. I will also study a case of loss, when the standard does not get translated into the practice it was intended to. This will show how the different versions of sustainability are enacted in the documents and the sustainability group and how care is sometimes enabled through the standard while in other settings the local practices are not touched by the standard. I will not give away any more of the excitement for now; instead, I will say a few words about how the ISO 26000 standard is structured.

\section{ISO 26000: A standard for social responsibility}

The ISO 26000 standard was developed through a complex process involving more than 300 experts from 50 countries. The idea behind including such a large number of participants was to give the process legitimacy, but it ended up creating great difficulties in the organization and decision-making process (Tamm Hallström 2008). Even with such broad participation in its development, the standard has been criticized for isolating certain complex and contested social issues (Schwarz \& Tilling 2009). For example, complex sustainable development issues in organizations are at risk of becoming decontextualized with the application of standardized approaches such as the ISO (Ibid.).

The standard is presented as a way for organizations to gain a competitive advantage, attract talented candidates for employment, get a good reputation, maintain employee morale, and improve their relationship with different stakeholders (International Organization for Standardization 2010). There is no ISO 26000 certification; instead, organizations are encouraged to say that they work "according to ISO 26000 principles". The standard takes a holistic approach and focuses on seven core subjects and the same number of sustainability principles. The core subjects are presented in figure 4 . 


\section{Social responsibility: core subjects}

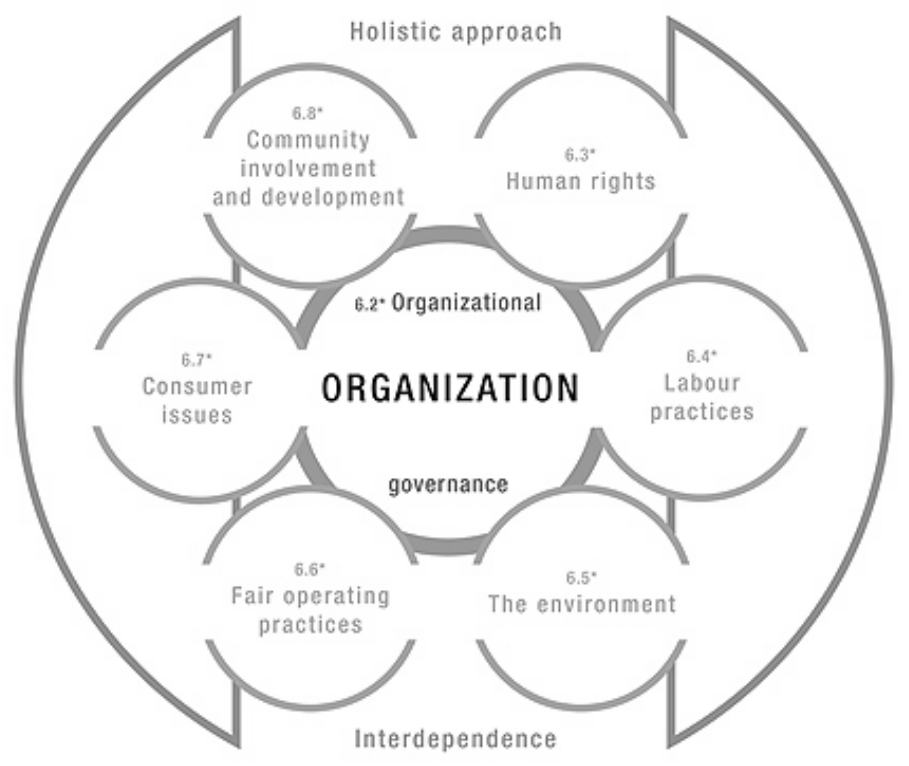

- The figures denote the corresponding clause numbers in I\$ 26000.

Figure 4. picture from International Standardization Organization explaining the core subjects of ISO 26000 (International Organization for Standardization 2010, p. 4).

In addition, the sustainability principles an organization has to relate to are:

- Accountability

- Transparency

- Ethical behaviour

- Respect for stakeholder interests

- Respect for the rule of law

- Respect for international norms of behaviour

- Respect for human rights

These principles are meant to guide all the work in the seven core subjects. Each core subject has a number of subheadings explaining how borders are drawn between the different areas. The different parts of the standard and the relationship between them are presented by the standardization organization in the complex figure in the 
introduction of this chapter (figure 3). The efforts made though committing to work with the standard will help the organization achieve maximum contribution to sustainable development according to ISO. One area that receives little attention in the standard is the economic aspect. This is partly because this standard is supposed to fit all organizations, including non-profit organizations. The economic aspect therefore varies, just as the core processes do, from company to company and is not included in the core values or the principles.

The standard is perceived as complex by the employees at HygieneTech as well. "I don't really get all of it," Therese told me when she showed me the large binder with all the documents that are included in the standard. "That's why we're working with Consult $\mathrm{AB}$, since they are more used to working with it. It would take me forever to go through all the information in the standard." Therese concluded. The standard is complex and hard to understand for those working with it for the first time. There are core subjects and values that relate to each other, and the multitude of concepts can leave anyone confused. Even though the standard is meant to be used by all types of organizations, from multinational companies to NGOs and small firms, its structure is not the intuitive choice for organizations with few resources to put into the supporting processes. This problem has been known for quite some time (Lazarte 2013), and to address it, an EU-funded organization that works with SMEs provides written guides for smaller companies on how to implement ISO 26000 (NORMAPME 2011). The standard is widely recognized as an attempt to make the corporate sphere contribute to sustainable development and is part of the EU's strategy to promote corporate social responsibility (European Commission 2011).

\section{The GAP reports}

In HygieneTech's work with ISO 26000, they worked with Consult AB, a consultancy company that conducted an investigation of HygieneTech's compliance with ISO 26 000. In this section I look at the issues Consult $\mathrm{AB}$ raised in its first review, which HygieneTech needs to address in order to comply with ISO 26000. The resulting report, the first GAP report, was transformed into the action plan that guides HygieneTech's sustainability workgroup meetings. I show a few interesting issues that exemplify how sustainability was enacted in the two GAP reports. However, I will start by briefly showing how the first review was conducted by the consulting firm.

The initial investigation by Consult $\mathrm{AB}$ was guided by questions about HygieneTech:

- Where are we today?

- What should we prioritize in the future? 
- What are our risks?

- What are our strengths?

- What are our most important sustainability aspects?

The first GAP report starts by formulating the strengths and an overview of the GAP report of Clean Hygiene with the seven core subjects as headings. The report is written by Consult $\mathrm{AB}$ and looks at the difference between the ISO standard and the company practices. Clean Hygiene scored lowest on human rights and ethical business methods while its numbers for labour practices and environmental concerns were high. The report proclaimed that during the workshop organized by Consult $\mathrm{AB}$, the participants made it clear that their aim was to get the highest score in all areas, but particular efforts were to be made in working with labour practices, environmental issues and human rights. I will take a close look at one of the core subjects that is central in the two GAP reports, human rights, and show how it was enacted by Consult $\mathrm{AB}$ and later by the employees at HygieneTech.

The core subject "human rights" is split in two: human rights internally and human rights in the supplier chain. Clean Hygiene get high scores on their work with human rights internally. The few remarks from Consult $\mathrm{AB}$ concern the compliance with their code of conduct (that the organization neither promotes nor lives by it) and the fact that they have not done any risk analysis when it comes to violation of human rights in the company. The last remark comes with an explanation: "This is probably due to the fact that there is a good and healthy culture within the company and therefore there was no need for this kind of investigation." Even so, to receive a higher grade HygieneTech need to do more risk analysis and work more with their code of conduct to make sure everyone adheres to the policy.

Under the section about human rights in the supply chain we are told that Clean Hygiene do not work with this issue at present. An empty spider chart shows the absence of efforts on this issue. The absence of structured work is not discussed further in the text, but it is brought up later as an important subject for the company to start working with.

In the concluding section, Consult $\mathrm{AB}$ gives some advice for how Clean Hygiene can proceed in their future work with sustainability. They identify the following as the most important issues to work with:

- Working with human rights in the supplier chain

- Strengthening the code of conduct - both in its content and how it is implemented 
- Identifying and communicating with stakeholders (this includes making an annual sustainability report)

- Conducting a carbon emission analysis of the company as a whole

- Expanding the diversity work and making it more visible in marketing materials

The report ends with a page containing general information about implementing ISO 26000. The company is advised to think strategically - What actions connect to their business idea? Clean Hygiene are furthermore encouraged to think about their level of ambition and focus at first on finding easily fixed issues ("low-hanging fruit"). It is also important to get the right people involved and to make sure that they have the knowledge they need to do their job.

This report tells us about a company that has a good culture, a soul and a will to care for sustainability, and that has already taken several steps in its sustainability work. We are told about how the company cares for its employees, how important the environment is for it and how the culture makes policies on how to behave seem unnecessary. However, the culture, how things are done in this company, is not as important as ISO 20000 requirements regarding policies. In order to get a good grade on human rights, Clean Hygiene needs to have a policy specifying how to behave so as not to violate human rights. In the present situation, it is impossible for HygieneTech themselves to know whether their suppliers violate human rights in their own organizations. Therefore, the report stresses the significance of strategies, policies and the making of various additional documents.

The processes of producing and delivering hygiene products that are at the core of HygieneTech are made absent in this report. Instead, the supporting processes are put at the centre. Since ISO 26000 has to be so general that it can be applied to all types of organizations, it cannot be specific about the core processes. Moreover, the basis for the report is fairly limited, consisting of self-evaluation interviews with 20 key people in HygieneTech focused on the supporting processes, and a workshop, thus it would be difficult for Consult $\mathrm{AB}$ to form opinions on the processes or choices made in the company. The ISO 26000 standard is too complex to be interpreted by the employees at Clean Hygiene, while the consultants from Consult $\mathrm{AB}$ have little knowledge about the core processes of the company. This is a problem foremost encountered by SMEs, and since it is not handled in the standard it indicates that the standard is more suitable for organizations with the in-house capacity to interpret the standard.

\section{The follow-up report}

After two years the employees at HygieneTech felt that they wanted another review of their sustainability work. Another report was ordered from Consult AB in 2011. In this section, I will look at the evaluation of HygieneTech's efforts to comply with the GAP 
report from 2009. What I find interesting in this follow-up report is what is valued as progress. I will not recap the entire report; instead, I will again focus on the core subject of human rights. Between the first report and this new one, final touches had been made to the standard before it was made official in 2010. The only apparent differences are in the choice of words, the report from Consult $A B$ tells us. The consultants' work in preparing the follow-up report was very similar to that for the first report, except that this time they only conducted interviews and did not hold a workshop.

In this report, Clean Hygiene is praised for their recent work with human rights and organizational governance. The first report from 2009 was based on a preliminary version of the ISO 26000 standard and due to changes in the standard the new report takes a slightly different approach to the subject human rights. Even so, a comparison with the results from the old the report is presented which shows that the company now is rated as a 3.2 instead of a 1.2 in human rights (maximum is 4). On organizational governance, the rating has gone up from 2 to 4 . The other areas have either increased a little (ethical business methods and labour practices) or stayed the same (consumer issues, environmental issues and local development). Let's look at what made the rating go up so much for human rights according to the report.

When it comes to human rights the change is drastic according to the spider chart. The rating on civil political rights rose from 2 to 4 , and basic rights in the workplace also rose from 2 to 4 . What has been done to achieve these high ratings?

Firstly, the code of conduct has been revised and communicated in the organization. The employees have worked with the code in small groups in order to implement the policy throughout the organization. Clean Hygiene have also created a code of conduct for their suppliers which they now attach to business agreements. In addition, they have developed a new self-evaluation tool for their suppliers that is connected to the code. A policy around ethical business methods (anti-corruption) has also been developed, and the employees have also been involved in the making of this policy. In this way the employees are made aware of the policy and feel included in the making of the policy, and thus it is seen as implemented in the organization. According to the report, Clean Hygiene has new procedures for analysing the risk of human rights violations in the supplier chain. However, they still lack whistle-blower policies to encourage employees to speak up when they suspect, for example, when an employee suspects that a customer is violating human rights.

The concluding section of the follow-up report states that a lot of work has been done at Clean Hygiene in order to comply with the suggestions in the first GAP report. Some issues are still not resolved, such as how the company should deal with 
customers' unethical behaviour. Consult $\mathrm{AB}$ identifies this as a particularly important issue, since many of the company's customers work in the restaurant business where unethical business methods are common. Clean Hygiene is advised to think about how to move forward and to regularly do follow-ups to evaluate their work with the standard.

In the reports, care is enacted for things that can be shown and materialized, such as calculating carbon dioxide or making new policies. The outcomes are things that can be touched and measured in a spider chart. The materiality of the standard is not just its binders and reports; it is also the many documents that it indicates the need for. Sustainability is materialized in these reports as the need for policies and written strategies. There are also more general and practical suggestions, such as the need for more work with human rights in the supply chain, but otherwise, what is cared for is mainly the making of sustainability on paper. The suggestions from Consult $\mathrm{AB}$ mostly concern processes that include making new guidelines and policies that care for sustainability at the company. The issues that receive the most attention are things that can be measured (such as the number of pages used to print a document) and the matters that appear on paper. The result of the work that followed the first GAP analysis shows that more documents have been produced, but that other actions have been taken as well. As we can see, the report often focuses on the making of policies, strategies and side processes. This version of making social responsibility as paperwork diverges from HygieneTech's more usual version of sustainability as saving resources. I will come back to the tensions between the different versions later in this chapter.

Moreover, Clean Hygiene has to take more responsibility, both the reports tell us; Clean Hygiene is accountable for the wrongdoings of their suppliers and their customers. The ISO 26000 standard cares for taking responsibility, and this is done in the side processes. The core processes, the products and services the company offers, are left out. Even though the life cycle analysis is held up as a way to take responsibility, few words are used in the report to care for the effects the products have on the environment and society. Laws and security regulations address the corrosive products and environmentally harmful chemicals, hence it is assumed there is no need to take further responsibility for these processes. Nowhere is the accountability for producing chemical products brought up; instead, the need for these products is taken for granted. The message of the standard is that caring is taking responsibility for what you already do, not changing the core of the organization. The standard's job is to make a company more accountable, aware and caring, but this is done by caring for the side processes. 
The care for sustainability enacted through the ISO 26000 standard is not all about paperwork. The employees have to interpret the reports from Consult $\mathrm{AB}$ so that they know what issues to focus on in order to work even more closely in accordance with the standard. The next step in translating the standard is turning it into an action plan. The version of sustainability that is enacted in the standard is different from other versions we have encountered in this thesis. To understand how these versions can coexist, and how the standard is translated into practice, we will follow the process by which the consultant's report is turned into the action plan.

\section{The action plan}

The GAP analysis and the follow-up report are just the start of the chain of papers produced to comply with ISO 26000 . Next in line in the paperwork of sustainability is the action plan. The action plan is a document that HygieneTech produced in response to Consult AB's analysis of the company's compliance with ISO 26000. The identity of a company relies partly on paper practices (Cooren 2004), and HygieneTech's identity as a responsible company produces documents on documents that in the end will turn into other practices. Some documents are more important than others; the action plan is one of those directly practice-affecting documents. Pernilla, who was the sustainability manager before Therese took over the position, created the action plan after the first GAP analysis. The action plan has since been transformed, but it is still the main document leading the sustainability group's actions. As the name suggests, it is a plan to take action.

The action plan is organized according to the focus areas in ISO 26000, and within each area the suggestions from the GAP analysis are presented through different activities. For each activity, there is a column for the person responsible, a comment field, and a deadline. The action plan comes in different versions (literarily!) and I will look at one version that was used in August 2012. The plan is 10 pages long and contains 49 suggestions for improvements and about 70 activities that are meant to implement the suggestions. This document is present in different settings throughout this thesis, and the empirical chapters show how the suggestions are translated into action. I will not present all actions and suggestions since there is considerable overlap and repetition among them. Instead, I follow the company's progress as it interprets and implements Consult AB's suggestions. I have chosen this area in order to understand what lies behind the impressive improvement in the ratings in the followup report in 2011 and what the company will work with to follow up on this achievement. In what ways is the action plan guiding this transformation of the 
approach to human rights? I will study how care for human rights is translated into a plan for action following the GAP reports.

Due to the initial low rating on human rights, HygieneTech turned this core subject into a focus subject that they worked with more intensively during the years following the first GAP report. This work was continuous and the action plan offers seven suggestions for improvements in this area. Two of the suggestions concern the company's work with their suppliers. The first suggestion is to focus on the supplier chain. In the action plan this is translated into the activities that involve working with business deals and with evaluations and reviews of suppliers. The sustainability manager together with the purchasing manager are responsible for these activities, but no comments or deadlines are given.

The next suggestion is to do a risk analysis on the ways in which human rights issues are relevant for Clean Hygiene. In the comment field for this suggestion is a note: "Unclear, find out more on what this means." The sustainability group has not been able to translate Consult AB's interpretation of this aspect of ISO 26000 into practice. There is no given activity that will produce this risk analysis. It would be hard for a group of people that who have never done any risk analysis of human rights to visualize what the first step should be. The person responsible for this action is Therese, and her deadline is October 2012.

This planned action ("find out more!") is repeated for the next suggestion on human rights: Extend the follow-up on performance in human rights outside the employee survey. Once again the sustainability group is at a loss as to how to turn this into action. Evaluating the employees' efforts to comply with human rights is not easily done, but Therese has until October 2012 to find out more about how this could be interpreted.

The next suggestion turns out to be easier: to develop a procedure for employees to follow should they suspect that a customer is violating human rights. As an action, the company make Lisa (HR manager) responsible for developing a whistle-blower process that can include this as well as other issues.

A more comprehensive suggestion is that HygieneTech should make two visits to their suppliers to investigate their compliance with human rights. Sven, as purchasing manager, is responsible for developing overall goals, creating a checklist, and planning and booking visits to suppliers. The goal of making a checklist is to be met in autumn 2012. This checklist will also be made available on the Internet to be used by the suppliers as a self-monitoring tool. The deadline for this suggestion is 2012 . 
The largest suggested action is to systematically work with communicating policies internally. Six activities are specified, but they all come with a question mark. Will the company do this at the internal conference? Do they need a procedure? Should it be done consciously during the year? Therese is responsible for this process and the comment field is full of suggestions on how to deal with this issue; these include starting a campaign to promote a policy each month; clarifying the word "policy"; checking how information is distributed in the organization; figuring out how to reach out with policies; and making policies more accessible by putting them on the intranet or maybe in a Dropbox file. Once again the deadline is the end of the year. The last suggestion in this section is to translate the document that is used in discussions with the suppliers into English. This suggestion has already been taken care of.

What we have witnessed in this action plan document is a series of interpretations of the ISO 26000 standard. Slowly, the large binder with the complex text about social responsibility is translated into action. This is done through Consult AB's interpretation, which in turn was written in a GAP report, which was the basis for a follow-up report that then was interpreted in this action plan. Putting ISO 26000 into practice takes a lot of work, and specifically paperwork. Furthermore, at their meetings the sustainability group work with this document and try to interpret it again to make it part of everyday practice. What practices are indicated by the action plan in the core subject of human rights? Let us look at the activity plans in the document. In practice, the plans entail having discussions and making new contracts with suppliers. This involves both paperwork and communication practices. The plans also involve finding out more information about - that is, interpreting - what it means to do a risk analysis and to promote socially responsible performance among the employees. The company's existing whistle-blower policy will be extended to also include customers violating human rights - this means additional paperwork. The plan also includes visiting suppliers to make sure they are observing human rights, a practice that involves travelling, discussions and developing relations. However, at this stage the company have as yet only scheduled time to do the paperwork connected to these practices. They need a checklist, a new categorization and to write down new goals. They also want to communicate their policies better (and also to define clearly what they mean by "policy") and to spread them using e-mail and the intranet.

Not everything in this action plan is about paperwork, but most of it is tightly connected to formulating new processes and making new documents. I believe that this penchant for making new documents is a way to handle a confusing and uncertain reality. Since no one knows what sustainability really is, translations are needed to handle this uncertainty. Standards are used as foundations in drawing borders to define what sustainability is all about, both through ISO 26000 and, as we will see in the other chapters, through labelling products and other practices. Sustainability is crafted 
into something that is measured by standards, a box that can be ticked in an action plan. In the same way that environmental labels enabled care for the sustainable product, the ISO standard enables care for sustainability in the side processes. ISO 26000 is a care enabler that makes it possible to make processes outside of the core production into a matter of care. The processes outside the production and sales of detergents are at risk of being neglected since they do not appear in the economic reporting. In the sustainability that is enacted in the processes following this standard, things other than the economy of producing cleaning products are made visible. The strength of the standard is partly its ability to focus on care for the things that are sometimes absent and partly due to the way it provides a structure and guidelines for approaching sustainability.

Even if the standard provides a structure, it is not easily translated into practice. The work with ISO 26000 translates sustainability into something tangible, like a document, rather than an approach. To be able to do a follow-up, or a GAP analysis, the data has to be measured. In this way sustainability is made into care for indicators, for the things that can be measured. The messiness of the concept of sustainability leads ISO, Consult $\mathrm{AB}$ and Clean Hygiene to attempt to create structure through policies, written processes and more documents. However, even though the practices of the standard mostly focus on this paperwork, HygieneTech tries to translate them into actions. The question marks in the action plan show how the sustainability group struggles to translate the GAP reports into practice. The action plan creates other challenges as well. In their efforts to implement the action plan, the members of the sustainability group stumble upon interesting questions, often caused by clashing versions of sustainability. In the following sections I will show some of the challenges that come with implementing the suggested actions in the action plan.

\section{Translating the standard: A time trouble?}

The translation of the standard into an action plan was the result of a rather messy series of interpretations of the international standard. In describing the practices of implementing the standard I can show how the employees handle the complexity of the standard in relation to their everyday lives and study the friction that sometimes occurs when the action plan and the local practices at HygieneTech are hard to entangle. One example of the practices of implementing the ISO 26000 standard can be found in a recurring subject in the sustainability work group: how do they handle the unrestricted working hours for the sellers? This issue was brought up as a part of the ISO 26000 revision in 2011 and is now included in the sustainability group's action plan. Here it is brought up and discussed at a sustainability meeting: 
We are once again seated in the bright conference room on the ground floor at HygieneTech's head office. Eight people are gathered around the table and Therese chairs the meeting as usual.

Therese Since the sellers control their own time, it becomes difficult to control how much they work.

Wilma This is hard! Since we don't meet our staff, we need to know that they work their hours. Do we know how it works today?

Anders All sellers report their hours to regional managers, but only five people report exactly how they work; everyone else fills in that they work between eight and five o'clock every weekday according to Lisa.

Erik We sell consulting hours and so we have to keep an eye on the hours, so we should really be able to get everyone to report exactly how they plan their workdays.

Lisa But isn't that a bit excessive?

Fredrik Well, I think it's a lot of work for nothing. I think they probably work about the right amount of hours in general.

Lisa But don't regional managers control this?

Anders No, not really.

Wilma Each team leader should have that discussion.

Anders Yes, but we do know because we see where they've been every day in the weekly report.

Therese Is there a problem with people working too little?

Anders No.

Sven Perhaps it's more that people are working too much. We can conduct random checks on on-board computers and see how much they actually work. There are some whose working hours I doubt. Like that guy we had in Falberg before who, without our knowledge, sold our pallets. And then there are many who do not submit their trip reports. This is a problem. One time a guy was fined because the police wanted all the reports, but they were difficult to find. Still, many sellers' reports are poorly done, at least some.

Therese Can you check the trip computer while servicing the cars?

Erik Good suggestion! We will ensure that it is done.

The members of the sustainability group conclude that this is not a widespread problem. No action is taken other than Erik's suggestion that the sellers' tachographs be checked when the vehicles are serviced. During this meeting there is a discussion 
about what responsibilities they have in controlling the sellers. Anders, who has close contact with the sellers, does not think this is a problem. He thinks that the responsibility lies with the sellers and that they are controlled through their weekly plans. Lisa and Wilma like the region managers and the team leaders to maintain close contact with the sellers and to be responsible for overseeing their work. It turns out that the solution to the problem is to defer the responsibility from a human actor to a technical device, the tachograph. However, this is not the end of the discussion. The question is brought up again at the next sustainability meeting in May.

Therese Maybe our solution of seeing the sellers' work hours isn't the best. It's starting to feel a bit like we're putting tags on the sellers.

Lisa The question is whether there is a problem.

Therese No, we do not know; it was mostly what came up in the GAP report. We need to know more about it.

Anders I usually do random checks to see how they work, with the aid of Tim [an employee responsible for servicing the company's cars].

Fredrik One of our competitors forces all sellers to start at the warehouse at eight in the morning in order to keep track of their sellers. But that's not what we want, is it? We want to be able to rely on our sellers.

Lisa How do you know that your boss is working his or her hours? It's the same thing!

Anders It's true!

Fredrik But is this a problem?

Sven It can become a problem if they work at lunch and don't receive their statutory rest. Even so, there may be shop talk even at lunch. One can, for example, talk about the ISO 26000 !

[The group laughs]

Lisa The things is that we need to have people who work in customer service at all times, just as we need to have sellers who are available when customers call. It's important that managers check that things are working, and that they work closely with their sellers.

Therese It might be good if Tim came out and met with the sellers and talked about why it's important.

Fredrik It might be included in the new iPad system. 
Erik Yes, we looked at it, but the iPad has no input that you can connect to.

Erik becomes responsible for looking into the possibility of checking the sellers' work schedules with the tachographs or through spot-checking. The issue is brought up again at the following sustainability meeting in August, but once again the question is put off to the future. The new trucks that will be ordered will be able to provide the data they need in order to check the sellers' weekly schedules. In the meantime they will have to trust the sellers and the region managers' communication with the sellers. Fredrik points to the responsibilities the sellers have towards their customers and colleagues. In order to fulfil these responsibilities and deliver the services they have promised, the sellers have to work as much as they are expected to. This is similar to the responsibilities the employees at the head office have towards their customers and colleagues. However, their responsibilities do not work in the same way, according to Wilma. Office employees' responsibilities and expectations are explicitly set out in such a way that controlling their work hours is not a problem. Therese also suggests that they need to talk more about responsibilities and working hours with the sellers in order to make the expectations more explicit. When the technological solution is too expensive, the company instead try to communicate what they expect from their employees.

Anders, who is a region manager, thinks that the system works as it is. He thinks that the sellers do what they are supposed to and he does not want to make them do more administrative work by requiring them to fill in more forms. The motivation behind the need to check how the sellers spend their days is a bit vague. Therese brings the question to the table as a part of the review of their work with ISO 26000, but she does not argue that there is a real problem to be solved. The question of whether this really is a problem or if they can trust their sellers to do their job keeps coming back into the conversation. Since no one is engaged in the question and the proposed solutions are either complicated (more spot checks) or expensive (the iPad app), the issue is deferred to the future. This is an example of the divide between the paperwork of ISO 26000 and the practices at HygieneTech. The members of the sustainability group imply that they do not see the need for all these policies the action plan urges them to invent and implement. Once again, the group members find it difficult not only to implement the policies, but also to fully accept the reasoning behind them. What is it that they are actually caring for by following the suggestion to control the sellers' work hours? Such an action is unlikely to be viewed as reflecting care for the sellers' well-being, but instead as a form of increased control over - and decreased respect for - them. This negotiation shows how difficult it is to incorporate the standard into the company's work when the company practices do not fit with the aims of the standard. In HygieneTech, the relationship between the seller and the seller's manager should be 
the means by which to identify any deviations from the expected workload, preferably without the use of standardized timesheets. Maybe due to the company's relatively small size, the seller-manager relationships are seen as more important than caring for standards and increased control. The care initiated by the standard (both for the employees and for the economic well-being of the company) is replaced with the care that is enacted as a professional relationship between sellers and managers.

In the sustainability group, the sellers' work hours do not seem to be an issue, even though the ISO standard requires the company to control their sellers better. However, the time issue is enacted differently in other settings. At a sales training session, the trainers talk about how to find time to visit new customers. This session is headed by the trainer Magnus and the participants are sellers and a few members from the head office, including Lisa who is the HR manager.

Magnus There are many people standing at the restaurant's door waiting to get in. How many new customers do you plan on each week, Ali?

Ali Three.

Magnus And how many do you want?

Ali Four or five.

Magnus And you, Henry?

Henry Not many. There is no time.

Magnus We must find the time to do these visits; you have to plan for it. You can work until six-seven-eight in the evening. [Scattered laughter]. If you want to get good at it, you have to invest the time... But now I'm getting the evil eye from Lisa.

Lisa We require 40 hours of our employees, no more.

Magnus It's about setting goals. Do you go to the gym Lisa? How often?

Lisa Well, five days a week.

Magnus How do you get time to do that?

Lisa Well... you've got to prioritize.

Magnus Exactly, that's what it's about. You have to prioritize. You don't have time to do this during a normal working day.

Markus It's all about where you are in life; young children require a bit more time. Especially if you want to have a social life with those you live with.

Magnus Yes, sure. There are situations where you need to prioritize other things, like family. But I mean, most of us don't have 
small children, and then it is easier [to decide how to use your own time].

The sellers have their own responsibilities, they need to keep their current customers satisfied and also look for new ones. If you want to get good at this, you need to put in the hours Magnus tells us. Lisa feels the need to put forward the regulatory side of the story: the sellers are expected to work 40 hours a week. However, the expectations on the sellers are not as simple as just looking at the details of the contract of employment. When the team leader or the region manager set the budget for each month it is only the sales that are taken into account. There is no extra room for additional new customer visits, car problems or training. The sellers are responsible for their own budgets and for planning their own time. The problem of making these two go together is delegated to the sellers. The proposed solution is for the sellers to prioritize, just as Lisa does to make time to go to the gym. However, I believe there is an important difference in the fact that Lisa goes to the gym in her spare time whereas the sellers will have to increase their working hours. Lisa can choose how to spend her free time as she wishes, as long as she works her 40 hours per week. What I believe that this story of the sellers and their workday shows us is how responsibility is delegated to the sellers, but this responsibility comes with expectations. The sellers are expected to commit to the weekly plans that they made with their team leaders. Formally, they are expected to work 40 hours a week, but this framing of their workday is played down at the sales training session. "If you want to get good at it, you have to invest the time." It is about priorities. The question that is left for the sellers to decide is what they need to prioritize lower in order to be able to reach their goals. There is a deferral of the decision when enough is enough to the sellers.

The formal rules say that the sellers not should work more than 40 hours a week, but the rules do not clearly state the expectations regarding what the sellers have to be able to do during these hours. Instead of controlling the time spent on customer visits to ensure the well-being of both sellers and the company, the focus is on the company's ability to make profit. This is not an enactment of care for the employees and, following the framing of care in this thesis, it cannot be seen as a caring action at all. If we focus on the relationships in the room, the trainers hold a powerful position, they are turned into spokespersons for the company, teaching the sellers how they ought to act. They set the standard for how to act like a "good seller" and enact what it takes to be good at selling HygieneTech. As spokespersons for the sellers' employer, the trainers have a large responsibility for the effects their words have on the lives of the sellers. When the trainers tell the sellers to prioritize more sales meetings over leisure activities, they impose on the sellers' free time in order to create more sales opportunities. This uncaring action is problematic in several ways and is one reason that the working hours are sometimes stressful for the sellers. 
Tobias, one of the sellers I followed, often finds his workdays stressful. He has many customers and he feels that he does not have enough time to take care of them the way he would like to. He has high sales objectives and more customers than another seller that I followed, Ali, who works in a city of similar size. Ali may not seem as stressed as Tobias, but he has some problems with his sales objectives, which came up at one of the region meetings I attended. He has not been achieving his goals and has a smaller customer clientele than most of the other sellers. Moreover, the sellers are supposed to take care of several things that lie outside their sales objectives, which sometimes creates stress. For example, when Tobias's truck breaks down, he needs to take it to a special workshop that can handle the company's specially designed trucks. These workshops are located several hours away from Tobias's hometown and he often needs to ask for help from other sellers to work out the transport and to take care of his customers. This is sometimes not taken into account when his budget result is calculated in the end of each period. Neither do his customers lower their expectations that he will deliver their products on time.

The sellers' responsibilities are diverse and directed not only to HygieneTech as a company, but also to the sellers' customers and colleagues. To handle this mess of entangled responsibilities to different actors, the sellers might benefit from more regulation, or at least more explicit directions clarifying what they are and are not expected to achieve during their 40 hours. However, since the members of the sustainability group consider the supervision of the sellers' workday as gaining control rather than making their expectations more explicit, they do not see this as a priority. For the sellers, there are time-related issues in their everyday work, since the demands are sometimes too high and there is more to do than can be fit into a normal workday. ${ }^{6}$

Furthermore, the sellers and their responsibilities are enacted differently in the sales training room than in the sustainability meeting room. The links between the two meetings in this case are Lisa and the policy stating that sellers are expected to work 40 hours a week. Lisa tries to bring the policy to life in this meeting by referring to formalized responsibilities, but her argument is not accepted. She has less power over the enactment of the "good seller" since she is just an observer at this sales training meeting. Instead, the sellers are enacted as employees who want to be good sellers and

\footnotetext{
${ }^{6}$ Of course, this particular situation cannot be understood as representative of the company's approach to their employees in general. I have indeed witnessed many relationships between the head office employees and the sellers where care for the sellers' welfare was important. Even so, this situation shows a practice where the company enacts a lack of care for their employees and as such it needs to be discussed and made present. In discussing the negative sides of HygieneTech, I aim to highlight the struggles of doing sustainability, and in doing this I enact care for the company as well as for sustainability at large.
} 
want to contribute as much as possible to the company. The care for HygieneTech is enacted as more important than spare-time activities but not as important as caring for one's family. Anyone who has small children has to prioritize the additional responsibilities that come with them.

The use of the sellers' time should be controlled, according to ISO 26000. Even so, this issue does not catch on in the sustainability group. The issue is lost in anxieties about costs and unnecessary control that sends signals that the employer does not trust the employees. The ISO standard was not able to make this issue into a concern due to the differences between the reality of the sellers and the reality of the sustainability group. The employees at the head office are not faced with demands from the employer on new sales meeting and do not consider more control to be the answer to the stressful workdays some sellers experience. For the members of the sustainability group, the strengthened control just entails more bureaucracy and shows distrust in the sellers. The ISO 26000 standard, for its part, tries to care for the control, the sellers' rights and the profit of the company by suggesting more regulations. The members of the sustainability group care for the sellers' freedom and they do not trust the standard to make judgements on what a doable, justified sustainability action looks like in this case. The standard failed as a care enabler with respect to the time-related issues that the sellers sometimes encounter. This lack of trust in the standard will also be evident when it comes to its requirements related to policies.

\section{Caring for policy}

At a sustainability meeting in August 2012 the meeting participants discuss the need for a policy about how the employees are allowed to talk about politics as representatives of HygieneTech.

Anders The customers often discuss politics, about Turks who are at war with others and such. It is really very common.

Fredrik Yeah, but it's much more common to talk about prices!

Therese There probably hasn't been a problem, but we might have to be more clear on this matter.

Wilma It should be in our code of conduct.

Markus It connects to the question about whether we are allowed to hand out political flyers in the office, is that ok?

Wilma No, I don't think that is ok, but on the other hand, Bosse has handed out pretty political flyers before...

Anders But isn't this just creating a problem that doesn't exist in reality? 
Fredrik Isn't there a policy for "common sense"? Then we wouldn't have to sit here and argue about this!

Unfortunately for Fredrik, there is no such thing as a common-sense policy at HygieneTech. Instead there are policies about travelling, sexual harassment, bribery, code of conduct, vehicles and equal opportunities, just to mention a few. These documents are sometimes discussed in the sustainability meetings, but the documents in themselves are seldom up for discussion; the recurring subject is instead how to make the sellers read the documents and whether some of the policies should even exist. The contents of the policies have little influence on the discussions in the sustainability group, probably because no new policies are created or discussed during these meetings. Neither have I ever heard a seller mention the policies or the guidelines that the policies specify. Following the material-semiotic approach offered by actor-network theory (ANT), I look for actors, both human and non-human, that influence the making of sustainability at HygieneTech. The policies' existence seems to be important to the sustainability group, but otherwise these documents do not seem to be active in enacting sustainability. Therefore, I will not go into the specific content of each policy. Instead, I will show how the policies' existence is made important. In the discussions about policies, two issues often recur: the seemingly almost impossible project of making the sellers aware of the different policies, and the sustainability group members' hesitant attitude about the need for policies. In this chapter, I will study how sustainability is done through making policies, but also how the employees are hesitant about putting the paperwork in focus.

Some of the policies that HygieneTech employ were created as a result of the process of working with ISO 26000. A version of sustainability based on ISO 26000 affects the other common versions of sustainability. The ISO standard is used to identify sustainability, but in this situation it clashes with the fact that the sustainability group finds other issues more important. There is a strong tension between ISO 26000's requirement for the creation of new policies and the idea that the company should be working with other issues. The idea of what "a policy" is and why it is necessary is often discussed in sustainability meetings. At times there is some frustration, in this case voiced by Fredrik: "Isn't there a policy for "common sense'?" Some of the employees also believe that there are risks associated with making things into documents and texts: "The risk," Sven states, "is that when we make all these policies and laws, everything that is not subject to regulations is allowed." When things are put into writing, they become clear, but by making certain actions invisible, what is absent is interpreted as morally acceptable. To avoid this, and instead protect the spirit of the policy against corruption, the members of the sustainability group discuss whether the sellers should work in small groups with cases about corruption. The frustration 
expressed by some of the employees in the sustainability group is entangled with the discussion of how policies should be spread in the organization.

HygieneTech try to disseminate policies to their employees in different ways. All policies are available on HygieneTech's intranet, a very useful but content-heavy web resource that is not always easy to navigate. The operational policy for Clean Hygiene is also displayed on the inside doors of the toilets in the head office. The sustainability group go to great lengths to promote policies, yet employee surveys show that few of the employees are aware of the contents of the documents. The sustainability group have invented "the policy of the month" - an internal campaign to promote one policy per month. The policy is highlighted in the monthly newsletter and should be brought up at the region managers' meetings with the sellers. During a sustainability meeting the issue of trying to spread and implement policies is raised. In the next month their anti-corruption policy will be in focus. This policy was created at an internal conference and the members of the sustainability group are all satisfied with its contents. Wilma raises the question of how effective the policy is and whether just having a policy is really enough. According to the last employee survey, only $12 \%$ of the employees knew that HygieneTech has an anti-corruption policy. This is a surprisingly bad result according to the sustainability group, since the last internal conference had worked with this policy. The members of the sustainability group all agree that the risk of being subject to bribery is in some ways high, since their customer base is mostly restaurants, which is an area of business that is known for its corruption problems.

At a sustainability meeting, the issue of the policy of the month is raised.

Therese Then we have the policy of the month. Has this been communicated, Anders?

Anders We don't have time to do it; we have a meeting between 10:00 and 14:00 and we have a lot of stuff to work through. There is no time or interest; the risk is that it just goes in and out again. Could we make it into a contest instead?

Therese There are just so many contests all the time...

Fredrik I'm with Anders on this. There is no time to go through the policy of the month in the monthly meeting. I think it's good that Anders is being straightforward about this. Can't we work with it in another way?

Anders And do they [the policies] have to be so long? It's hard to fit into the schedule when they are so long. 
Erik When we get the iPads this won't be an issue anymore; then they can just go into the intranet and look for themselves.

Fredrik Well, the intranet doesn't work that well right now.

Sven And not everyone can read it there now. They don't use their mobiles to log onto the intranet and no one checks the policies on their home computers after work.

$[\ldots]$

Markus And we do have policies that they really need to know, like against sexual harassment.

Erik Yes and the latest employee survey showed that people don't know that we have such policies.

Anders I think the biggest problem is that the sellers can't get easily hold of the policy [to read on their own]. There's no benefit in going through it with them at the meetings.

Anders says that the sellers are not interested in the policies; they take too much time away from more important things in the monthly meeting with the region manager. They are too long and do not give anything back to the employees. Anders would rather see the responsibility given to human resources instead. Later on he asks Lisa what HR's role is if he is supposed to be responsible for communicating the policies as well. Slightly annoyed, Lisa explains that she is responsible for many other things and that it had been decided previously that the region managers would be responsible for communicating the policies. No one really wants the responsibility for talking to the employees about these policies. The policies do not seem genuinely important to some of the sustainability group members. "Is there a need for this policy?" is a question that is regularly raised when policies are discussed. This issue becomes very evident when it comes to implementing the monthly policy. Anders, as a representative for the region managers, says that he does not have time to work with the policies, and that nothing is gained by doing so. Other issues are more pressing at his meetings with the sellers.

This is in a way a problem for the employees, partly because of the employee survey results that show that the employees are ignorant about these policies, but also partly because some policies actually are enacted as important to know. Some policies seem to be more important than others; for example, the sexual harassment policy is one that employees must know, according to Markus. Other policies pale in the shadow of this one, which is actually more of a clarification of the law against harassment in the workplace. Some policies matter while others are legitimized as a part of working according to the ISO 26000 standard. As we have seen in the previous chapter, creating documents such as policies and strategies was an important outcome of the 
GAP reports. The version of social responsibility that was done in the reports does not match the work with versions of sustainability shared by the members of the sustainability group. There is a clash, and therefore there are tensions and questions around working with policies. Time constraints and accountability issues stand in the way of implementing policies with the sellers. The sustainability group does not feel that the most pressing matter is inventing and implementing new policies or regulations. In fact, they see that there are risks involved in doing too much paperwork. When some things are forbidden, other things consequently come to be allowed.

This discussion ends with Sven and Markus questioning whether this is the most important topic to work with at the moment. Therese replies that it could wait until the next revision of ISO 26000, just to see what Consult AB thinks about it. The plan is that HygieneTech and the consultancy firm will do a new revision of the standard the following year (2013). The sustainability group tries to care for policy, they want people to know the policies exist and to have general idea of what they say. The discussions concentrate on the policies, but there is little focus on whether people are actually living by them. The first step is to spread information on the policies, then figure out how to get people to understand and act in accordance with them. However, the sustainability group cannot get past the step of informing the employees about the policies' existence. The care that is enacted is done through care for policies, not for the content of the policies.

Creating and implementing policies in HygieneTech is a costly process that entails a considerable investment of time and effort. There is a need for care for the policies to make them a part of HygieneTech. Such care is not easily mobilized when policy is not an important part of the sustainability group's version of sustainability. The creation of policies gives the company high grades in accordance with ISO 26000 and is therefore valuable, but implementation of the policies has little value attached to it. Neither the members of the sustainability group nor the sellers believe that the policies have an important role in their lives. Policies need to be in place, but not cared for. The ISO 26000 process creates care for policies, but not so much for compliance with policies. The change is accomplished in the intranet, not in the everyday actions of the employees.

\section{Making others care}

As a part of the ISO 26000 process HygieneTech has started working with their suppliers to make sure that no one in their supplier chain is failing to protect human rights. This work is done by attaching a code of conduct to the business deal with the 
supplier, and discussing it with them. Some of the suppliers are fine with this attachment; others find it strange and exotic. Some suppliers do not have their own code of conduct, which was very surprising to the sustainability group at HygieneTech. HygieneTech's code of conduct was written by some members of the sustainability group, with the assistance of a lawyer. It sets out the company's expectations of how suppliers should treat their own employees and describes the matters of care that are important to HygieneTech. This document is attached to the deals with all suppliers with whom they have large business transactions. Along with this, HygieneTech have an additional document that suppliers can use to monitor themselves and check how well they are meeting HygieneTech's requirements. This work progresses slowly, but it is going according to plan. Every quarter HygieneTech brings this attachment to a few new suppliers and discusses it with them. However, working with the really large suppliers can be a bit harder.

Sven As a small company we are exposed in contract laws.

Erik Yes, written contracts always trump oral contracts, but we can't place conditions on the large companies. They can do whatever they want anyway.

The members of the sustainability group are faced with a familiar dilemma. The suppliers commit to the code of conduct, but they do not implement it or follow it up in their own organizations. As with the issue of spreading information to the sellers in their own organization, the sustainability group meets similar resistance with respect to spreading the policies in others' organizations. HygieneTech cares for the policy, but their suppliers are reluctant to pay the cost of caring for the policy in their own organizations. The work with their suppliers is, just as a lot of the work is with the internal policy, a result of the GAP report from ISO 26000. The care for human rights in the supplier chain ends with a signature on a document provided by HygieneTech. Nonetheless, this is enough to get a good grade on compliance with the standard. The employees at HygieneTech invest care in trying to get their suppliers not only to commit to, but also to implement the provided code of conduct. The suppliers' lack of interest makes their task difficult, and the fact that HygieneTech is so small means that they do not have enough clout to make strong demands. Any supplier that finds them too hard to work with can easily choose to stop selling them products since losing such a small customer would not affect them much.

The suppliers are, just like the region managers at HygieneTech, reluctant to take on the responsibility to work with the policies that they might not find valuable. The members of the sustainability group try to care for this issue by approaching the suppliers with questions and evaluation tools, but are not met with the same interest, or 
care, for their policies. Considering how small they are in relation to other customers, they believe themselves to have little chance of influencing the large suppliers. The enactment of sustainability through policies is a struggle of trying to manage what is doable in the world of large international actors that do not need to care for the demands made by a small customer such as HygieneTech. Sustainability is enacted as doing things that are a matter of care, and that are doable; it can have a positive effect on the world.

\section{Standard care as caring (for) paperwork}

The work with ISO 26000 centres on documents that have been developed in cooperation by a large number of different stakeholders in corporate responsibility. Navigating in the dark jungle of corporate sustainability is a confusing journey. In this perspective the option to rely on the well-known and legitimate standard (ISO) makes the work doable and trustworthy for HygieneTech. The standard is also a way to develop HygieneTech's sustainability work. An organization like HygieneTech that values measures, numbers and charts, in which documents are a part of the identity, will look for allies to guide them - preferably allies that already have legitimacy on their side. Committing to this way of enacting sustainability is a safer road than having to make all the decisions in-house. The standard offers a standardized care, already defined and processed through many discussions. ISO 26000 legitimizes their care as care for sustainability.

I view the standard as a care enabler since it legitimizes care for the processes outside the core business of the company - that is, producing, selling and delivering hygiene products - and provides a structure for this care. Even though some issues were already on HygieneTech's agenda, the standard creates a structure and protection from criticism since the company always can rely on ISO to know about sustainability. The standard takes the side processes seriously and provides structure for the work with the many core subjects and principles it upholds. The responsibility that the standard enacts is not about making the most profit for shareholders (even though these are briefly mentioned in the text of the standard); instead, it focuses mainly on other areas, such as the environment and suppliers' observance of human rights. Care for profit is taken for granted, it does not need to be highlighted in a process for corporate responsibility. The standard is thus a way to care for other matters, such as human rights. However, it comes with challenges due to its complex structure and the different realities that it tries to bring together.

The enactment of sustainability in relation to the ISO 26000 standard evokes different versions of sustainability. The standard is mainly aimed at larger organizations and 
therefore it is difficult to interpret for HygieneTech. With help from Consult AB, they translate the standard into different practices. Due to the aim of being able to measure and make visible changes, many of the suggested actions from the two GAP reports tend to focus mostly on creating new (written down) processes, policies and guidelines. The consulting firm and HygieneTech struggle to make sense of sustainability and the ISO standard, and in this issue they often find themselves relying on paperwork. The reports indicate a need for more policies, new ways of calculating environmental impact and more work with the suppliers. The follow-up report measures success through paperwork and through the creation of new policies. Thus, the versions of sustainability that are enacted through the work with the ISO 26000 standard rely partly on different types of paperwork. There are other versions of sustainability made present in the many different enactments of the standard, such as caring for equal access to skills development and gender equality, to mention a few. Interestingly, sustainability as saving resources is not made present (other than in small remarks, such as about saving paper in the office) in the GAP reports, probably since these documents mostly focus on processes at the head office and on paperwork.

There are practices where some versions of sustainability presented in the GAP reports become problematic for the employees at HygieneTech. In the sustainability group, there is some frustration concerning a version of sustainability as caring for policy. Some employees do not feel that there is a need for yet another policy or for doing more work in order to disseminate the policies. Instead, they ask for a policy of common sense. The entanglement of the standard with the practices at the company takes a lot of work. This is evident in the example of the GAP report suggestion about implementing a control system for the sellers' workdays. In the sustainability group, the care for the sellers' freedom and the trust in the sellers is unproblematic; it is mostly enacted as a positive part of being an employee at HygieneTech. The problem arises in the reality of the sellers where the employer's requirements are somewhat unclear and the enactment of the "good seller" puts high demands on the sellers' engagement. In this reality, the standard could have played a different role by making the sellers' work hours visible. Through thinking with care, I find that different realities and power positions create a split in what is enacted as a problem in sustainability work. The standard tried to enable care for the employees but did not succeed in reaching the reality of the sellers due to the divide between the sellers' reality and the members of the sustainability group's reality. Instead, I showed a situation where the company was uncaring towards the employees, making unfair demands on them to engage outside of their work-related responsibility.

The choice to not control the sellers' workdays shows how the standard fails to be entwined in the practices of the organization. This version of sustainability clashes with other matters that are valued more highly. Likewise, the care for policies that ISO 
26000 requires HygieneTech to commit to also clashes with the enactment of sustainability as something that is about practice, a doable action that will have a positive effect on the world. Some of the members of the sustainability group deem that matters other than caring for policies are more important, therefore care for policy is made absent in their daily practices, such as in region meetings with the sellers. The care that the standard tries to create is sometimes turned into the practices of making sustainability at HygieneTech (as in the case of talking with suppliers about sustainability) while other practices is not made into matters of care. The care that is enacted as sustainability through the ISO 26000 standard in HygieneTech does not clash with other important matters of care. No matters of care are endangered by attaching a policy to contracts with suppliers, while the care for the trust in the sellers is seen as more important than caring for controlling the sellers' workday.

In order to facilitate care in a better way, the standard could to be negotiated by the involved employees before its objectives is settled (cf. Jerak-Zuiderent 2013). In this way, the matters of care that the employees hold high could more directly guide their action plan. Due to the aim of ISO 26000 to incorporate all types of organizations and offer practical guidance, this type of negotiation might be hard to put in practice. Even so, the company has the opportunity to tinker with the standard to fit their own situation since it does not come with a certification. 


\section{7}

\section{Selling sustainability, service or detergents}

Karin and I are on our way to our next customer visit at an Italian restaurant. We arrive an hour before the lunch rush will begin, and the restaurant is almost empty. An older man who seems to be the owner of the restaurant greets us from behind the bar and Karin chats casually with him about everyday things. Meanwhile a young waitress appears from the kitchen and starts wiping off tables. Karin tells the owner that she will look at the dishwasher and she finds her way into the kitchen without directions. The dishwasher is placed in a small corner of the restaurant just behind the bar. Two meters from the entrance to the dish room a chef cuts tomatoes, which he puts into a large stainless steel food container. Karin services the machine and together we get hygiene products from the truck and put them on the restaurant's selves. The service is complimentary and Karin always leaves a protocol on the service for the customers. In the small dish room it is striking how many different routines and people the sellers encounter each day. At the doorway between the dish room and the kitchen, fragrances mix from cleaning products, garbage and the most savoury Italian mushroom pasta sauce. A few products from HygieneTech that come with an environmental label are the only sign of care for sustainability: here the effort to bring customers the best food for a good price is in focus. Sustainability does not seem to have a natural place in this swarm of fragrances, activities and people. Back in her truck, Karin explains that most restaurant owners actually think of environmental issues as something that just adds costs to their services; sustainability is therefore rarely an effective sales argument. 
Then again, sometimes prices are not the best argument for persuading a customer either. Karin tells me that she has friendly relationships with all her customers and they trust her; for some customers this is important and prevents a shift to a competitor who can deliver a similar product for a lower price.

Karin is the connection between HygieneTech and its customers. She has a very important role in caring for customers' needs and providing them with the products and services they pay for. Every customer has their own routines and preferences and the sellers have to be able to follow each customer seamlessly. The diversity in HygieneTech's clientele is a challenge for the sellers since they encounter a broad spectrum of matters of care. Some customers care about the services the sellers provide, others think that it is very convenient not to have to care about detergents the products just appear on the shelves before they run out. Still others care about labels and environmental concerns, and for them, HygieneTech's sustainability work is worth more than buying the cheapest product on the market. The employees at HygieneTech are thus faced with an uncertainty - the product they sell has to appeal to all different customers. This chapter is about handling this challenge, that of transforming hygiene products into a valuable service, economic gain and sustainability. The different matters of care that are enacted in relation to selling sustainability and hygiene products can sometimes coexist without any problem, while in some situations they create unsolvable clashes. This chapter will show some of the differences in the realities that are needed for enacting the sustainable HygieneTech.

To study this I follow the employees as they go about their daily work and attend sales training sessions and observe the challenges they are faced with in the sustainable delivery of goods. The company uses biogas trucks in some cities as a part of their agenda to become more environmentally friendly. This practice does, however, create tension between the sustainability agenda and the sellers' other obligations and aims. Moreover, the relationship with the customer is central to being a successful seller at HygieneTech, and in this chapter I will study the relationship between the customer and the company in different ways. I will show how the company's relations with their customers both create different relations to sustainability and affect how the employees in HygieneTech communicate sustainability. How do the employees enact what is really for sale in these messy practices of selling hygiene products, services and sustainability? Through thinking with care, I will study how HygieneTech create an environmentally friendly profile and how they make their products valuable through the practices of the sellers and through marketing.

First, I will take you to a chilly parking lot where the sellers are gathered after a lunch break. In this empirical chapter I will show how the use of biogas trucks is important 
for HygieneTech's understanding of themselves as a sustainable company and also how these practices are deferred to the sellers to handle. By starting with the sellers' everyday life, I care for the sellers' situation and make their issues come to life. Moving on, I study the relationship between the customers and the company, both from the perspective of the seller and from the view of the employees at the head office. The customers play an important role at HygieneTech, but they are not always as present in the sustainability work as the employees would like. I will show how the customers and their diverse realities affect enactments of sustainability and how, together, they change the service that HygieneTech actually sells. As we will find in this chapter, the products HygieneTech sells require a bit of tinkering to appeal to all customers. Since the sellers are the ones who have the most communication with the customers, I will start by showing an example of the enactment of different versions of the customer and the significance of these versions for the care for sustainability. First, I will show how the high prices of HygieneTech's products are justified; in the subsequent sections, two versions of customers are evoked to hold together a reality of diverse matters of care. Last, a concluding section discusses what is for sale at HygieneTech and how the coproduction of sustainability, the biogas truck and the customer affects sustainability practices.

\section{Delivering sustainability}

In the middle of April, I meet up with Karin and she picks me up in her large white truck with HygieneTech's logo on it. The truck is shiny clean, and when I climb the three steep stairs into the cab, I can see that it is quite clean on the inside as well. The sellers I followed all took good care of their trucks, and I got the feeling that they saw the truck as their workplace and wanted to feel at home in it. When I comment on the large size of the truck, Karin tells me that it is more efficient to have a large truck and, since she worked with deliveries before, she is used to the size. It is a beautiful spring day, and for lunch, all sellers in the Stockholm area are gathered at a golf restaurant. They often meet up and have lunch together even if it means that it takes some time to get to the restaurants. One important criterion when they choose a restaurant is that it has to have a large parking lot since their trucks take up a lot of space. Karin warns me before we arrive at the restaurant that, although the other sellers are good guys, they have a very special jargon. What she means becomes clear very quickly when I meet the rest of the sellers; they are very friendly but there is a good bit of rough humour among them. At this 
lunch six sellers, me and Fredrik from the head office are present, and after lunch everyone stays and talks a while in the parking lot. Karin explains to me that they cannot leave until they have had at least a 45minute break. Every truck has a trip computer that records their travels, and according to the labour law, they need to be standing still for one longer period during their workday. Even though it is sunny, it is still a bit chilly, and standing still in the windy parking lot I soon start to feel cold. The sellers talk about plans for summer vacation, but after a while they start talking about one of the sellers who is not present and who will soon have a new truck.

Erik He is so glad he's getting a new truck, but I bet he'll get an old biogas truck!

[The group laughs]

Anders That would be so fun! Then he would have to stand in line and spend half his day just to get gas!

Erik Yeah, he'd love that!

[The group laughs]

Maria So I guess you don't like the biogas trucks?

Anders No, I mean they don't really work for us. There are always long lines at the gas stations and it takes forever to refuel.

Markus I remember one winter when I drove a biogas truck; it could only do $60 \mathrm{~km}$ per hour uphill. It was horrible!

Anders They are really slow. And sometimes the truck doesn't start during the winter. I had one once but I refused to work with it. It wasn't humane.

Markus It was some part of HygieneTech's environmental policy; I suppose that's the thing you're interested in?

Maria Yes, sure. And it is interesting to hear what you think about the biogas trucks.

Karin I was so glad that they had given up on the biogas trucks in Stockholm when I got a new truck two years ago.

The discussion moves on and after a short while Karin and I get into her truck and drive on to her next customer. During my day with Karin I observe how well she handles her truck; she reverses perfectly and manoeuvres the big vehicle expertly in tight spaces. When the day is over she drives me to the central station and navigates easily through the narrow streets of the older parts of the city. The truck is her work tool and she has mastered it very well. 
All sellers have their own truck, either a larger truck or a smaller one if they do not have the licence required for driving a heavy vehicle. Their trucks are much more than just a means for transporting goods; they are working companions through a sometimes lonely workday, and the sellers depend on the trucks to enable them to do their assigned duties. The trucks, along with their handheld computers, are the sellers' main working tools, and the sellers have a strong connection to their vehicles. The engine that can't take the cold weather, the technology that requires extra time to find a suitable gas station and then the lengthy refuelling process are some of the important material aspects that influence the sellers' workday. These non-human agents frame the sellers' day, and the sellers feel trapped by the practices that the biogas trucks force on them. The truck is a friend in their everyday work, but when this friend fails to perform, the sellers' feelings towards it turn to frustration and irritation. Working with a biogas truck is not enacted as caring for the environment; instead, it is a source of practical problems. As I showed in this scene from the parking lot and as we will find later on in this chapter, the use of biogas stirs up strong feelings among the sellers. Even though the truck is an important work tool for the sellers, it holds several different positions in the company. Their use of biogas trucks is often stressed as important in HygieneTech's sustainability. To sell sustainability one has to be credible, in both actions and appearance, and the truck is a tool in this work. The trucks are marked with HygieneTech's logo and information about the use of biogas as fuel. In this way, they enact HygieneTech as a sustainable company while clashing with other matters of care. Next, I will look at how and why HygieneTech work with biogas trucks and how these vehicles are a part of enacting sustainability despite clashing with several other matters of care and different realities.

\section{The fragile biogas truck}

HygieneTech has sellers all over Sweden, and the transport of goods from the factory to the head office, to the sellers, and then out to the customers means that the goods travel a long distance within the country. One of the company's most important environmental impacts comes from transporting goods, according to the assessment of the sustainability group at HygieneTech. To handle the resulting emissions HygieneTech works with several different tools, including logistic projects, ecodriving education and eco-cars. Today, 39\% of all vehicles in HygieneTech run on biofuels, and among the service vehicles $95 \%$ are green cars. However, using biogas trucks is not the easy environmentally friendly solution one might hope for when it comes to delivering hygiene products. The employees at the head office tried to make an environmentally friendly act by deciding to use biogas trucks, but by committing to this objective they unwittingly imposed certain changes on the sellers. It was the sellers whose practices had to change; they now had to find gas stations, wait in line to refuel and deal with vehicles that often broke down. 
All sellers have their sales objectives that they have to reach quarterly, but if their truck breaks down it complicates things for them. This is not taken into account when the goals are set for the sellers, and if they do not reach their objectives this will be shown during the region meetings when their region manager shows how everyone performed in the last quarter. Since part of the sellers' salary is performance based, it will also affect their income. The practices related to the biogas trucks were imposed on the sellers by the company, they were not chosen by the sellers themselves. This opinion is made very clear in a conversation between Lars, region manager, and Conny, seller, at a region meeting with the sellers:

Lars I'm surprised at how much time we spend on getting our trucks fixed. They are 'time thieves'. Tobias usually writes on his report - it becomes much more real when it's in writing: the truck at the workshop. Every time the truck is at the workshop, this is damaging. We cannot have trucks at the workshop, so we now have an extra truck to use. [...] We use our biogas trucks even if it's a large problem for us. We take it on because we have chosen it.

Conny It's the company that made it [the decision], not us. In wintertime when my truck doesn't start, then I don't want it, but the company has made the decision.

Lars Well, yeah, that's true.

The sellers who have biogas trucks often refer to the problems they are having with their vehicles, and Conny would rather have another type of truck. However, the company made the choice for him, and he had no input into this decision. Considering how the biogas trucks affect work practices, taking up the sellers' time with their constant breakdowns and specific fuel requirements, it might be unsurprising that the sellers are not so eager to drive them. They care for time, and want to be able to control their own time and not have to depend on the fragile biogas truck. Lars agrees that the company makes the choice and that it is only connected to the sustainability work at HygieneTech. In the discussion, HygieneTech's decision to use biogas trucks is not connected to marketing or cheaper fuels; it is simply about choosing to "do the right thing". Lars justifies the poorly working trucks with this idealistic statement. Furthermore, the sellers' salary is partly based on how much they sell, and being stranded due to a failing truck affects their income. The sellers face the choice of caring for a sustainable transport for the company or caring for control over their own time, provision of reliable customer service and their own salary. The biogas truck is an idealistic idea that has practical influence on the sellers, and it is hard for the sellers to care for a work companion that does not live up to their expectations. Sustainability is, in this setting, a conscious idealistic choice with practical (negative) effects. 
Even so, some sellers do not mind driving biogas trucks. One of these sellers is Karl, who is located outside Stockholm. When Therese was preparing the sustainability report for HygieneTech she called all the sellers who had a biogas truck and asked them for their views on it. Karl had told her that because he now drives a biogas truck he thinks twice before he throws anything edible into the regular trash since that could be turned into biogas! In his case the biogas truck has other practices attached to it besides spending time looking for gas stations. For him, the biogas truck is his tool but also a way to contribute to the sustainability of HygieneTech. It has affected the practices of what trash is and what can be turned into fuel. When I was presenting my results at a breakfast meeting with a mixed group of employees at HygieneTech's head office, I talked about the sellers' view of the truck and I was met with an objection from Karl: "Not all sellers think that their biogas trucks are problematic." Karl told me, and argued intensely, that his truck works fine. This shows how the trucks evoke emotional responses, both positive and negative. Both the sellers and the employees at the head office care for the biogas trucks in different ways. At one point, they tried to use biogas trucks everywhere that there were biogas stations, but after a while, this project was abandoned. Wilma explains to me during the interview:

Wilma We used biogas trucks in Stockholm for a while and this became a huge problem since there were no filling stations. It wasn't economical; we couldn't go to the customers and then there was no business. We have to do things both economically and environmentally. So then we said that only the cities that are good with biogas, such as Linköping, will use biogas. We had to change our policy so we used biogas were it was feasible to do so. 'Cause, otherwise, we won't contribute, and if we don't exist we won't contribute. It is always a balancing act. How far can we stretch it? But the goal has to be there. We just have to try to take it a bit further all the time.

Neither the sellers (at least most of them) nor the employees at the head office were pleased with the results of the biogas truck trials in Stockholm. The costs were too high and the benefits were too small. This led to a change in policy, so that now all service vehicles are to be green vehicles and the trucks are to be biogas where it is feasible. The feasibility depends on how much time the sellers would have to spend to find gas stations and refuel their trucks.

This question is sometimes brought up in discussions about HygieneTech's goals for green cars. During the follow-up of the sustainability goals for 2012 at a sustainability meeting, Therese concludes that they did not reach their goal of having $40 \%$ biogas 
vehicles, and they actually sold more green cars than they bought. Therese argues that they can have biogas trucks in Stockholm, but Fredrik (a region manager) reflects that the real problem is not the gas stations, it is the engines. The quality of the cars is too low, and only one brand produces suitable biogas trucks. The members of the sustainability group end up discussing whether or not this is a goal they should keep. Could they replace the goal with courses in eco-driving instead? Therese tells the group that it would not lead to the same levels of reduced carbon emissions as working with biogas trucks. The previous sustainability goals have not been met, and instead the group tries to find new ways to reach the goals by changing them. As an alternative to having a goal that is separate from the economic development of the company, the new goal should be connected to the aim of expanding the company's business, the sustainability group concludes. To progress in this regard, HygieneTech later start educating the sellers in eco-driving and give up on the goal of having more biogas trucks in Stockholm. The fragility of the biogas truck together with the lack of gas stations where biogas is available hinder HygieneTech from reaching their goal, therefore what sustainability is becomes renegotiated. The tension between being economical, actually reaching customers on time, and being environmentally friendly and using biogas presents a tough challenge. Sustainability needs to fit within the existing frame of being economically viable, and they thus tinker with their care for the environment. Instead of risking their finances by changing the sellers' practices by giving them time to refuel and providing extra cars, or trying to make the suppliers produce better biogas trucks, HygieneTech tries to find other ways around the issue. Care for lowered emissions is translated to eco-driving and turned into a manageable challenge; it will not greatly affect the sellers' routines, other than by requiring them to take some days for training. The biogas truck is made absent from the discussions about setting goals for reduced emissions since it is too hard to care for as it clashes with other matters of care.

This is an example of how a company that wants to push the development of new fuels for vehicles eventually lowers their goals due to clashes of different matters of care such as issues of quality, reliability and environmental friendliness. They have already decided to work with green cars and biogas trucks even though it would cost them more than the traditional vehicles would. However, even HygieneTech find themselves restricted by financial limits, and when these are overstepped the company will try to find more manageable ways forward. The biogas truck delivering sustainability to the customer is not enacted as sustainable due to the truck's low quality and the limited availability of suitable gas stations. The economy of caring for lower emissions makes using the sustainable biogas truck unfeasible. In the reality of the sellers, the biogas truck is fragile and a result of a choice made by employees at the head office. For the head office employees the truck is a sustainability tool as long as it does its job. When 
it fails to perform, it is no longer enacted as sustainable. The show must go on despite cold weather, otherwise HygieneTech will not survive. The head office employees thus tinker with their goals so that they can still care for sustainability. This is a framing of sustainability as part of the project of a company working in what is enacted as an already existing economic frame. The economic reasoning affects the company in other ways when it comes to their practices of selling and marketing their products. In the following sections I study the different ways the employees handle selling a sustainable product.

\section{Selling the cheapest product at a high price}

There is so much more to HygieneTech than just cleaning products!

This argument is very often used when the customer starts talking price per kilo. HygieneTech's detergent is significantly more expensive per kilo than the cheapest detergents on the market, therefore the sellers avoid comparing "per kilo prices". Even so, the customers often compare different detergents in terms of per kilo prices since this is an easy form of comparison. Most of HygieneTech's customers are small restaurant owners that try to get by with small margins. This becomes evident during a sales meeting between one of the sellers, Kalle, and a prospective customer, Nimo. Kalle and I meet Nimo, who owns a café and a restaurant together with a business partner. This meeting takes place in the middle of December at Nimo's coffee shop in Stockholm. After some small talk about other restaurants and a presentation of HygieneTech, Kalle asks Nimo:

\begin{tabular}{|c|c|}
\hline Kalle & $\begin{array}{l}\text { How much do you pay for your detergent and desiccant } \\
\text { today? }\end{array}$ \\
\hline Nimo & $\begin{array}{l}\text { I don't know. I just get it from the other restaurant my } \\
\text { partner owns, I don't know what the prices are. }\end{array}$ \\
\hline Kalle & $\begin{array}{l}\text { Okay, but maybe we should try to meet with your partner } \\
\text { as well? }\end{array}$ \\
\hline Nimo & $\begin{array}{l}\text { No, no, he doesn't have time. I try to talk to him but no, he } \\
\text { does not have time. He hasn't even had time to change his } \\
\text { tires, to winter tires that is. He doesn't have time. So much }\end{array}$ \\
\hline
\end{tabular}

In a stressful reality where you don't even have time to take care of simple things like changing your tires, why would you make time to discuss detergents? Considering that detergents and desiccants only make up $0.6 \%$ of the restaurant industry's turnover, you would probably have more profitable questions to handle. In this situation, considering 
the price per kilo might be the easiest way to determine what detergents you will use in your restaurant. To the restaurant owners, HygieneTech plays only a small supporting role in their operations, and therefore HygieneTech's sellers often have difficulty getting access to the owners. Selling an expensive product, even an effective one, is sometimes a challenge for the sellers. When the potential customers start talking about economy, the sellers' reply will also be about profit. To sell an expensive product you need to make it worth the price.

Kalle and I are shown into the restaurant's kitchen by Nimo. Two young men are working there, one is preparing a salad and the other is sweeping the floor. They both look up when we enter the kitchen and Nimo tells them we are here about the dishwasher and that he is considering switching to HygieneTech's detergents.

Kalle Yes, this is a reliable machine. [Kalle says, casting an experienced eye at the well-used dishwasher] But it is quite small, isn't it? You have to run it many times each day, don't you?

Cleaner Yes, we keep it going almost all day. But it works ok. [he puts away the broom he used to sweep the floors with. He opens a cupboard close to the machine and takes out a container]

Cleaner This is the product we use; it's the cheapest one. I get it from our supermarket. It costs only 300 kronor for one container.

Kalle Ok. How much is that per litre?

[The cleaner looks at the container and makes some calculations in his head.]

Cleaner About 46 kronor per litre. How much do your detergents cost?

Kalle Hmm, a bit more per kilo, but our product is much better. I can guarantee you that it will be cheaper in the long run [Kalle says, turned to Nimo]

Cleaner But this is really as cheap as it gets. I have checked and no one sells it cheaper

Kalle It is cheaper per kilo, but not per wash. [Kalle turns to Nimo] Our product is much more effective and you will use less. I know that you will save money by changing to our products. I can promise you this. 
Kalle is so sure that his product will save money for Nimo that he make a promise and repeats his words over and over: HygieneTech's product will save money! It is an economic argument that Nimo seems to be pleased with, although the employee who is in charge of buying detergents is more reluctant. An ignorant customer will not easily accept an answer that means a higher per-kilo price even when the seller promises better long-term economy. This type of ignorant customer is seen as a problem at HygieneTech. This issue comes up at a sales training session at the head office. We are gathered in the large training room, fifteen sellers from all around Sweden and me. Magnus and Markus, the two trainers at this session, talks with the sellers about convincing potential customers to switch to HygieneTech from other suppliers.

Markus Then we have some customers that we barely want to sell to, they always want to discuss prices. How many problematic customers do we have per district? Five maybe? In some districts price is the only thing that matters.

Magnus First, it is about prices but then other things come up. The customers discover the crappy quality [of the cheaper products] after a while. Even if it is cheap it does not mean that it is cheap in the end. Like the customer that bought garbage bags from our competitors and had to use double bags since they always broke otherwise. Then he wanted to buy our products for the same price as our competitor's. He did not get any discount and now he buys our bags anyway. Our garbage bags can be dragged across cement floors and it doesn't take as much time as it does to work with double bags.

Sam I have one customer that is impossible to convince. He thinks that it's too expensive so he prefers to work with double bags.

Anton Our garbage bags are really good. I don't know anyone who has switched from that bag.

Sam I have heard about one of our largest customers who would never buy the blue bags since they are too expensive.

Magnus Well, that customer should buy in accordance with our agreed contract, and sometimes you have to stand up and just tell them to shut up!

As we can see, the customer is not always right! Some things are allowed to cost more, and the sellers have to stand up for their products - that is what we are taught in the sales training session. The products are not as cheap as the competitors', but they are 
better and therefore worth their price. Many times the products save time and have to be seen as more of a long-term investment. The detergents and the garbage bags are more expensive but they also last longer. The quality of the products is better and therefore they saves resources. This is not talked about as a sustainability aspect in the sales training sessions or between the sellers, but it is brought up by the employees at the head office. It is a business concept that springs from Bosse's idea of saving resources by offering higher quality and better service. Care for the customers is manifested by thinking for the customers, since they do not know what is best for themselves (and for the environment). The long-term effect of using HygieneTech's blue garbage bags instead of the less durable bags from the competitors is not evident to all customers and it is the sellers' job to make them realize what they are missing.

The customers are enacted as unknowing at this meeting; the customers need to be educated for their own good. Sometimes you even have to go so far as to tell them off. These ignorant customers are not the desired customers since they always want to talk prices. The problematic customers have got it all wrong: HygieneTech do not only sell hygiene products, they sell high quality and economic profit. Even though their products are more expensive, the effectiveness of the products will save the customer money. If the customers do not understand this, the sellers need to educate them, and if this does not work, the sellers have to make a stand; their products are the best! There is care in this relationship with the customers, but it is mixed up with frustration about the customers' inability to understand their own good. The sellers care for their products, but also but also for their customers' bottom line. By changing to HygieneTech's detergents, customers will save money and become more economically sustainable. Since the restaurant owners show little care for the process of cleaning their dishes in the most efficient manner, HygieneTech has to take on that responsibility for them. I think this is important in the relationship between HygieneTech and their customers. Since the customers do not know any better, HygieneTech's employees feel the need to care in their place. This care is done through educating the customers, selling them sustainable products even though they do not request them and sometimes may not even want them. Some customers do not understand that the high-quality product is the most economically profitable one, and therefore HygieneTech has to educate them so that they do understand, and they do this using economic arguments. Likewise, some customers do not understand that sustainability is good for them, and how this issue is handled by the employees at HygieneTech will be shown later in this chapter.

The high quality of the products also reduces the use of resources, but this is not an issue that is mentioned in price discussions. The focus is on the economic aspect, and specifically on the right economic aspect - the high quality, highly efficient product. What is being cared for is the economy through saving resources - which is in line 
with Bosse's version of sustainability. Even so, sustainability is made absent in these discussions. The economic argument (this product is too expensive!) is countered with another economic argument (it is actually cheaper due to its high quality/efficiency!). On this economic battleground there is no place for sustainability. Why is this? Why don't the sellers fight back with an argument that is at least partly based on sustainability? The next section in this chapter will shed some light on how the employees at HygieneTech think about their customers when it comes to sustainability.

\section{The need for guerrilla marketing}

During a management meeting, a discussion arises about how to proceed with a new sustainability campaign as a part of HygieneTech's sustainability work and how to communicate their sustainability efforts. Wilma (CEO), Therese (sustainability manager), Markus (marketing manager), Lars (region sales manager), Martin (FCO) and Emil (IT manager) are part of this discussion.

Lars How is sustainability part of our communication plan? All of this [the sustainability work] is pointless if no one else knows about it.

Therese I agree that we have to communicate it more, but...

Lars It is good that we are proud over it and all, but considering how much effort we put in, we have to advertise it better.

Therese Sure, but at the same time we have to be able to really show what we are doing to be convincing. That is not always easily done.

[...]

Wilma I just have to comment on the discussion earlier, to say that our sustainability work is useless if no one else knows about it is a bit harsh. There are other values in working with sustainability as well. But I agree that we need to market it better. We make the right choices, and we should get payback for it.

Markus It [the sustainability work] should be shown on our web page and we should highlight all the improvements that we do. We can use the web page as a special place for our mission. 
Lars I think that our product is a great communication channel. Write more about environmental issues on the labels. They're often displayed at eye level. Print our mission and put it there, I think it can have an immediate effect.

Martin Yes, that's just perfect!

Emil It's a bit like guerrilla marketing. Like placing flyers on a well-planned position, it can have tremendous effects!

[The group laughs]

Lars Our product containers are our milk cartons. It's hard to avoid reading them.

The need for marketing goes beyond text on the home page; something much more radical is needed! The participants in the management meeting believe they have to make customers read their labels in order to inform them about HygieneTech's sustainability work. How did they come to this point, where they feel the need to impose the information on the customers? The customers spend relatively small amounts on hygiene products and, as we have already seen in this chapter, they are often short of time. They have to concentrate on the things that they can handle and have control over in their everyday life. Since the customers on average spend only 14200 SEK (1 500 Euro) per year on hygiene products, it is rarely profitable to put that much effort into discussing and thinking about the services HygieneTech provides. In their latest customer survey HygieneTech asked customers what they thought about HygieneTech's sustainability work and how important they rated it. Almost 1700 of HygieneTech's customers were emailed information about the webbased survey, and 203 participated in the survey. For a web-based survey the participation rate was considered acceptable according to the members at the management meeting in which the results were discussed. HygieneTech's products, their sellers and service receive high grades, from 8.3 to 8.9 on a scale from 1 to 10 . On the question about how price-worthy HygieneTech's products are, the grade is a bit lower, 7.0. The question on whether the customer would recommend HygieneTech to someone is rated at 8.6. The question after that concerns whether the customer is satisfied with HygieneTech's sustainability work (explained as environmental concerns and social responsibility); it has a lower response rate and more customers answered that they did not know. The average rating on this question is 7.7 and some customers commented in their written responses to subsequent questions in the survey that they were not aware of what HygieneTech is doing, or they stated that the company should focus instead on lowering its prices. The participants in the management meeting concluded that few of their customers knew enough about their sustainability work and they discussed possible solutions to inform the customers better. This is where the solution of guerrilla marketing came up. What I find interesting in this example is how 
the management meeting participants never discussed the finding that few of their customers ask for more information. Most customers do not seem to care about HygieneTech's sustainability work, the survey tells us. Many customers did not answer the questions about sustainability and several customers told the company to focus on lowering prices instead. Even so, the feeling at the management meeting was that the customers should be interested in ways they can help make the world more sustainable. Instead of the customers taking responsibility and making demands on their suppliers (in this case HygieneTech), HygieneTech takes on the role of informing the customers that they should care about how their suppliers work with sustainability. The ignorant customer is enacted as not yet informed enough.

What is interesting in HygieneTech's case is that they sometimes do not care about customer resistance. The customer is enacted as an ignorant client that needs to be educated to understand why environmental issues are interesting and important for them. In several different settings, I have asked employees at HygieneTech whether they think their customers care about sustainability or environmental issues. Most of their responses are similar to Tobias's:

Tobias No, not really. Or... well... Some do care. Or at least they should. And then you have the customers that really care, they are fun to work with! They really get it! For the other ones, we have to explain more what it's all about.

Education and communication are the solutions to making customers care about sustainability. Wilma and Therese are the most prominent actors who believe that sustainability is an important principle and that as soon as customers understand how important sustainability is, they will understand how valuable HygieneTech's sustainability efforts are. The ignorant customers are sometimes enacted as problematic, and even unwanted, due to their strong focus on low prices. To satisfy these customers, HygieneTech has to sell products of such high quality that they will make up for their high price. Sometimes sustainability is a hard sell when the sellers are confronted with ignorant customers, customers that might think that putting an environmental label on a product just makes it more expensive. To handle them, the employees at HygieneTech's head office try to find ways to educate them.

There is of course another side to the story about the customer. There are customers that care for sustainability and that make demands on the way HygieneTech works. It was a customer that asked if HygieneTech worked with ISO 26000, and this question sped up the company's work with sustainability. The caring customer also showed up in the customer survey. For that customer, the choice of hiring HygieneTech was partly due to their high profile as a sustainable company. The employees often talk 
with warmth when the caring customers are brought up. "They are fun to work with!" and "The customers who really care make us better" are some of the things that the employees say about the customers that make demands on HygieneTech's sustainability work. These customers are often schools, hotels with environmental labels or restaurants that have an ecological profile. This version of the customer is the caring customer, who chooses suppliers with his/her heart, or at least chooses based on whether the supplier uses environmental labels. These customers are often referred to when sustainability is questioned in the organization. Even though they are said to be few, they have an important role as a way to legitimize some of the sustainability efforts. The caring customer is used to legitimize sustainability when some efforts are questioned. "Some customers do really care!" the employees told me overenthusiastically. Caring customers are not only buying hygiene products, they are also buying a better world. Their interests in these issues are enacted as a driving force, but during my stay at HygieneTech they were almost never around in person. They are absent in most everyday activities in the company but they were made present to support sustainability. During my stay at HygieneTech, I never got to meet any of these caring customers, but they did show up in discussions sometimes, for example, in a case concerning recycling containers.

\section{Problematic recycling}

During the past few years HygieneTech had been recycling the five-litre containers in which they deliver some types of detergents. However, in my first interview with Wilma and Therese, they told me that they were unsure of how much they and the environment gained from this recycling process. Later on Therese investigated this issue and concluded that it was neither profitable for them nor good for the environment since cleaning the containers took up too much hot water and time. After a short discussion at a management team meeting, it was decided to stop recycling these containers. Later on, several customers complained about the new routines when they noticed that the sellers were no longer taking the containers back with them, and they felt that HygieneTech's sustainability work had deteriorated. HygieneTech's communication with their customers is not always easily manageable. Statements like "HygieneTech's environmental work was really very good before, but now they do not seem to care as much. I was disappointed when they stopped recycling the containers" showed up on their latest customer survey. Considering how important the recycling of the containers had been in the way HygieneTech talked about their sustainability, this change was a bit hard for HygieneTech's customers to digest.

The logic behind the decision to stop recycling the containers was never contested within HygieneTech; if it is neither economical nor good for the environment, there is no value in the process. It was thought that any objections customers might have to 
this change could be addressed through communication. "We just need to be really explicit about why we stopped recycling," Therese says at a management meeting when this issue is brought up. "We failed to communicate why we stopped recycling. It was actually for environmental reasons that we stopped, not despite the environment." Fredrik responds. For the members of the management meeting, even the caring customer can be an unknowing customer, at least in some cases. To manage the ignorant customer as well as the caring customer, the employees at HygieneTech make both versions of the customer an unknowing partner that just needs to be informed. However, informing someone who is not very interested is not that easy. This is only one part of the problem in HygieneTech's communication with their customers. The other is that the head office employees have little direct contact with the customers; almost all communication is done through the sellers. Thus, there is a challenge for the head office to get the sellers interested in the processes of sustainability in order to reach the customers.

Therese We need to communicate ISO 26000 internally as well. We had a sustainability booth at the internal conference last year but it was hard to get people interested.

Fredrik Well, you had the booth next to the one about the new iPad system. It's like showing a Volkswagen next to a Ferrari.

[The group laughs]

Wilma I talk about it every year, but it doesn't get through. I guess we just have to continue doing it...

This conversation took place at a sustainability meeting where the participants were trying to determine how best to communicate about their work with ISO and the reasons behind that work. The challenge of sharing information with the sellers is a common issue, not only when it comes to ISO 26000. Therese communicates with the sellers through "the mail bus", which is an email that she sends each week. In this email she includes all information that the employees at the head office would like the sellers to have. The email often mentions sustainability or the policies the sustainability group is promoting each month. Furthermore, the region managers talk to all their sellers on a weekly basis and they meet up in their teams every month. Even if there are formal and informal communication paths to the sellers, the distances between the sellers and the head office cause problems. Because the sellers are located all over Sweden, they face different dilemmas in different parts of the country. The distances between the north sales regions and the head office are sometimes not only about the kilometres between them. "It's not the same company," one seller says to me and compares the parts of HygieneTech that are situated in the large cities with the parts that cover the rural areas. They share the same logo and the same head office, but they offer different services and have to think differently. The distances between the 
sellers and the customers in the north of Sweden are much longer than those in the southern parts of the country. "We need to communicate this better" is a very common statement, and communication is viewed as the solution to many problems, including sellers who are inexperienced at handling complaints, customers who don't understand why it is so important to work with environmental issues and the fact that so few seem to care about HygieneTech's policies. At almost every meeting the issue of spreading information - whether to the sellers or to the customers - is seen as a problem.

Something that does travel easily through the organization, at least according to the employees at the head office, is rumours. When the company changed the salary system for the sellers, the employees at the head office found that many different rumours flourished between the sellers. To curb these rumours a representative from the HR department visited region meetings with the sellers to straighten out any issues with the new system. This was a successful approach and the sellers appreciated that they had an opportunity to speak directly to the person who knew the most about the changes. This was an important change for the sellers, one that affected their everyday work and life outside work. This can be contrasted with the efforts made to spread care for the customers' sustainability, where the sellers struggle to find the same relevance for them in their everyday setting. Likewise, sustainability fades in competition with the new gadget that will be their new work companion (the new iPad). Almost all sellers that I have met agree that sustainability is important, but sustainability is often lost in the mess of practices they have to juggle in the course of their daily work, with many different types of customers as well as regulations and policies.

\section{The everyday practice of selling sustainability}

The sellers' everyday mission is to sell and deliver HygieneTech's products to established and new customers. In this quest, they have a range of different partners, including the head office, their colleagues, the handheld computer and, very importantly, their truck. The trucks run either on diesel or a biogas fuel and need to be treated differently depending on the fuel they use. Committing to using biogas trucks is an enactment of care for the environment since this reduces carbon emissions, but it also comes with a different set of practices. As I have shown, the biogas truck is connected to care in different ways. The head office cares for the environment through the biogas truck. In this way, the biogas truck is a tool in the enactment of sustainability. Sometimes it is an expensive tool, but still it is a way to care for the principle of sustainability. However, for the sellers, the biogas truck has a different role. The sellers are not too keen on the biogas truck since it hinders them in their everyday work due to breakdowns and the time required to refuel at out-of-the-way 
gas stations. The biogas truck, being more fragile and harder to find suitable gas stations for, requires more care than the diesel truck. The sellers have to care more for the functionality of the biogas truck than they have to when using the diesel truck. The biogas truck adds to the sellers' workload and is enacted more as a liability than an ability to care for sustainability.

HygieneTech has been forced to change their sustainability goals to adjust to the failure of the biogas truck, and the company has raised their own limits on carbon emissions. However, there are still several biogas trucks in the company's fleet, and some regions still use mainly biogas trucks. The balancing act Wilma talks about concerns the economic challenges versus the sustainability goals. Selling sustainability is not an easy task when saving some resources (such as natural resources) causes higher use of other resources (such as economic resources). What sustainability is in this case becomes limited by the economic necessity of being able to contribute at all of being able to exist. A company has to be profitable; otherwise, there is no use in working with sustainability goals. The biogas truck is too costly to use; it is not, unlike HygieneTech's high-quality products, enacted as price-worthy, and therefore not valuable in the eyes of the company's employees. Moreover, in the case of the biogas truck, sustainability is enacted as a conscious choice, since other versions of sustainability do not cover the use of this vehicle; it is not labelled by any organization, it does not save (relevant) resources or care for people. What is cared for through the biogas truck is the lowering of emissions, but as we have seen in this chapter, this matter of care is difficult to enact and instead the company has turned to eco-driving. The biogas truck is not a fully successful actor for sustainability since it only enrols a version of sustainability that holds little legitimacy in the organization.

However, there are other ways to care for sustainability in the act of selling hygiene products. HygieneTech is not just a company that sells cleaning products; the employees provide their customers with high-quality and long-lasting products, service and sustainability. Their business idea still stays true to Bosse's mission to save resources - money as well as time and natural resources. As we have seen in this chapter, the employees enact this business idea in ways that enlighten issues concerning what sustainable delivery is and who, other than HygieneTech, should care for sustainability. The two different versions of the customer relate to different versions of sustainability. First, we have the small restaurant owner who is enacted as not caring about environmental issues and who is very price focused. In contrast, there is also the interested customer who is enacted as caring for sustainability. The interested customers are either schools or hotels with the environmental label Svanen. For them, sustainability is important either for idealistic reasons and/or for marketing reasons (i.e., with the Svanen label). The sellers enjoy working with them and HygieneTech likes to listen to these customers. The sellers think that some of their 
customers understand their efforts.

These two different versions of the customers come with different sets of practices when it comes to sustainability. The ignorant customer needs to be educated; there is a need for more communication and education. The practices of doing sustainability in these relations are largely about communicating: communicating the message not only within the organization but also to the customers and other interested partners. Getting time with the customers to talk about their use of detergents is challenging enough. For the sellers to be able to talk environmental issues with a stressed-out owner of a small restaurant who does not even have time to change the tires of his car seems like a mission set up to fail. In this situation, sustainability is a matter of care for the employees, mostly at the head office, and to some extent also for the sellers, but not so much for the customers.

The version of the customer as ignorant is done in relation to a version of sustainability as a matter of care that needs to be unveiled for the customers. In the training sessions at HygieneTech, it is made clear to the sellers that their most important matter of care is selling the company's (mostly environmental labelled) products. There is a passion for the economic value of HygieneTech's product at the sales training sessions: customers that do not understand the value of high quality are enacted as less admirable and less wanted. Sometimes it is even acceptable to tell the customers off if they do not agree about the value of a durable and high-quality product! Such customers need to be disciplined, while customers who are ignorant about sustainability need to be educated. The employees at the head office enact economic profit as a given matter of care, while sustainability has to be imposed on an already existing system. Sustainability can be a matter of care if it contributes to this economic framing, but if it does not, it is not awarded more space than necessary. The sellers are strongly encouraged to talk sustainability with potential new customers customer, and it might even be an effective sales argument. This is why sustainability is used in sales meetings but has little relevance outside these meetings. In addition, the difficulties that HygieneTech experience in communicating internally become a hindrance to caring for sustainability. The region managers are reluctant to spend time on sustainability issues during their monthly meetings and the sellers agree that they have more pressing matters to discuss. Care for sustainability does not travel easily to the customer when the sellers seldom face caring customers. Sustainability becomes a Volkswagen that is harder to care about than a fancy Ferrari that will have a direct effect on the sellers' working life.

Sustainability is enacted as a matter of care at HygieneTech despite the uninterested market, and sustainability thus has values attached to it other than marketing-related ones. By enacting the ignorant customer as someone that does not yet know the value 
of sustainability, HygieneTech avoid questioning the legitimacy of sustainability. The market is not the answer to what products the company should produce; rather, the company tries to create the market they want. This version of sustainability is disconnected from the market since the customers' requests do not affect their willingness to work with sustainability at HygieneTech. The coproduction of the ignorant customer and sustainability as a matter of care separated from the market's requests has consequences for how sustainability is enacted towards the customer. The employees believe that sustainability needs to be pushed onto the customer, or as Emil puts it, the company needs to use guerrilla marketing to interest the customer in these issues. Through this guerrilla marketing strategy, the ignorant customer is practically forced to read about sustainability and about how HygieneTech not only give them better hygiene but also a better world. In this way, HygieneTech can turn the ignorant customer into an interested customer who cares about sustainability.

Moreover, sustainability has other benefits than as a marketing tool; it is part of HygieneTech's identity. This is shown in the idealistic statement made by Wilma in the conversation about guerrilla marketing, when she stated that sustainability has other values besides those related to marketing, while Lars believes that sustainability is mostly about marketing and should be treated as such. Lars and Wilma enact slightly different versions of sustainability; Lars believes that sustainability is mostly a way to gain marketing benefits, while Wilma believes that sustainability is a matter of care since doing sustainability is important. Despite their differences, they both believe that sustainability can create value for their customers, whether or not sustainability is an important principle to care for. These versions of sustainability can coexist with only a little bit of friction since they both enact the customer as an ignorant consumer who needs to be enlightened about the benefits of sustainability, whether they are related to saving resources or to other values. 
156 - Chapter 7 


\section{Enacting sustainability through care of water}

The importance of water, clean water in particular, was introduced to me on my first visit to HygieneTech. Therese, the sustainability manager, was my first informant, but since she was so new in this position she also wanted me to meet with Wilma, the CEO. Therese and I first met in a conference room downstairs at the head office, and then we went up to meet Wilma in her office. Wilma's office is the brightest room in the building, with large windows overlooking the street. In her large office there is a shiny white table with modern plastic chairs, where we sit down. During the interview, Wilma tells me about their sustainability work.

Wilma We had a water campaign; I think that water is rather important. We had a shorter campaign that was called "Water - no life without it, but a rich one with it". And we told people how hard it is to clean water and how water will be a scarce resource. And indeed, that campaign made a huge impact. Many customers put up our campaign in their dish room, that is really awesome! We work a lot with water, both in the dishwashers and in the dish rooms, so I think it connects well to us and it is fun to work with. We take part in different water projects, working with the local lake conservation group and UNICEF. It's fun to connect what we do with something outside. We have talked about using water footprint instead of carbon footprint, but it is quite hard. You have to find the standards - how do we 
calculate the parts and what methods do we use? So when we work with sustainability we think about where we have the greatest impact.

This chapter is devoted to water. We need water to survive and water is inherently political due to its material imbrications in the socio-technical formations through which political processes unfold (Bakker 2012). Water is thus both the outcome of and productive in the making of political relations. In this chapter, I will turn to the network in which sustainability is done and engage with water. This supports our understanding of the network of sustainability, since we, in a similar way as in studying technologies, have to attend closely to the material substances that flow in and through the object we study (Barnes \& Alatout 2012) I wanted to write about water since it has strong connections to sustainability at HygieneTech. It is an actor in several of the networks where sustainability is enacted and it can show us some important enactments of sustainability. HygieneTech's products are connected to water in several ways; the chemical cleaning products are combined with water and are washed down the sink, and the company sells dishwashing machines that use water. Even so, water is not a resource in the same sense as fuel or chemicals, since the direct use of water does not come with economic costs. This makes water especially interesting; sustainability as caring for water cannot be legitimized as saving economic resources, and yet water holds a special place in the sustainability work at HygieneTech. Water will help me illustrate how cleanliness is connected to sustainability, and also how resource management can sometimes be problematic as a sustainability practice. I will introduce you to different versions of water, how in some situations water can have a great deal of power while in others it can be seen as weak, and how these different versions affect the sustainability work at the company. I will also show how the employees care for water in different ways as a part of the company's sustainability work.

For Wilma, water is an important part of their sustainability work, it is indeed a matter of care. Wilma refers to the water project "Water - no life without it, but a rich one with it." several times in different situations during my time at HygieneTech. For her, water is connected to sustainability since it is a scarce resource, and saving water means saving resources. And it is also "fun to work with!". As in the case with labelling products, Wilma and the employees at HygieneTech like working with environmentally friendly products since it means something more than just making profit. There are other matters of care connected to saving water than just making profit; there is a connection to something bigger, something important, outside the walls of HygieneTech. By working with the charity organization UNICEF, Wilma also feels like they are doing something good for the world, caring for water and for those who do not have easy access to clean water. Clean water means a clean conscience. 
A bit later in the interview Wilma adds:

Wilma If we could get information from them [the customers] about how much money we help them save through our business, we could use that as a sales advantage. Through cutting back on the last part of the dishwashing process, we can help the customer save water. Then we could use that in our business. That would be awesome, and then the circle would be closed.

Water does not only involve giving; it is also something to be conserved. Closing the circle would mean that both the customer and HygieneTech would benefit from saving water while taking care of nature. There could be a practice where HygieneTech could show others that their care for customers' use of water could also save money because it would lead to improved efficiency. The efficiency of saving water was unpacked in the discussions during my stay at HygieneTech, and I will show how water and sustainability are negotiated in terms of profit and care for a scarce resource. Firstly, I will show how care for water is enacted as giving and the difficulties that arise when the employees try to frame water as a matter of care for all.

\section{A water project for everyone}

As we have already seen, water is a way to care. In this section I study how water translates to different objects through a discussion of how HygieneTech can enact sustainability as charity. Wilma mentioned in the interview a water project they worked on a few years ago, in cooperation with UNICEF, for which HygieneTech contributed its profits for certain products. Wilma loved this project, and now the management group has decided they need to find a similar project to adopt as part of their sustainability work. The purpose of the meeting I am attending is to look at ways HygieneTech can include a charity project in their sales strategy. Therese has just met with a representative from an environmental NGO, the Swedish Society for Nature Conservation (Naturskyddsföreningen), and has an appointment with Markus (marketing manager) to discuss possible project ideas. In this conversation they try to establish criteria for what a water project can be. They struggle with how their own definition of water projects does not seem to apply to the projects of the Swedish Society for Nature Conservation. Water, like sustainability, is multiple and displays different properties in different situations (c.f. Barnes \& Alatout 2012) and it is not surprising that water project can turn into many different things; what is more interesting is the struggle to find the best versions of a water project that match 
HygieneTech's interests. Difficulties arise when they need to find a general reason to care for water even though water is neither a product nor an economic resource for the company.

A Tuesday afternoon in January at the main office. Markus, Therese and I have gathered in Therese's small office. Markus is as usual dressed in a stylish suit and has taken a seat at the end of Therese's desk with his laptop. Therese picks up her notepad and looks through her notes.

Therese I met with the guy from the Swedish Society for Nature Conservation and we talked about projects, but there were no definite suggestions of projects. He told me what they are working on right now, with chemicals, but that is too late now, if we think of the REACH conference [a restaurant conference]. But they will also be working with restaurants, mostly with ecological food, but they thought that cleaning and dishwashing could be included there as well. Then we also have the opportunity to create something on our own within their organization. But we then have to make up that project ourselves. The thing they will be working on from now on is about accumulated chemicals in the ocean. Now we don't have any of those, and otherwise it was about reduced proliferation of junk, dioxins in fish - but none of that relates to us. Then they talked about sponsorship, but I checked it out and you don't get that much out of it.

Markus The downside with sponsorship is that it doesn't have a natural connection to the business. Our co-workers and the customer want to feel that they're contributing. There should be a natural connection.

Therese Yeah... I agree with that.

Markus concludes that there needs to be a natural connection to their company, and he and Therese both agree that junk in the oceans and dioxins in fish do not relate to their business. Sponsorship is not relevant since HygieneTech would not get that much out of it. Working with charity is not only about giving money to environmental projects; it is also about getting something in return. Sponsorship is not enough, but involvement in a more specific project might work since they would get something in return - a good connection to their business. However, what this natural connection should look like is not so easy to determine. 
Therese and Markus continue their conversation and use Markus's laptop to look at the Swedish Society for Nature Conservation's home page.

Markus Look [Markus points to a headline under "Water projects" on the web page] - you can choose the focus of the project. The use of two-stroke engines is exactly what we want to get on top of!

[Both laugh]

$$
\text { get on top of! }
$$

Therese I think we should do our own project. Maybe with the Baltic Sea or something.

Markus Do you think we should go through the Swedish Society for Nature Conservation or UNICEF or...

Therese I think either would work.

Markus Umhum... I think we should be clearer on our web page about how we will work with it.

Therese I think we need to highlight this with local and global perspectives. UNICEF is good, but does it concern our customers? Then you have to wonder if working with the Baltic Sea would work for those who are located in Gothenburg. I thought if everyone should feel related to the project, maybe we shouldn't pick the Baltic Sea.

Markus No, I agree on that.

Therese But maybe from coast to coast... Or something about beaches.

Markus But what do you think Åre will say to that? Maybe we need to find more places; in the north we could support the Pink Ribbon or something that has a local connection.

Therese Or someone who has NTA in their detergents should do that, since it is carcinogenic! [Both laugh] No, but something more specific maybe.

Markus Yeah, something more central than the others.

$[\ldots]$

Therese But how much does it really have to be connected to environmental issues?

Markus Yeah...well... About water, we could say something about how we transport the steel balls on water.

Therese Yeah, from Kina! [She laughs]

Markus Exactly! It's too expensive to make them here or fly them here, so we transport them from the other side of the world 
on water! [Both laugh] Very environmental... No but really, we could look at a sponsorship deal on water and fishing.

Therese It should be called something with water.

Markus Yes it should. On their home page there's a lot related to fishing. It's either that or it's about phosphates.

Therese We have phosphates in some of our products.

Markus What? Really? I didn't know that.

Therese Yeah, I didn't know it either, but I found it out last autumn.

Markus I didn't think that was allowed - is it?

Therese No, it's not in consumer products, but it's ok on the professional side. It's so small scale in terms of products, so one might wonder if that's something we should put our money on.

$[\ldots]$

Therese Actually, it's just that we have to find a suitable headline. Something that speaks to everybody, like Swedish fish or something.

Markus Or something about that your grandchildren should be able to eat the same fish that you do today. You could wonder about where the benefit lies. Yes, it is in the future, like that, the fish stock will remain. Then we can connect this to the brochure, then the brochure contains more as well.

The conversation between Markus and Therese shows an interesting example of how water and sustainability are connected. One important aspect of their conversation is how they try to formulate a water project that relates to them, but only in the "right" way. In some situations a water project can include two-stroke engines while other water projects focus on chemicals in fish. None of these are seen as a "proper water project" for HygieneTech; they want a project that has a natural connection with their customers and sellers. They negotiate on what a water project is and what practices can be tied to it. This project needs to be able to translate into a matter of care for all customers, regardless of where they live. Markus and Therese need to draw borders to define what can count as a water project and what they believe is something that everyone can care about.

The water project starts as a charity project, just like the last project Wilma was so fond of. Wilma wanted them to do a similar project in which a part of the profit was given to a charity organization that works with water in poor countries. However, the Swedish Society for Nature Conservation has a different idea about what constitutes taking care of water resources. For them, water is about clean oceans and sustainable 
fish populations. It is about being able to swim in the Baltic Sea and having fish for dinner. It is also about material actors, like two-stroke engines and phosphates, since they cause water pollution. Their version of a water project is different from Markus and Therese's version. For Markus and Therese, a water project cannot be about the Baltic Sea, phosphates or engines; it is something else. A water project has to be connected to their practices, and to a material actor to which everyone has a close connection. A material object that they are closely connected to, phosphates, cannot be included in their version of a water project, however. The fact that HygieneTech has used phosphates in their own products indicates that phosphate use has not been a matter of care for the company. This makes it hard for Markus and Therese to make phosphate use the focus of a water project demonstrating the company's care; instead, other versions of a water project are privileged.

They struggle to make this care for water into sustainability since the different versions of sustainability they usually encounter do not fit with this situation. Sustainability as investing in a water project is not about saving resources for customers or the company; instead, it is about giving away resources. The care has to be shaped in the right way to fit another version of sustainability, and in this case they turn to care for children. Saving water is a means to an end, and has to be legitimized in a way that everyone can relate to, according to Markus and Therese. Saving resources is a common and well-accepted way to talk about sustainability in the company, but care for other matters, such as clean water, needs to have an additional purpose. This is a result of the choice to work with an issue that is not their main product, even though it has a strong connection to their processes. Therese and Markus try out different ways of creating a water project, through saving shorelines or beaches. None of these seem to work since they are not connected to all the employees. The water project changes; it becomes a project about being able to eat particular species of fish. This is a matter of care that they think all their employees and customers can agree on. The materiality of the water project changes during this conversation, but the water project is still not being questioned. Likewise, the practices connected to the water project change during the conversation. The Swedish Society for Nature Conservation believes that a water project should be about being able to swim in the Baltic Sea. For Markus and Therese, the practices of the water project have to be more closely related to their own business. Saving shores is not interesting for the people working in Åre, Markus suggests. However, they all seem to eat the same fish. Furthermore, the water project is not only about the environmental aspect, it is also about marketing. The connections between the water project and marketing practices are strong in Markus and Therese's conversation. The project has several important purposes for HygieneTech, one of which is to create marketing value for the company. 
Caring for water through charity needs to be (somewhat) profitable and legitimized with other means. It cannot involve just any kind of water, it has to be water that is close to the customers and the sellers and have relevance for everyone. Even so, the project in itself is never questioned, neither in this example nor in other conversations that I heard on the subject. One problem for Markus and Therese is that care for (material) matters that are not part of the core process is less common in the company than care for such things as less environmentally polluting chemicals in cleaning products. There is no already existing version of sustainability that easily includes a charity project since this kind of care does not directly concern saving resources or caring for people. Therefore Markus and Therese need to transform the water project into care for people, through caring for the opportunity to eat certain types of fish.

\section{Is water clean enough?}

In other parts of the organization, water has other sets of practices attached to it. With help from Sara, a leader at a product training session for the sellers, and from the sellers, I will show a different version of water.

At the product training session, Sara introduces some non-chemical products and explains:

Sara This is our new polishing mop. It polishes glass and stainless steel and can be used on large surfaces. It has a good ergonomic handle and is ideally used on large areas like tables. In the kit there is a spray bottle which is transparent so you can show that you are actually using only water. These are new sales products and a lot of them are non-chemical, and that can be a bit scary. But it just comes down to being trustworthy and using the right methods.

Some products are designed to work without any chemical cleaning products and the manufacturer takes pride in showing that they do not need to use chemicals by using a transparent container. These products are labelled with the environmental label Svanen and are seen as environmentally friendly since they reduce the use of chemicals. Even so, these products are seen as problematic by some. It is seen as scary to work with non-chemical methods since there is a fear that they won't clean well enough. For the sellers, the practical side of cleanliness is strongly connected to chemicals and those practices are hard to disconnect. Water alone is not seen as strong enough to clean hotels or restaurants. Thus, there is a weakness connected to water. In this setting, 
water is not connected to the strong lifesaving activities of the water project Wilma talked about. Instead, water is translated into something weak.

This version of water is also shown in this next example from a product development meeting:

Therese Cleanup - we have tested that product now. It is a lot better than the last version.

Mikaela Yes, the test showed that it is twice as good as water!

Therese Yeah, but we probably shouldn't use that as the slogan!

[The group laughs]

Their new recipe for "Cleanup" has significantly improved, but to "only" be twice as good as water does not sound impressive enough. Water is not enacted as clean in itself; to make something clean, you need chemicals to assist the water. The employees at HygieneTech's head office do not themselves believe that water is strong enough to properly clean hotels and restaurants. This makes the products Sara introduces sound scary since there is a fear about leaving dirt behind. Instead of caring for water in this setting, cleanliness is made into a matter of care. Cleanliness is essential to HygieneTech; it is the reason they exist. HygieneTech aim to be the best hygiene partner a customer can have, and this comes with expectations of cleanliness. For the sellers, cleanliness is connected to chemicals, which leads them to care for the use of chemicals rather than caring for clean water instead of chemicals. In this case, using water on its own poses a threat to cleanliness, and that worries some of the employees. Caring for clean water can be a good thing as long as it does not compromise cleanliness, since making things clean is the core process in HygieneTech. Caring for cleanliness is more important than caring for clean water in this situation.

By thinking with care, I believe that I can show that using chemicals rather than chemical-free products also includes care, but care for cleanliness rather than care for clean water. The conflict between caring for clean water and caring for cleanliness is a recurring theme in discussions about water. In HygieneTech's latest environmental assessment, a small work group led by Therese concluded that chemicals were one of the three most important environmental impacts they needed to reduce. However, in their reality cleanliness requires chemicals even though this stands in contrast to their sustainability work. The chemical products are also tightly connected to their understanding of cleanliness and also to their business idea. So far, we have seen two versions of water: the enactment of water as scarce, in need of care and important for human life; and the enactment of water as weak and in need of chemicals to produce cleanliness. These two versions are enacted in slightly different settings. Wilma is asked about sustainability and brings up water as an important part of their work; it is a 
matter of care. On the other hand, Therese and Sara bring up water as weak and an ineffective cleaner in settings where products and the products' effectiveness are discussed. The different meetings have different agendas even though both connect to the company's sustainability work. By considering water as weak and inefficient, they further legitimize the need for chemicals. Hotels needs to be clean, therefore HygieneTech needs to sell chemicals.

HygieneTech's matter of care is their ability to clean, whether it is dishes or hotel rooms. If they wanted to work more sustainably according to their own assessment, they would need to reduce their use of chemicals. However, since their enactment of water as inefficient cannot at the same time include the enactment of water as scarce, there is a need to privilege one version over the other. When products are discussed, the enactment of water as inefficient is privileged and thus the chemicals become necessary. Caring for clean water cannot coexist with the version of cleanliness that is most dominant in HygieneTech. Cleanliness is enacted with chemicals, and water alone is not strong enough. In order for them to be able to take better care of water, they first need to change their practices connected to cleanliness. Water is seen as important and valuable and it can help me illustrate another interesting challenge for HygieneTech in the following section, the negotiation between environment and economics.

\section{Saving water and killing business}

We are located at the head office in a flashy conference room. Nine people are gathered around the slightly too small conference table for a sustainability work group meeting. Therese chairs the meeting and uses a projector to show the ISO 26000 action plan on a wall. This is the steering document for the sustainability group, and at each meeting they use the action plan as their agenda. At the end of the table is Sven, head of purchases, next to him sits Fredrik, technical manager, and then Markus, marketing manager, and Therese, sustainability manager. At the other end of the table I sit with my computer, and next to me is Erik, CFO, and next to him Wilma, CEO, Anders, sales manager, and Lisa, HR manager.

After a while, they reach a recurring subject in the action plan: how HygieneTech can influence their suppliers of dishwashing machines to make their machines more efficient.

Therese Ok, next on our list, how do we work with our suppliers? 
Erik We are working on it.

Sven We have a new supplier on the way in, and this time we also included our code of conduct with the contract. They didn't have their own code of conduct, which was strange.

Erik We will do supplier assessments of seven suppliers during the first quarter and seven more during the next quarter.

Sven We need to get it on paper how we should work with them. Some suppliers are more trouble than others. Take Supply $\mathrm{AB}$ [a supplier of dishwashing machines] as an example; they are just morons!

[The group laughs]

Fredrik Yeah, they never get back to me when I try to get in contact with them! And they never want to change anything after our requests.

Erik But if they don't live up to our demands, we should change supplier!

Sven Yeah! Doing business is so much more than just price. It is also about service and handling the customer.

Fredrik We have a good deal with them, but it could be even better.

Wilma What about their products, are they better than their competitors'?

Sven Yes, I would say that they are.

Therese But we know very little about how efficient they really are, and how much water they use.

Erik Do we really not know anything about this, Fredrik?

Fredrik No, and they were not interested in reporting this to us when I asked them. But it's the same with Machine AB [a supplier of dishwashing machines]. When I visited them and asked them about their water consumption they said that it was something they never thought about. It was the same with sustainable development, but when we talked about it they told me it was something they saw as important and wanted to work with.

Later on in the meeting a related question comes up. This subject is also directed to Fredrik and concerns the energy efficiency of dishwashers.

Fredrik Supply AB don't measure the use of energy, there is no energy classification on the professional side. Another supplier that they talked to said that $99 \%$ of their 
dishwasher was recyclable, but you can do that with almost all machines today, so that's not so impressive. And when I talked to White $\mathrm{AB}$, [a supplier of dishwashing machines] who wants to get into the professional side, I found that they are far from us in this question. They haven't started thinking about this at all. They said that having birdie birds on the products doesn't impress anymore since everyone has them. And we're more interested in how much [water the dishwashers] can save.

Sven Are all dishwashers Svanen labelled? Nowadays all monitors have the Svanen label, so it doesn't make any difference anymore.

Fredrik There is no labelling for industrial dishwashers.

Wilma But this is where we can be a part and have some influence! And push the development of better dishwashers!

Fredrik I asked Machine $\mathrm{AB}$ what their view on energy and water use is and they said that it is important but that they haven't started working on it yet.

Sven Maybe we can approach Svanen so that they will develop criteria for industrial dishwashers too, and then preferably with the criteria that we advocate, with water measuring and such.

The discussion ends and the meeting moves on. But let us dwell a while on what happened with the question of water efficiency. First, I believe that it is interesting that HygieneTech as a trader raises the question of water efficiency for the dishwashers they sell. They believe that it is their responsibility to consider their customers' interests. The subject of saving water arises in a discussion of suppliers and how to deal with "morons", but later it turns into a more idealistic discussion of what HygieneTech can do regarding the development of new standards for industrial dishwashers. Wilma is very enthusiastic when she sees an opportunity to be a part of the development of new standards. She sees an opportunity to change the way water is used, and in this way to care for the environment. Later on, I understand that the company's involvement in developing environmental standards is both a result of an environmental concern and also a strategic move since it will enable HygieneTech to push the issues that they think are important and that suit their products. Fredrik, who is responsible for dealing with this question, struggles to turn the issue into practice. The suppliers do not seem to care; some of them have not even thought about these concerns. 
Handling the issue of water efficiency is not simple: How do they get the suppliers to care for this issue, and how can they measure the efficiency themselves? One suggestion is to install water meters on some customers' dishwashers to see how much water they use. This project never gets launched, however, even though everyone thinks it is a good idea. The subject is brought up again in a sustainability meeting in May 2012. The same people are participating in the discussion except for Wilma, who not is present at the meeting.

Therese Ok, what's happening with environmental demands on technical equipment?

Fredrik It lies at the EU level. They are about to develop that.

Therese What can we do to influence the process?

Anders White $\mathrm{AB}$ is following some kind of criteria; all their components are recyclable.

Fredrik Everyone's components are recyclable today.

Therese How can we find out more about the process?

Fredrik I don't know, how do you mean?

Therese Well... like Google it maybe?

Fredrik Hmm... well there is no criterion today in the industrial kitchen side. Sven, what did Blue [a supplier of dishwashing machines] tell you about this?

Sven Not much. There is a great difference between the consumer and the professional side. They presuppose that the professionals know what they're doing; it's not the same with consumers.

HygieneTech is just a small company trying to influence their large appliance suppliers to care more for environmental concerns. Fredrik is hesitant about whether they can have any influence in this question. There is also a picture of the professional customer as more knowledgeable and demanding that the non-professional consumer. Professional customers know what is important for them and therefore there is no need for a label on industrial dishwashers. Consumers, on the other hand, need to be taken care of by the supplier so that they will understand what they are buying. However, as we have seen in the previous chapter, the restaurant owner who doesn't even have time to change the tires on his car will probably not take time to read up on water and energy efficiency demands on dishwashers. Even so, professional customers are expected to care more (or not care at all?) for the efficiency of their dishwashers and do not need a label to tell them which machine is the most efficient. There are of course professional customers that know and care about the efficiency of their dishwashers, but as shown in this thesis, professional customers are a heterogeneous group just like the non-professional consumers. 
The conversation about environmental demands on dishwashers continues.

Fredrik Supply AB says nothing about environmental issues, but they have just released new low-flushing machines. It only uses one litre per flushing. Why are they doing this? Water costs nothing in Sweden. It [environmental concerns] has to be something that will also happen here.

Sven Water is expensive in Denmark.

Anders This is going to kill us!

[Short, tense silence]

Fredrik Well, yes, we will sell less detergent.

Erik Yes it is actually dangerous.

Fredrik Supply's machines use enormous amounts of water; they really haven't any control over their water use. But is it really up to us to take on that issue? Aren't there others who can do it better than us?

Therese: We don't have to push the issue, we just need to ask some questions.

Fredrik But we already are...

Sven It might have to be a trade organization that can deal with this.

Anders It's too dangerous for us to push this issue; we might end up killing our own business.

Therese But we can't think like that! We have other products as well. It is a part of our action plan to work with demands on the technological development.

Erik Yeah, we do have other products, but not at all on the same scale.

Fredrik Something is already happening on the professional side of dishwashers; if we push this issue further we won't make as much profit.

The first process that I would like to look into is the translation of the water-use issue from a separate matter into one that has been fully merged into the discussion of labelling of technical products. This first translation has consequences for how HygieneTech deal with the issue. The issue is now paired with an environmental label. Working with environmental labels is a very familiar process to HygieneTech and can be seen as a way to handle sustainability issues in a more structured way. As they translate an issue into a label issue, they also change the practices attached to it. When a label organization becomes involved, there are processes and paths to follow. There 
will be processes that have already been developed and forms to be filled out. There is also another actor, the label organization, that will pursue the project, which will give it more strength than if HygieneTech were left to do it themselves. Since their relationship with Svanen is well developed and they are familiar with these processes, it is easier for them to handle the matter through labels than to take it on by themselves.

A new issue also arises in this process: The quest to sell their products suddenly clashes with the aim of improving their environmental impact. This translation happens when Anders brings up the downside of making the industrial dishwashers more water efficient. Many difficult matters are brought up during these meetings, and in many cases the participants' opinions differ. In the case of water use, Therese believes that this is an important question but the other participants think there are high risks involved. What was seen as an opportunity to be a part of developing the new standards for industrial dishwashers is now turned into a risk. A new set of practices is again attached to water efficiency, that of selling less detergents. The water efficiency battle is also about negotiating what their responsibility is as a company, a customer and as a supplier. In this question, Therese finds it hard to get the response she hoped for. There is one important difference in the two meetings; Wilma was not present during the second meeting. Wilma seems to be an important ally to Therese.

Let us visit HygieneTech again and follow the discussions in the next sustainability meeting. Therese once again brings up the question, but now it is no longer about water efficiency but only concerns the environmental labelling of technical products.

Sustainability meeting August 2012

Therese How are things progressing with product classification of electric products?

Fredrik We are in the hands of the EU; there are no criteria today.

Therese But can we set some criteria?

Fredrik No we can't; our influence is too small.

Wilma But to work with energy efficiency, isn't that good for everybody?

Erik But that is already happening. And the dishwashers are already more efficient, which is maybe not only a positive thing...

Wilma Yes, that is both good and scary. It can affect our sales.

Anders I really find these new products very scary. One can just imagine what it will do to our sales of detergents... 
Fredrik Yes, but I look forward to the classification. It will be clearer how the machines work. It will be more like the consumer side.

Therese I guess it's the same thing as with our imported products; we know very little about those. Like how much silver ions they use.

Wilma That's something we have to take care of when we get some information about it.

In this conversation, Wilma acknowledges both the danger and the positive (environmental) aspects of more efficient industrial dishwashers. Once again, this discussion is set aside, and even though the group knows that there are positive aspects of labelling the dishwashers, no joint action is considered. Fredrik is made responsible for checking this out before the next meeting. At the next meeting, the issue is brought up once more.

Sustainability meeting November 2012

Therese Environmental classification of electric products, an issue we have talked about earlier. Have you heard anything Fredrik?

Fredrik No, but it will be reality. The classification will be done in the same house as the other electric products.

Therese So nothing has happened?

Fredrik No - I mean, yes - there will be a classification like the one on consumer products.

Therese When it comes to energy I think it will be very interesting to see how our suppliers' products will be classified.

Fredrik Yes, and it can also expand to include fridges, freezers and dishwashers.

Anders I think the declaration that we use for our chemical products should also include these kinds of products. There are some products that have a silver coating and that do not fill its function.

Erik Yes, technical products should be handled the same way as other products. But you have your own way, don't you?

Fredrik Not really. You are very welcome to help me find the best questions to ask our suppliers about this.

This example can show the difficulties in being a company that aims to lower their environmental impact when doing so stands in conflict with the desire to sell 
detergents. The issue was resolved by Fredrik, who reassured the sustainability group that development in this area was already taking place. Therefore, it was not HygieneTech's issue anymore. What started out as an environmental question that could save money and resources turned into a discussion about labelling technical products and about energy efficiency issues. Water efficiency seems to be a difficult subject to talk about, and even though Therese brought it up at every sustainability meeting I attended, it did not lead to much action. The discussions touch upon important questions about the responsibility of HygieneTech and what questions fit within sustainability. The water efficiency issue relates to a recurrent question: Can environmental concerns have priority over economic concerns? In this case, the issue leads to very little action, other than raising the question to some of their suppliers. The participants at the sustainability meeting instead work with other sustainability challenges than the ones that might affect their sales numbers. I discuss this issue with Nils, who is the son of the owner and responsible for the divisions outside Sweden. He responds:

Nils I can assure you that this is not an issue that we are engaged in. That is not a question that we ought to push.

And at the last sustainability meeting where this issue is brought up, the discussion ends like this:

Therese Then we have environmental demands on technical equipment. I have talked to Fredrik, but have not gotten any further. There are no environmental criteria today.

Anders But Therese, let's remove this from the agenda.

Erik We can't work with something that they [the suppliers] aren't working with themselves.

Anders I agree. I think we can have a larger influence on other issues.

There are different opinions on how this challenge should be met, and knowledge about what questions are treated in the sustainability group is not spread throughout the organization. This is an interesting challenge since this is an example of how borders are drawn to delineate what sustainability is. In the first sustainability meeting when this issue was brought up, the participants had a discussion on the company's environmental impact and how they can help their customers save the money. When the risks of lower sales of detergents were highlighted, the quest to make the industrial dishwashers more efficient changed. Therese's version of sustainability was too weak in regard to this issue, especially in those meetings were Wilma did not attend. The question of water efficiency turned into a question of environmental labelling, and in 
this, the energy issue was seen as most important. The water issue therefore disappeared from the agenda; it did not meet the sustainability group's criteria for what they see as an important sustainability issue. Water is made absent in this practice. Energy efficiency is good for everybody, but water efficiency is not that beneficial for HygieneTech and therefore the water efficiency issue is left outside. As I showed in previous chapters, a version of sustainability as resource management has a strong position in the company. The employees do not think that sustainability contradicts profitability, since both mean saving resources. However, in this case a different version of sustainability comes about since the members of the sustainability group are afraid that they will kill their own business by saving resources. The thought that "sustainability as saving resources" and losing money could be connected is never mentioned in the discussion between the employees at HygieneTech. Even so, this question shows that in practice this problem does arise. By making care for water absent they can instead care for the survival of the company, arguing that "we ought not to push this issue" since it is not in their interest. Saving water is not enacted as a matter of care strong enough to risk losing profit and, in the long run, losing the company. In this situation the employees feel that they have to care for the self, that is, for the survival of the company.

Another example where this happens is when new types of products are introduced. HygieneTech recently started selling a new type of sponge that is meant to be used without any chemical cleaning products. This sponge uses water and mechanics to clean surfaces, but it comes with a set of practices that some sellers find troublesome. At a product training session Sara shows us this sponge and talks about it with two sellers, Daniel and Mark:
Sara This white sponge takes away a lot, you don't have to use "Clean off" or other strong cleaning products.
Daniel But then you don't have to use as much chemical products, and then we'll sell less.
Mark That's true!

The sellers directly make the connection between lowered profit and saving resources. For them the practice of using water instead of chemicals will not be advantageous since they will sell less and, considering that they have a partly sales-based salary, also earn less. Water does not come with the same practices for them as it does for the members of the sustainability group; likewise, sustainability is enacted differently in their reality. Using non-chemical products is not only a cleanliness issue (as we saw in the previous section), it is also a matter of economics. Chemicals are the main products that HygieneTech sells, and turning instead to non-chemical products is not a sustainability aim in any policy or on any agenda. To do so, they would need to be a 
different company altogether. Therefore, the non-chemical products meet resistance since they are enacted as unprofitable products.

\section{The absent and present water}

In this chapter, I have shown that water as part of sustainability practices at HygieneTech has different practices attached to it; it comes in different versions. HygieneTech's products use a lot of water and Wilma talks about polluted water as one of their major environmental impacts. At the same time, water presents an opportunity to save money. Making this connection between a resource and economics is a common way to argue for sustainability at HygieneTech. A version of sustainability as saving resources is very common in HygieneTech and is used to justify working with sustainability. However, enacting sustainability through saving resources is not always a straightforward practice.

Water has certain properties and desires ascribed to it at HygieneTech. By looking at how the employees enact care for water, I study how water is turned into different objects and different matters of care. The enactment of caring for water in some settings tells us that Wilma believes that water should be clean and it is a resource we need to take care of. Caring for water is also a way of doing sustainability; by saving water or paying for clean water in poor countries, HygieneTech becomes a sustainable company. The care for water is not explicitly questioned in the company, even though it is made absent in some discussions. Caring for water is, like sustainability, a matter of care that has acceptance throughout the company. Interestingly, this matter of care has only indirect relevance for the company's core products and the customers do not ask them to work with this issue. There are no apparent economic reasons for HygieneTech to care for water, but Wilma and Therese often spoke about the company's responsibility for working for clean water. Caring for water is a way to do sustainability as taking conscious choices for the company's negative impact, and this is done in different ways in HygieneTech.

Water has a very different set of attachments in other settings. When the employees talk about the non-chemical products they often turn to cleanliness. They are not convinced that water alone will make things clean enough! Water is made present in these conversations, not so much as a matter of care, but rather as a liability. Water is weak, a poor cleaner, and will not generate any profit for HygieneTech. In this situation, caring for clean water by selling non-chemical products makes little sense. Instead, the sellers trust what they have learned from HygieneTech earlier, that the chemical products they sell are the best on the market and are needed in order to have a clean restaurant. It is even about the company's survival since, if water alone can 
make things clean enough, HygieneTech's products won't be needed at all. There are some areas in a kitchen that will need to be cleaned with chemicals to meet demands from, for example, health authorities, but in other areas, such as hotel lobbies, just using water could be enough. However, caring for cleanliness, and through this also caring for the customers' trust, is more important than clean water. Water is thus enacted as a liability, a risk of not achieving cleanliness. Water now has very different properties than in the previous discussion, where caring for water meant caring for the diversity of fish stocks. Since cleanliness is the reason HygieneTech exists, some of the employees have a hesitant attitude towards the non-chemical products. To be able to care for water through selling non-chemical products, HygieneTech has to reinvent the concept of "cleanliness" and disconnect it from chemical products. This could make the cleaner way a bit less chemical in the situations where the demands related to bacteria levels are moderate.

I have shown in this chapter how sustainability comes in different versions, and when it comes to water, these versions become visible. In the discussion between Therese and Markus about the water project there is yet another tension that is made visible, that between caring for water and caring for the trademark of the company. Caring is not always easy and affectionate. Sometimes care can involve killing (e.g. Law 2010) and other times care for oneself is important to being able to cope (Law 2010, Puig de la Bellacasa 2010). Some versions of a water project did not meet HygieneTech's criteria since they could expose the reluctance to care for other matters, such as the use of phosphates. Bosse's care for the employees and Therese and Markus's care for the trademark of HygieneTech are types of care for the self/the company. To a certain extent, this care for HygieneTech is necessary for the company's survival, including when it comes to sustainability issues. Enacting sustainability through care for water will sometimes lead to caring for HygieneTech at the expense of water. Caring for the company's survival and caring for clean water sometimes clash and sometimes go very well together. In the first example in this chapter, I show how a charity project related to water worked well with the vision of what it means to be HygieneTech - a company that cares (about clean water in developing countries). However, as seen in the other sections, the relationship between sustainability and caring for water is more complicated. Water is tightly connected to sustainability in some practices, while it is made absent (Law 2004) in other sustainability practices. When water is paired with a practice of selling less detergents (and thus saving resources), this becomes problematic for the employees at HygieneTech. Even though their sustainability action plan cared for saving water, the employees at HygieneTech give other matters of care priority over saving clean water, and water is thus made absent in the later parts of the discussions. 
Even though care for water is made absent in the previous example, I do believe that, in this case, there is also care in the practice of saving economic resources over environmental resources. As Bosse told me in an interview, "My first priority is to see that my employees have a job to go to in the morning." He does care, and more so for his employees than for, always, saving water. Sometimes care for economic needs has to be more important than care for water in order to survive as a company. The struggle between different matters of care is made visible in this example, and the version of sustainability as saving resources is made absent in order to legitimize the necessity of caring for the company's survival. The economic aspect is enacted as something more "real"; it is a fact they need to relate to, in contrast to working with water efficiency, which is enacted more as a voluntary choice. The economic reality is put up against care for a matter they have little control over - influencing the suppliers to produce more water-efficient dishwashing machines. I will get back to this discussion in the following chapter. 
178 • Chapter 8 


\title{
Conclusions: Enacting sustainability in care practices at HygieneTech
}

\author{
Bosse I belong to the generation that lived when we had few \\ resources, when it was real sustainability!
}

Writing about sustainability comes with many challenges. Due to the elusive nature of sustainability, the practices of sustainability change in different situations. Sustainability transforms during my interview with Bosse, it changes with ease from saving resources to caring for employees. Even though sustainability is multiple and has several versions, it in other settings is enacted by the employees at HygieneTech as if it were a single object. This is shown in the way the employees enact that there is such a thing as a sustainable company, they just need to figure out how best to comply with the sustainability criteria that the external actors have defined. Traditionally, for example in the Brundtland report, sustainability is split into environmental, economic and social sustainability (see Chapter 1 for further discussion about the definition of sustainability). The members of HygieneTech refer to this division when they are asked what sustainability means, but the components play different parts in different situations. Even though the employees at HygieneTech most often enact sustainability as simple and singular; there is awareness that sustainability can be many things and that the employees at HygieneTech have to decide what issues they want to work with.

The process of uncovering what the sustainable company is can be difficult, and the employees often find themselves in situations where tensions arise between different matters of care-matters they care about. Thinking with care (Puig de la Bellacasa 2012) has helped me to understand and care for the people and their realities behind 
the company logo and the big words about sustainability. In this study, I do not tell the cynics' story, in which HygieneTech only cares about profit, neither do I describe the company as the perfect, sustainable company. The stories in this thesis shows how enactments of sustainability sometimes can include working with economic profit, while in other setting sustainability is done despite economic costs. I have thus written stories about the hard work, the tinkering and the sensitivities that are needed to care for sustainability in a company. In this chapter, I conclude my understanding of how sustainability is enacted at HygieneTech. First, I discuss different versions of sustainability and identify some of the more important ones. I then look at the different ways that versions of sustainability can clash, and how in other situations they can be added together, and at how sustainability can be made absent in relation to other matters of care. The last part of the chapter discusses how the employees are able to enact sustainability through tending to this range of matters of care and how they are a part of enacting an entity that still coheres, despite its multiple faces.

\section{Different versions of sustainability}

Sustainability comes in different versions, with various forms of care and a diversity of matters of care. In this thesis, I have studied how some of these versions are done in practice. The different versions have been shown through stories about how the employees care for sustainability as labels, sustainability as policies and sustainability through care for water, just to mention a few. To make a list of all the versions that I have encountered at HygieneTech would indicate that sustainability is finite and stable. It is not. The versions of sustainability are not separate entities, nor are they stable; instead, the versions change and are entangled in each other in innumerable ways. New versions are created and others are forgotten through changes in the organization. There are, however, some versions that are stronger in HygieneTech and are more often enrolled in the enactments of sustainability. In this first part of this chapter, I will discuss some of these more frequent versions since they have a strong influence in the making of sustainability at HygieneTech.

Sustainability as labels: In HygieneTech, a sustainable product is enacted as a product that carries an environmental label. Sustainability "as labels" frequently occurs in HygieneTech. The labelling process is important for their view of themselves as a sustainable company and in their marketing practices, and all employees refer to HygieneTech's high quota of labelled products when they talk about their sustainability work. There is joy and pride in making sustainability through environmental labels, and since $95 \%$ of HygieneTech's self-produced products are labelled, all of these are considered sustainable. The employees talk with pride about 
being part of a company that has such a high percentage of labelled products and that cares for things other than profit. The employees often say that it is fun to work with environmental labelled products and that the customers that care for sustainability and environmental labels are the most rewarding ones to work with. HygieneTech is enacted as sustainable by the employees since they produce and sell as many environmental labelled products as possible, and consequently the labelled product is their way of turning sustainability into practice. This version of enacting sustainability as environmental labelled products is important for the company and thus the labelling process in a way defines what sustainability looks like in these practices.

Sustainability as the ISO 26000 standard: This is another way sustainability is made is through HygieneTech's work with ISO 26000. This work is mostly focused on the sustainability group, a group that has an important role in HygieneTech's sustainability work. This group makes sustainability come to life and decides what actions should be done in the name of sustainability. Therese, the sustainability manager, leads the group, and their meetings are most often guided by the action plan which resulted from working with ISO 26000. To understand how they come to commit to certain objectives we first need to understand the use of paperwork and the interpretations of the ISO 26000 standard. HygieneTech has engaged a consulting firm to help the employees work with the standard. Through these processes HygieneTech received a report (GAP report) that they themselves turned into an action plan. The GAP report enacts sustainability as care for the seven core subjects that are part of the ISO 26000 standard, but since the standard was developed to work for all types of organizations, the report focuses only on practices outside the production process. Two GAP reports were produced. The first one says that HygieneTech should improve in their work with human rights. The second, follow-up, report praises their efforts in this area as, by the time it was written, the company had introduced more human rights policies. Several of the suggested actions in this second report concern making more policies or making processes clearer (actions that, in turn, result in more written documents).

One of the most important reasons that HygieneTech works with both labels and the standard is that they make sustainability comprehensible and limited. As I understand it, the drive to make sustainability as standards is prompted by the need to address sustainability's multifaceted nature, since "To standardize an action, thing or process means, at some level, to screen out unlimited diversity" (Lampland \& Star 2009 p. 8). The two versions of sustainability, sustainability as environmental labels and sustainability as ISO 26000 , offers a systematic way to approach the challenge of working with such a multifaceted concept as sustainability. Through the Svanen environmental label and the International Organization for Standardization (ISO), HygieneTech receive guidelines, protocols and rules concerning how they can be a 
part of making the sustainable society. Through these structures, HygieneTech can more easily care for sustainability.

The processes provided by either the standardization organization or the labelling organization bring structure and justify that the company's products and their efforts ought to be named sustainable. The labelling process engages a range of different employees, from chemists to marketing managers, and enables them to participate in caring for environmental concerns. This distribution of participating in the enactment of sustainability enables more actors to be involved and thus to care for sustainability through their different practices, whether by changing a recipe or choosing a shorter route between two customers. For HygieneTech, these care enablers are important since they both "screen out unlimited diversity", in the words of Lampland and Star (2009), and bring a sense of legitimization through the unbiased actors. The practices of the standard as well as the labelling process include checking boxes and following procedures and action plans. The enactment of sustainability is thus sometimes made very explicit, as in the case with the demands from the environmental label organization; however, in other settings the control is less strict. The members of the sustainability group found themselves struggling to navigate through the ISO 26000 standard and thus having to make decisions about how to enact sustainability on their own. One of these situations occurred when the standard encouraged the company to work on reducing the amount of water used in the dishwashers they sell. The members of the sustainability group found it hard to engage in an issue that might lower their sales even though it was a suggestion in the action plan for ISO 26000. Responsibility for caring for the use of water in the dishwashers was distributed through the standard to the members of the sustainability group; they, however, did not think this was an appropriate issue for them to work on due to the complexities involved and the risk of lowering their sales numbers. Consequently, the care for using less water cannot in this case be enacted through standards. Likewise, as I have shown in Chapter 4, caring for reducing the corrosiveness of the detergents is not a part of the enactment of environmental labels.

In this thesis, the standards and labels are called "care enablers" since they offer a legitimized way to care for sustainability and to distribute care within the organization. Care is usually portrayed as done by a single person towards another person. However, following the symmetrical approach taken in this thesis, HygieneTech, as a non-human actor, can care. In reports and policies we are told about the spirit of the company and about the many ways this organization takes care of the environment and people. In these textual practices it is HygieneTech that is enacted as the caring actor. In other settings, as when Wilma and Therese argue for the value of caring for sustainability despite the costs, care is done by individuals. Thus, care can be done both through collectives and by individual actors. However, this care can be enacted differently, and 
care can be organized within a collective in different ways. In the same way as technical aids for disabled persons (e.g. Winance 2010) make it possible to share care, some arrangements, such as the labelling process and the work with ISO 26000, enable care to be shared within the organization. These ordering processes distribute care in a similar way as a technical aid does. These actors create processes and devices that enable care and make it travel in different ways. This study shows care being ordered in sometimes successful, and at other times less successful, ways through different care enablers and other practices.

Sustainability as saving resources: The use of labels and standards are common ways to enact sustainability at HygieneTech, but maybe even more common is the view of sustainability as saving resources. In HygieneTech's sustainability report, Bosse tells us in relation to the commitment to do sustainability that "saving the environment/nature was free". For Bosse, sustainability is (mostly) about saving resources. He is the strongest spokesperson for sustainability as saving resources and his vision of HygieneTech as a sustainable company are evoked in most situations where sustainability is discussed. This version of sustainability combines economic gain and care for environmental resources. Through saving fuel by optimizing logistics, the company can reduce both their expenses for gas and their emissions of carbon dioxide. Sustainability is here enacted as simple and obvious - it's about survival! Following the thinking of ecological modernization (e.g. Spaargaren \& Mol 1992; Mol 2001), saving the environment and caring for business opportunities go hand in hand. This version of sustainability is widespread in the business world and argues that both economy and ecology can flourish through expanding the economy. By consuming more sustainable products, more money is invested in the businesses that promote sustainability as saving resources.

Care for the economy and care for the environment go hand in hand in many of the publications from HygieneTech, and this logic is present in all of the interviews I had with the employees. Saving nature does not come with costs, only with economic benefits, according to this version of sustainability. In this way, sustainability is a resource that everyone ought to work with in order to save both the environment and the economy of the company. This approach is visible when it comes to the employees' enactment of HygieneTech's customers. The customer who does not appreciate HygieneTech's sustainability work is treated like an ignorant individual who has not yet discovered the benefits of sustainability. This customer thus needs to be educated in order to understand why sustainability is profitable and good for the environment. The version of sustainability as saving resources is most often made present in conversations seeking to justify sustainability by referring to the economic benefits of working with saving resources. 
Sustainability as care for people: Even though Bosse always refers to sustainability as saving resources, at the same time he embodies a strong passion for caring for people. In our first interview, he told me how his care for his employees is part of doing sustainability, and he shared stories of how he has personally extended help to employees during times of difficulty. Besides the stories, his energetic presence and interest in all the employees shows care for the people close to him. He talks with all employees he meets and makes an effort to have something positive to say to each of them. Moreover, HygieneTech invested in various local sport associations, partly as marketing but also as a way to contribute to the local community. These efforts are part of the action plan for working with sustainability as caring for the community. This care for people is furthermore made explicit in other ways in the company. One of the sellers, Claes, told me how the sellers in the larger cities try to meet for lunch every week to "check in" with each other, making sure that everyone is doing fine. "It is about energy," Claes told me. "When you are feeling down, they give support and energy, and when someone else is drained we give them some of our energy," Claes explained when I asked about why they valued these lunches so highly. Even though these informal lunches mean that the sellers use more resources (such as time and fuel) by meeting together in one place, this care for people is encouraged by HygieneTech. Even in the smaller cities, sellers are paired up and help each other out and they regularly meet for lunch.

In some ways, this system with sellers working in pairs and the group lunches can be interpreted as the managers wanting to have more control over the sellers, since they rarely meet. Even so, the way the sellers and managers talk about the lunches and the way they try to cover for each other during flu season is more in line with care than control. Furthermore, I was told many stories of how Bosse cared for his employees in ways that went far beyond what would normally be expected of an employer. His care for the employees created stories that travelled through the company and inspired others to care. This kind of care is hard to institutionalize and requires more personal tinkering than care as standards or labels. Enacting care for people also requires more attention to feelings and to others' needs in a variety of situations. It is furthermore more tacit and hard to put into reports and marketing materials - it is hard to capture in catchy slogans and pretty words. Even so, it is enacted in the sustainability report, where care for people has a separate section presenting how the company works with equality issues and noting the high levels of employee satisfaction in the company. This version of sustainability as caring for people is rarely justified. In our interview, Bosse mentioned the economic benefits of having a happy, healthy staff, but otherwise this version of sustainability is enacted as a matter of care that, unlike sustainability as saving resources, does not need to be justified in economic terms. It is a version of 
enacting sustainability that is not as visible in the company as some of the other versions and is rarely put forward when employees address the concept sustainability.

Sustainability as choice: Likewise, sustainability sometimes is a conscious choice in HygieneTech, not in order to save money, but rather done despite the costs. For some years, HygieneTech have bought wind power instead of choosing the cheapest power source available. This decision was made for the sake of sustainability even though it came at a higher cost. It was not made as part of marketing the company as sustainable since it was not included in the marketing material until two years ago, when Therese discovered that the head office was practically carbon neutral when it came to electricity use. In the same way, the choice to start using biogas trucks was an effort to push the development in the right direction, Wilma told me. The biogas trucks were not a way to save (economic) resources; instead, they increased the company's costs, but they were seen as an investment in a better environment. The sellers who work with the biogas trucks sometimes consider them a hindrance to a smooth workday due to the trucks' fragile nature. The trucks often break down and it takes more time to refuel them than ordinary diesel trucks. In these situations, the choice to use biogas trucks is enacted as an idealistic choice the company has made at the sellers' expense, especially since the sellers get commissions on the products they sell regardless of how much time they are forced to spend on repairing and refuelling their trucks.

Nonetheless, investment in a better environment has to live up to some economic demands to be acceptable. The balancing act between idealistic investment and economic calculation shows how sustainability is a matter of care despite the cost, but not at any cost. The company needs to survive to be able to contribute; therefore, the bottom line holds power also when it comes to making idealistic choices. As Law (2010) writes in his study of veterinary practices, sometimes care for the self has an important part in caring for others in the long run. Likewise, to care for the self (or the survival of the organization) sometimes has to be endorsed to be able to care for sustainability in other situations. Caring is about responding, but not responding too much (Law 2010) and thus care for the self as a way to survive. Some of the versions of sustainability enacted in HygieneTech can only be cared for during certain circumstances, such as a solid economic situation.

Sustainability as caring for the right choice is a fragile practice and, to succeed, it has to be connected to other versions of sustainability, or at least not induce large changes in the local practices. Furthermore, sustainability as choice is not structured formally in HygieneTech and I argue that this care is rather personal. The people who talk most about caring for sustainability as an idealistic choice are Bosse, Wilma and Therese, and they all speak with passion about the importance of sustainability. In a conversation about how to market sustainability, Wilma makes her argument explicit 
when another employee expresses his view that sustainability is only about marketing. Wilma argues that she believes that sustainability has a value outside marketing and business strategies. Instead of further justifying her statement or relating to others' opinions, she enacts care for sustainability as an idealistic choice as her own standpoint. Likewise, Therese, Bosse, and some of the employees told me how they felt that it is important to care for sustainability, not because of the effects but because it is the right thing to do. Caring for sustainability as doing the right thing is both personal and affectional.

While sustainability can be all these versions and more, it still holds certain stability. Sustainability changes in the different practices of HygieneTech, and this contributes to the confusion that exists about how to define sustainability. Even so, this weakness also comes with possibilities. As de Laet and Mol show in their study about a bush pump that can transform in many different ways (de Laet \& Mol 2000), its ability to change is what enables it to survive. The bush pump's flexibility becomes its strength in an environment that presents different demands. Since sustainability can be evoked in caring for people, saving resources or caring for a greater principle, it has many uses in HygieneTech. Sustainability holds a strong position in HygieneTech not despite but rather because of its ability to enrol many things, goals and actors. Sustainability has many faces and includes a range of different matters of care, and this is why the different versions of the concept strengthen rather than weaken it.

\section{The lives of different versions of sustainability}

While the different versions of sustainability give the concept flexibility, they can also create tensions. These tensions can be initiated by clashes between different versions of sustainability that cannot be enacted in the same situation. Some practices are mutually excluding, as Mol shows in her study of atherosclerosis (Mol 2002). For example can a cross-section of an artery not be done on a live patient; it can only be done during an autopsy. Therefore the practice of doing a cross-section of an artery is excluded when the patient is alive. Likewise, different versions of sustainability exclude other versions. These clashes tell of the struggle of doing sustainability and the challenges that come with the negotiations of what sustainability - in this situation - looks like. All versions of sustainability come with limitations, since caring also means exclusion. We cannot care for everything at the same time and thus we choose to care for some matters more than others (Puig de la Bellacasa 2011). In order to make some version of sustainability present, other versions have to be excluded, or made "absent" in the terms of John Law (2004). Using the concept of "absent" will mean that I tend to the matters that are significant for the situation but made silent. By 
studying what versions clash and what versions are given priority over other versions, I have (in previous chapters) shown the enactment of sustainability through controversies and what is made absent. In this section, I will go over some of the tensions and clashes that are present in the enactment of sustainability at HygieneTech in order to learn more about the struggles behind the enactment of the sustainable company. Moreover, several versions are more or less entangled in each other: in some situations they can easily be added together while in others they clash. I will also show how some versions can easily coexist and even be combined to strengthen sustainability in different ways.

Clashes with sustainability as labels: One example of the struggles between different versions of sustainability can be found in the effort to sell chemical products. Selling more quantities of spray foam, a less efficient product, can be positive for the company in that it increases their profits. However, this approach stands in contrast to the version of sustainability as saving resources. Products with the environmental label are enacted as sustainable due to the label and therefore the higher use of resources is not seen as an issue that needs to be considered for such products. The different versions of sustainability cannot coexist since they include competing matters of care. Thus, the employees cannot work to raise their sales numbers while at the same time also focusing on sustainability as reducing all use of resources. The same problem arises when a customer wants to use a product in the wrong way, for example, by using oven-cleaning products to clean the floors. The sellers hesitate to argue with the customer over their misuse of the product since the stronger chemicals also cost more and thus bring more profit to HygieneTech. However, as long as a product is labelled, it is sustainable and almost untouchable by other versions of sustainability. When other versions of sustainability clash with sustainability as labels, these versions are made absent.

The version of sustainability as saving resources is, in this situation, made absent in order to be able to have a profitable corporation. In this way, the employees can work with increasing the sales of chemical products without being troubled by making an effort to save resources at the same time. Furthermore, there are other situations where a version of sustainability that is mainly enacted through labels can clash with a version of sustainability as saving resources. This tension can be seen in the way the management group handles a suggestion to mix old detergent products with new products in order to save resources, even though it might go against their commitment to Svanen. The old products contained a substance that was not allowed in the new product, and mixing them with the new products would have meant breaking the company's agreement with Svanen to not change the recipe for the certified product. If they chose not to use the product, their only choice would be to destroy several pallets of functional detergents and thus waste a considerable amount of resources. In this 
case, labelling products was deemed more important than saving resources. Therese told me about the unease she experienced in this case. She and all members of the management group showed concern about how to reconcile Bosse's oft-repeated arguments about saving resources with the need to honour their commitment to Svanen and to the sustainability of their environmental labelled products. The labels have such important positions and are so tightly connected to the pride of being HygieneTech, a company that keeps agreements and cares for labels, that even the version of sustainability as saving resources had to stand down and they decided not to change the recipe.

Clashes with standards: Like sustainability as labels, the enactment of sustainability as standards comes with the challenge of implementing standardized structures and processes in the organization. The version of sustainability that is most vivid at HygieneTech is concerned with saving resources and caring for the people close at hand. These versions sometimes clash with the version of sustainability as following the GAP report in accordance with ISO 26000. The work of creating more policies to live up to the demands of the standard prompts one of the members of the sustainability group to wonder why there is no "policy of common sense". The requirement from the standard to institute yet another policy is difficult for the sustainability group to endorse due to their unwillingness to accept that sustainability entails so much paperwork. HygieneTech's choice to commit to a standard while not always implementing the suggested actions that come out of it shows how the standard is sometimes made absent. This happens when the action suggested in the standard does not fit with the local practices of HygieneTech or when it clashes with other (more important) matters of care.

Adding up the caring customer and Bosse: HygieneTech's sellers meet a variety of customers during their workdays. Nevertheless, when the employees talk about their customers in relation to sustainability, only two versions of the customer emerge. In the enactment of the two versions of the customers I have shown how different versions of sustainability can coexist and be added together. Most customers are enacted by the employees at HygieneTech as ignorant about sustainability and as having their focus set on the lowest price possible. This version of the customer is contrasted with the caring customer, who values high quality and sustainable products. The two versions of the customer are evoked in different settings; the caring customer is always made present when sustainability is justified while the ignorant customer is present when sustainability measures are questioned. The caring customer is very important; despite their low numbers, they are often present in sustainability meetings, marketing materials and in my interviews with employees. The caring customer holds the same properties as Bosse in HygieneTech's sustainability work; they are rarely present in person but often made present in text and talk. Both Bosse and the interested 
customer are absent but manifested (Law 2004) in the realities that are enacted as sustainability. They have important roles as drivers and initiators of sustainability even though they themselves are seldom active in the discussions in which they feature. Even though Bosse has retired, he was always mentioned when I asked the employees why they work with sustainability. In this way he, similar to the caring customer, was absent, but manifested, when it comes to justifying sustainability.

Adding up sustainability as choice and marketing: The enactment of the customer as unknowing is important for HygieneTech in different ways. In a conversation at a management board meeting, the issue of marketing sustainability is discussed. The members of the meeting conclude that they have to make the customers read about why sustainability is good for them. If the company were to heed most of their customers' initial responses to their products and prices, they would instead work on lowering their prices and caring less for high quality. Most customers first ask about prices, since price is the easiest point on which to compare different suppliers. Restaurant owners, often working under a lot of stress, are required to handle many decisions every day, and caring about detergents generally falls low on the list of priorities. To be able to handle customers whose main interest is in prices, the employees at HygieneTech have to enact them as a bit shortsighted and ignorant. It is HygieneTech's job to educate them and show them that sustainability is worth the effort they put in.

One way of making customers read about sustainability could be to print more information about this issue on the products' labels and thus force customers to become more aware of sustainability issues. The is called guerrilla marketing. Related to this issue, Wilma points out that, although sustainability is included in the company's marketing, it is more than that; the company has made a conscious choice to work with sustainability. Wilma states that sustainability has other matters of care besides marketing, whereas Lars (a region sales manager) believes that sustainability is mostly about marketing. Lars and Wilma enact different versions of sustainability, sustainability as conscious choice and sustainability as marketing. Nevertheless, they both agree that sustainability can create value for their customers. The customer needs to be enlightened on the benefits of sustainability, whether it is as saving resources or caring for sustainability. In this way, sustainability is justified as both as a conscious choice and as part of a business strategy. The versions of sustainability as choice and sustainability as saving resources are thus enacted in the same situation and can coexist without friction.

The enactment of sustainability is fluid, and thus the adding and clashing of different versions of sustainability bring about constant movement. Nevertheless, we can learn how sustainability is cared for by looking at clashes or the adding together of different 
versions of sustainability. This approach of adding together different versions of sustainability is often a way to enact sustainability as a resource that can contribute to the company in multiple ways, even when the economic incentives are not obvious. In studying clashes between different versions of sustainability, I have learned how the employees handle the ordering of different matters of care in relation to these different versions. In this chapter I have shown some of the ways that care for sustainability has excluded some matters of care that have been important in other enactments of sustainability.

\section{Sustainability made absent}

Different versions of sustainability have different connections and relations to employees, products and other matters. As I mentioned earlier, caring is a relation that builds on absence (one cannot care for all matters at the same time), and to care for sustainability is to choose not to care for some other matters. Thus, following how sustainability is sometimes made absent is important in understanding how it is organized in HygieneTech. In the following parts of this chapter I present how sustainability is made absent and explore the relationships between some other matters of care that sometimes clash with sustainability.

Cleanliness vs. sustainability: For HygieneTech, cleanliness is the most important matter of care they can bring the customer (see Chapter 7 for a more thorough discussion). They strive to be the best hygiene partner and aim to bring the customer not only detergents, but also clean dishes. Their service includes care for the customer's cleanliness as the result of using their (mostly chemical) products. The sellers work with water every day when they service the dishwashers, and caring for clean water is one component in enacting sustainability at the head office. Water has many different properties in this organization; it is seen as vital and lifesaving in charity projects, while it holds another role in the product cycle. As part of their sustainability efforts, HygieneTech has introduced new products that use only water to clean windows and other surfaces. Even so, water is not enacted as strong enough to create cleanliness, and a product that is twice as cleansing as water does not impress anyone. These non-chemical products are viewed with anxiety, and HygieneTech's employees are afraid that the products will not do the job sufficiently. Sustainability, in this case the absence of chemicals, is contrasted with another important matter of care - cleanliness. Cleanliness is strongly connected with chemicals, both by the sellers and at the head office. Striving for a clean kitchen can go against care for an environment free from harmful chemicals. In this situation, sustainability is made absent since cleanliness is a more important matter of care for the employees at 
HygieneTech. The non-chemical products are, despite their sustainable properties, not popular among the employees at HygieneTech.

Economy vs. sustainability: Also in relation to selling non-chemical products, clean water is not a matter that is cared for when contrasted with care for the profit of selling chemical products. The non-chemical products not only risk lowering profit, they also pose a risk to the achievement of cleanliness. Sustainability is thus made absent in relation to matters that risk the economic profit of the company and goes against other matters as well. As a part of their work with ISO 26000, HygieneTech decided to work to reduce the use of water in the dishwashers they sell. However, they soon discovered that working to make dishwashers more efficient would lead to a decrease in the need for detergents, thus affecting HygieneTech's sales.

This is going to kill us!

This statement was collected while observing a sustainability meeting where the members discussed their efforts to reduce the use of water in new dishwashers. During this discussion, they realized that these efforts also risked lowering their sales of detergents, since using water requires less detergent. This complexity takes the form of frustration within in the sustainability group. What are their responsibilities in this case; what and who should they care for? For the sustainability group, an environmental improvement that risks the foundation of the company - that of selling detergents - is a less important matter of care than working with sustainability. Therefore the issue of saving water receives little action and is finally left out of the action plan. The economics of sustainability is a very interesting topic in relation to these findings. On a very few occasions, economic sustainability was brought up by the employees at HygieneTech. On these rare occasions, it is always mentioned as a joke and to justify not adopting the most environmentally friendly alternative. Even though the participants of these meetings joke about the economic side of sustainability, this subject should not be taken lightly. As Sonja Jerak-Zuiderent (2015) shows in her study about the implementation of standardized measurements in health care, laughter can be a sign of unease. Laughter can be connected to the fear of others making different realities, and in relation to this study it can be a way of indicating clashes between matters of care.

As I have shown in previous chapters, care and economy can sometimes stand in contrast to one another, such as the contradiction between caring for reducing the use of water and selling more detergents. However, this is not always the case, and by thinking with care, I have an approach that does not presuppose that there has to be a clash between economy and care. Hans Harbers (2010) writes about how care and economy can be coupled and do not have to stand in contrast to each other. By taking 
us to his childhood farm, he tells a story of caring for animals not despite economics, but because of economics. This practice he calls an "economy of care". This economy of care is visible in this story of enacting sustainability at HygieneTech as well. The coupling of sustainability and gaining profit is evident when it comes to a version of sustainability as saving resources, a version of sustainability that builds on the same logic as ecological modernization. This care for nature, not despite, but because of economics, is also a care practice that deserves attention. Thinking with care enables me to think about care and economy as parts of the puzzle of making sustainability, which are sometimes in harmony and at other times create tensions. In a similar way, sustainability as saving resources is enacted together with labels through the labelling process in which the demands of the labelling organization require HygieneTech to work with efficiency issues. However, the complex entanglement of different versions makes them impossible to separate in practice.

Economic profitability is often mentioned in order to justify sustainability, and Bosse often stresses the economic aspect of sustainability when asked why it is important. It also shows in the way he cares for the survival of the company and the jobs of the employees. In the case of the biogas trucks, Wilma talks about the balancing act between caring for the environment and making sure the company stays profitable. There is a bottom line they have to relate to: "We have to contribute, otherwise we won't be able to survive". This is enacted as the reality of HygieneTech; the economic figures have to add up on the bottom line.

Caring for nature and the working conditions of the employees of their suppliers is another kind of matter of care. Social responsibility and environmental responsibility are applied to what is enacted as an already existing economic reality. Responsibilities towards nature and people can be negotiated while the economic reality is enacted as fixed. This happens in the case of their efforts to get their suppliers to produce more efficient dishwashers as well as in the case with biogas trucks. Economics is enrolled by the employees as unquestionable and the alternative matters of care are therefore made more voluntary. The economic arguments are enacted as in opposition to, rather than a part of, sustainability in these situations. In these versions, sustainability is not about saving resources, it is reduced to care for nature or for people. Economic results are made into a part of the world that sustainability relates to rather than a part of making sustainability. In these situations, sustainability is made absent due to care for profit.

This is, of course, not the whole truth about the relationship between economics and sustainability. Economic realities can sometimes be negotiated, for example, when the company decides to make a stand and when economics is sometimes included in sustainability. HygieneTech buys electricity generated by wind power even though it 
costs more and they have barely used it in their marketing. Likewise, HygieneTech's work with their suppliers has not provided any economic results; instead, it is seen as a conscious choice to take responsibility for the employees of the suppliers. The economic profit can sometimes be negotiated as long as its consequences do not pose a risk to the core of HygieneTech - a solid economic result and satisfied customers. Sustainability and economics are sometimes related in different ways as well, as in situations where sustainability is enacted as saving resources. When sustainability is enacted as saving resources, economic benefit is an outcome of caring for sustainability and thus not in opposition to sustainability.

In sum, by studying sustainability as caring practices, I have avoided the dualism that is sometimes made present in discussions about sustainability and economics and instead have shown how the relationship between economics and sustainability is complex and that they are entangled in each other. Thinking with care enables a different approach than the economic story in which companies only care about profit. Instead of the telling the story of the profit maximising business employee, I presuppose that the organization consists of actors with a number of different matters of care. This analytical stance enables a perspective that is flexible and sensitive to situations while still being analytically critical. Harbers (2010) is not critical of the coupling of economics and care; still, he argues that farming has become too industrial and that we ought to broaden the margins of care if we wish to change today's food industry. Likewise, I argue that the coupling of economics and sustainability can sometimes be a way to create a better world since it enables companies to care for sustainability within an economic discourse. Even so, since this version of sustainability is widely used in the corporate sphere it should be analysed symmetrically with other versions of doing sustainability. Other versions of care need to be made present in discussions about the value of sustainability, thus broadening the margins of care in relation to sustainability.

\section{Keeping the cares together through professional caring}

Care starts out from the fleshiness and fragility of life (Mol 2008, p. 11).

Studying with care, I follow the people that do sustainability, looking at how they create stories, embody care and enable others to care for nature. It is the fleshiness of their realities that I have tried to capture with my words and it is the fragility of their ordering of sustainability that has been dissected. Writing the fleshiness of life (and care) is a way to understand the realities of doing sustainability. When enactments of sustainability become difficult and fragile, different matters of care are present and 
turned against each other. The tensions between different matters of care make relations visible, and through these we understand the worlds of the employees at HygieneTech. Studying care practices has enabled a more caring approach to the people in the study and helped me in understanding their struggles, their worlds and the fragility of their sustainable realities.

Telling HygieneTech's stories, with care, is a step in making the organization of sustainability into a matter of care instead of a competitive advantage or words in flashy marketing folders. Thinking with care brings the actors and their realities into a discussion that too often is hidden behind words of structure. Instead of analysing the sustainability work at HygieneTech as a part of their organizational culture, I have written stories about struggles to create sustainable realities. The stories, the fleshiness and fragility of life, are put at the centre. In this way, people and non-human actors are made visible as active agents in creating sustainability rather than being controlled by existing structures. In addition to this actor-network approach, thinking with care brings attention to affective states as a part of enacting practices of sustainability. It also requires the researcher to care for the participants of the study, and the impact the study might have on their realities as well as those of others. Thinking with care is thus both an analytical concept and an attempt to take responsibility for the effects of the researcher's choices.

The different versions of sustainability that I discussed do not cover all the ways that sustainability is cared for. They do, however, work as tools to make visible ways of promoting sustainability done in HygieneTech. Thinking with care about enacting sustainability at HygieneTech has provided me with new thoughts about how the company handles their messy reality and the challenges that they meet. The versions of sustainability and the different matters of care attached to them come with challenges of coordinating and ordering. In relation to this challenge I would like to pause and marvel at the work done to navigate between different matters of care.

The difficulty of handling the coordination of matters can be discussed in the light of tinkering. To tinker is to adapt, to change and to compromise in order to care for (and about) things that matter. Caring is tinkering, according to some of the researchers studying care practices within science and technology studies (Mol 2008; Mol, Moser \& Pols 2010). Furthermore, Denis and Pontille (2013) shows in their study about maintenance work in electrical substations in France that since care of things such as maintenance draws on watchfulness, it cannot be normalized. Full information of what is needed in order to care cannot be obtained in advance and thus continual adaptation is required. I believe that this continual adaptation is very important in the work with sustainability at HygieneTech also. The ISO 26000 standard HygieneTech works with is rigid and has a somewhat different set of matters of care than the employees, and it 
requires continual adaptation to be made part of the everyday life of the head office at HygieneTech. In this adaptation, some matters of care are made absent since other matters are more important. This vulnerability, when things become rigid, difficult to bend to fit the local practices, it can be argued, is not a weakness; instead it is the reason that people and things deserve constant attention (Denis \& Pontille 2013). Furthermore, standards can be entagled with care, for example when accountability practices are negotiated by all involved before the terms are settled (Jerak-Zuiderent 2013). Therefore, instead of evaluating the success of the standard, I have studied it as part of the professionalism in caring for sustainability. Even though some initiatives from the standard not is accepted by the employees, this is not a failure of the standard per se, but could instead be seen as a part of caring for keeping the company together.

Care, whether it is for sustainability or for a dear friend, inevitably entails handling complexity. Caring is relational and therefore it creates multiplicity (Puig de la Bellacasa 2012), thus the different versions of sustainability are a result of the care for sustainability. The competing matters of care at the table show the struggles of caring. In a very different but related case, Janelle Taylor writes about her care for her mother with Alzheimers. She states that the most important question is how to keep together all the complexities and frictions involved in care and she works to grant her mother recognition instead of focusing on whether her mother recognizes her (Taylor 2008). "Keeping the care together" is what makes life worthwhile and instead of constantly being asked if her mother still recognizes her, she would prefer to be asked: Are you keeping the cares together?

In this study, I have written about the efforts that are put into caring for sustainability and the different versions that this care enacts. This study is another case of "trying to keep the cares together" and the stories in this thesis describe how this work is done. The struggles, the tensions between different versions of sustainability and the work of sometimes making sustainability absent, are the employees' way of caring for a range of matters of care. As the caregiver needs to be in tune with the changing needs of the patient in order to give good care (Mol 2010b), the employees need to tinker with their practices to be able to care for sustainability. In her study about food at a nursing home Mol concludes:

More generally, drawing a single good out of its complex setting all too often fails to serve the overall quality of care. The quality of care rather depends on compromises between goods. On a persistent willingness to tinker. Crucial for good care, then, are those who feel the tensions between different goods as these cause frictions in their daily practice (Mol 2010b, p. 228). 
In this study, good care (for sustainability) includes similar sensitivities as caring for the needs of the people at the nursing home. According to Mol, care is about tinkering and feeling the tensions between different goods. Care is also about making compromises and finding a way to care for several goods at the same time. The employees at HygieneTech are sometimes sensitive to this tension between different matters of care (goods), and as we have seen on numerous occasions in this thesis, need to tinker with their practices to care for the survival of the company along with care for sustainability. The choice to use biogas trucks in only some cities is one good example of where the employees had to tinker with their practices to to attend to several competing matters of care, such as, such as the opinions from the sellers, the economy of the company and care for the environment. Caring for sustainability can thus be viewed as a competence, or maybe more suitable, a sensitivity, that the employees at HygieneTech show when it comes to dealing with the uncertain, constantly changing reality they have to tinker with in order to make sustainability into a matter of care.

In care, it is good to tinker iteratively and find ways of temporarily reconciling noncoherent logics and practices by keeping differences in a state of (always precarious) balance. It is also good to know that it is highly likely that today's solution will not work for very long. It is good, in short, to understand that goods are necessarily in tension and cannot ultimately be reconciled (Law, Afdal et al. 2014, p. 189-190).

Even though care is ordered in different ways to enable distribution of care, following this statement by Law et al., it is ultimately down to the actor's ability and willingness to care. By working with care enablers, corporations can enable employees to care, while still allowing for sensitivity towards the uncertainty involved in the making of everyday life. Enacting care can be promoted in different ways, such as through working with labels (and thus distributing care) or supporting care in relationships through providing resources. Combined with the tinkering and sensitivity from the employees, they are able to care through(out) friction. This sensitivity brings attention to the needs and feelings of the actors involved as well as the stories behind the employees. Caring entails tending to the matter at hand, whether it is a person, environmental labels or an ethical position. Viewing the world as constantly changing and understanding the multiplicity of the matters of care the employees face inspire different stories. Instead of focusing on such things as the (at least partial) failure of the standard, the majority of the stories throughout this study tell about people and non-human actors who care. Who tinker to make reality hang together. 


\section{For the future: Some final thoughts on care and sustainability}

The words used to create this text were chosen with care - care for what they might bring to the world, a world that hopefully will be touched, and maybe even slightly changed, by the ideas, thoughts and stories within this book. Caring is acting for a better common future, and we have to figure out what that future looks like and how to take the next step in making it come true. I believe STS can help us on this journey.

In this study I have shown how sustainability can be many different practices and come in several versions. While sustainability can be all these versions and more, it still holds a certain stability. The enactment of sustainability holds together even though some versions clash, and it is possible for the employees at HygieneTech to tend to different matters of care. I have shown how some versions of sustainability (and thus some matters of care) are made separate through different ways of ordering. Sustainability as saving resources is enacted in the sustainability report in relation to the sustainable business transactions, while it is absent from sections about care for people. In this way, the cares are kept separate in order to make reality hold together. Detergents, places and trucks have, together with the human actors, told stories of organizing care in HygieneTech, allowing for new stories of doing care and sustainability. In the stories in this thesis, the practices of care become visible and through this we can learn about different ways care can be ordered and the consequences of these orderings.

Taking as a point of departure the closing words of this thesis, there are many new roads that would be interesting and productive to walk. I argue that studying care as practice in everyday life makes care present and important. Following the argumentation from Mol, Moser and Pols, care deserves to be studied, otherwise it might be made invisible (Mol, Moser \& Pols 2010). Consequently, an interesting topic would be to further study the care for sustainability, and such an approach could show how other types of organizations handle the distribution of responsibility for caring. Further studies could explore how care can be distributed in a range of different organizations, such as NGOs, multinational companies and government-owned companies in order to find new ways that care is ordered. Studying these different types of organizations with their various aims and challenges would show how ordering of care is done in different situations and thus let us know more about how we can facilitate care in practice. As I have shown, the care enablers in this study (environmental labels and ISO 26000) are important for the enactment of sustainability in HygieneTech and it would be interesting to follow the roles of other kinds of care enablers in the making of sustainability in organizational settings. Since rigid standards not are malleable to facilitate care in all settings, it would be interesting to as an alternative study care enablers that are less standardized and instead collectively 
negotiated by the actors that are involved (an idea also inspired from Jerak-Zuiderent 2013).

This brings me to the final thoughts that I want to conclude this thesis: How can we care about a better future in relation to the topics of this study? Sustainability can be accused of being too broad, of being too concerned about the economic well-being of the company or simply for its ability to incorporate almost everything and thus for being an empty concept. Even so, I have shown through the different stories in this book how sustainability enables companies to care for what they believe are their responsibilities - whether towards their employees, the company's survival or the society as a whole. Instead of passing final judgement about sustainability as the answer, we should consider whether it can be helpful in our current situation. Is this a setting where sustainability is a concept that can enable care for a better common world? Puig de la Bellacasa (Puig de la Bellacasa 2010) showed in her study of permaculture ethics how almost all ethical questions were answered with one single answer: "It depends." Likewise, there is no answer to whether working with sustainability is the best way to care for our common worlds. As unsettling as this statement might be, it also brings a sense of humbleness for the challenge of doing sustainability and a respect for the tinkering by people who do care for sustainability despite the mess of practices it may involve. 


\section{References}

Alvesson, M. \& Kärreman, D. (2011) Qualitative research and theory development. Wiltshire: SAGE Publications Ltd.

Ammenberg, J., Hjelm, O. \& Quotes, P. (2002) The connection between environmental management systems and continual environmental performance improvements. Corporate Environmental Strategy, 9(2): 183-192.

Asdal, K. (2008) Enacting things through numbers: Taking nature into account/ing. Geoforum, 39(1): 123-132.

Asdal, K. (2014) Versions of milk and versions of care: The emergence of mother's milk as an interested object and medicine as a form of dispassionate care. Science in Context, 27(02): 307-331.

Aspers, P. (2007) Etnografiska metoder: att förstå och förklara samtiden [Etnographic methods: To understand and explain the contemporary society]. Korotan Ljubljana: Liber

Bakker, K. (2012) Water: political, biopolitical, material. Social Studies of Science, 42(4): 616-623.

Barnes, J. \& Alatout, S. (2012) Water worlds: Introduction to the special issue of Social Studies of Science. Social Studies of Science, 42(4): 483-488.

Battisti, M. \& Perry, M. (2011) Walking the talk? Environmental responsibility from the perspective of small-business owners. Corporate Social Responsibility and Environmental Management, 18(3): 172-185.

Bishop, H. (2012) The politics of care and transnational mobility. Ph.D. thesis, Scool of Social Sciences. Cardiff: Cardiff University.

Bolagsverket (2014) Annual accounts. [Online] Available from:

https://www.verksamt.se/en/web/international/running/accounting/annual-accounts. [Accessed: 2014-04-15]

Boström, M. (2003) Environmental organisations in new forms of political participation: Ecological modernisation and the making of voluntary rules. Environmental Values, 12(2): 175-193.

Bowden, P. (1997) Caring: Gender sensitive ethics. London: Routledge. 
Bowker, G. C. \& Star, S. L. (2000) Sorting things out: Classification and its consequences. New Baskerville: MIT press.

Brown, S. D. \& Middleton, D. (2005) The baby as virtual object: agency and difference in a neonatal intensive care unit. Environment and Planning, 23(5): 695.

Caliskan, K. \& Callon, M. (2009) Economization, part 1: shifting attention from the economy towards processes of economization. Economy and Society, 38(3): 369-398.

Caliskan, K. \& Callon, M. (2010) Economization, part 2: a research programme for the study of markets. Economy and Society, 39(1): 1-32.

Cassells, S. \& Lewis, K. (2011) SMEs and environmental responsibility: Do actions reflect attitudes? Corporate Social Responsibility and Environmental Management, 18(3):186-199.

Cho, C. H. \& Patten, D. M. (2007) The role of environmental disclosures as tools of legitimacy: A research note. Accounting, Organizations and Society, 32(7): 639-647.

Comyns, B., Figge, F., Hahn, T. \& Barkemeyer, R. (2013) Sustainability reporting: The role of "Search", "Experience" and "Credence" information. Accounting Forum, 37(3): 231-243.

Cooren, F. (2004) Textual agency: How texts do things in organizational settings. Organization, 11(3): 373-393.

Creswell, J. W. \& Miller, D. L. (2000) Determining validity in qualitative inquiry. Theory into Practice, 39(3): 124-130.

Curtin, D. (1991) Toward an ecological ethic of care, Hypatia 6(1): 60-74.

Czarniawska, B. (2004) Narratives in social science research. London: SAGE Publications Ltd.

Czarniawska, B. \& Hernes, T. (2005) Actor-network theory and organizing. Malmö: Liber and Copenhagen Business School Press.

de Laet, M. \& Mol, A. (2000) The Zimbabwe bush pump: Mechanics of a fluid technology. Social Studies of Science, 30(2): 225-263.

Delmas, M. A. \& Cuerel Burbano, V. (2011) The drivers of greenwashing. California Management Review, 54(1): 64-87.

Denis, J., \& Pontille, D. (2013) Material ordering and the care of things. CSI Working Papers Series 034, [Online] Available from http://hal-ensmp.archives-ouvertes.fr/hal00875511. [Accessed: 2015-02-03] 
Dewhurst, H. \& Thomas, R. (2003) Encouraging sustainable business practices in a non-regulatory environment: A case study of small tourism firms in a UK national park. Journal of Sustainable Tourism, 11(5): 383-403.

Dow Jones Sustainability Indices (2015) Corporate sustainability assesment. [Online] Available from http://www.sustainability-indices.com/sustainabilityassessment/corporate-sustainability-assessment.jsp. [Accessed: 2015-02-01]

Ekonomifakta (2010) Småföretagslandet Sverige. [Sweden - the land of SMEs] [Online] Available from http://www.ekonomifakta.se/sv/Artiklar/2010/September/Smaforetagslandet-Sverige. [Accessed: 2015-02-01]

Ely, M. \& Anzyl, M. (1993) Kvalitativ forskningsmetodik i praktiken.[Qualititative reserach methods in practice] Lund: Studentlitteratur.

European Comission (2011) A renewed EU strategy 2011-14 for Corporate Social Responsibility COM(2011) 681. Brussels.

Fine, M. D. (2007) A caring society?: Care and the dilemmas of human service in the twenty-first century. Basingstoke: Palgrave Macmillan.

Foucault, M. (1988) The history of sexuality, Vol. 3: The care of the self. New York: Random House, Inc.

Furlow, N. E. (2010) Greenwashing in the new millennium. The Journal of Applied Business and Economics, 10(6): 22-26.

Gad, C., \& Jensen, C. B. (2010) On the consequences of post-ANT. Science, Technology and Human Values, 35(1): 55-80.

Gamper-Rabindran, S. \& Finger, S. R. (2013) Does industry self-regulation reduce pollution? Responsible care in the chemical industry. Journal of Regulatory Economics, 43(1): 1-30.

Geiger, S., Harrison, D., Kjellberg, H. \& Mallard, A. (2014) Concerned markets: economic ordering for multiple values. Padstow: Edward Elgar Publishing.

Georg, S. \& Tryggestad, K. (2009) On the emergence of roles in construction: the qualculative role of project management. Construction Management and Economics, 27(10): 969-981.

Grankvist, P. (2012) CSR i praktiken: hur företag jobbar med hållbarhet för att tjäna pengar. [CSR in practice: How companies work with sustainability in order to earn money] Malmö: Liber. 
Global Reporting Initiative (2014) About sustainability reporting. [Online] Available from https://www.globalreporting.org/information/sustainabilityreporting/Pages/default.aspx. [Accessed: 2014-04-15]

Guenther, E., Hoppe, H. \& Poser, C. (2006) Environmental corporate social responsibility of firms in the mining and oil and gas industries. Greener Management International, 2006(53): 6-25.

Hammersley, M. \& Atkinson, P. (2007) Ethnography : principles in practice. 3. ed. Milton Park, Abingdon, Oxon: Routledge.

Haraway, D. J. (1997) Modest-Witness@ Second-Millennium.FemaleManMeets-OncoMouse: Feminism and technoscience. New York and London: Routledge.

Harbers, H. (2010) Animal farm love stories. In: Mol, A., Moser, I. \& Pols, J. (eds.) Care in practice: Tinkering in clinics, homes and farms. Bielefeld: Transcript Publishers.

Held, V. (1993). Feminist morality: Transforming culture, society, and politics Chicago: University of Chicago Press.

Heuts, F. \& Mol, A. (2013) What is a good tomato? A case of valuing in practice. Valuation Studies, 1(2): 125-146.

Hillary, R. (2000) Small and medium-sized enterprises and the environment: Business imperatives. Sheffield: Greenleaf Publishing Limited.

Hillary, R. (2004) Environmental managment systems and the smaller entrerprise. Journal of Cleaner Production, 12(6): 561-569.

International Organization for Standardization (2010) Discovering ISO 26000. [Online] Available from http://www.iso.org/iso/discovering_iso_26000.pdf. [Accessed: 2014-08-15]

Jenkins, H. (2004) A critique of conventional CSR theory: An SME perspective. Journal of General Management, 9(4): 55-75.

Jerak-Zuiderent, S. (2013) Generative accountability: Comparing with care. Ph.D. thesis, Institute of Health Policy and Management, Rotterdam: Erasmus University.

Jerak-Zuiderent, S. (2015) Keeping open by re-imagining laughter and fear. The Sociological Review (forthcoming).

Kirchoff, S. (2000) Green business and blue angels: A model of voluntary overcompliance with asymmetric information. Environmental \& Resource Economics, 15(4): 403-420. 
Kjellberg, H. \& Helgesson, C.-F. (2006) Multiple versions of markets: Multiplicity and performativity in market practice. Industrial Marketing Management, 35(7): 839855 .

Kolk, A. (2003) Trends in sustainability reporting by the Fortune Global 250. Business Strategy and the Environment, 12(5): 279-291.

Kolk, A. (2004) A decade of sustainability reporting: developments and significance. International Journal of Environment and Sustainable Development, 3(1): 51-64.

Kvale, S. (1997) Den kvalitativa forskningsintervjun. [The qualitative research interview] Danmark: Studentlitteratur.

Lampland, M. \& Star, S. L. (2009) Standards and their stories: how quantifying, classifying, and formalizing practices shape everyday life. Ithaca: Cornell University Press.

Latour, B. (1999) Pandora's hope: essays on the reality of science studies. Cambridge, MA: Harvard University Press.

Latour, B. (2004) Why has critique run out of steam? From matters of fact to matters of concern. Critical inquiry, 30(2): 225-248.

Latour, B. (2005) Reassembling the social. An introduction to actor-network-theory. Oxford: Oxford University Press.

Latour, B. \& Woolgar, S. (1986). Laboratory life: The construction of scientific facts. (2nd ed). Princeton, NJ: Princeton University Press.

Laughland, P. \& Bansal, T. (2011) The top ten reasons why businesses aren't more sustainable [Online] Available from

http://www.iveybusinessjournal.com/topics/social-responsibility/the-top-ten-reasonswhy-businesses-aren\%E2\%80\%99t-more-sustainable\#.UW0PrPJdBBk. [Accessed: 2013-04-16]

Law, J. (1994) Organizing modernity: Social ordering and social theory. Oxford: Blackwell.

Law, J. (2004) After method: Mess in social science reserach. Abingdon and New York: Routledge.

Law, J. (2009) Actor-network theory and material semiotics. In: Turner, B. S. (ed.) The new blackwell companion to social theory. Chichester, West Sussex, United Kingdom; Malden, MA, USA: Wiley-Blackwell

Law, J. (2010) Care and killing: tensions in veterinary practice. In: Mol, A., Moser, I. \& Pols, J. (eds.) Care in practice: tinkering in clinics, homes and farms. Bielefeld: Transcript Publishers. 
Law, J., Afdal, G., Asdal, K., Lin, W., Moser, I. \& Singleton, V. (2014) Modes of syncretism: Notes on noncoherence. Common Knowledge, 20(1): 172-192.

Law, J. \& M. E. Lien (2013) Slippery: Field notes in empirical ontology. Social Studies of Science, 43(3): 363-378.

Law, J. \& Singleton, V. (2005) Object lessons. Organization, 12(3): 331-355.

Law, J. \& Urry, J. (2004). Enacting the social. Economy and society, 33(3): 390-410.

Lazarte, M. (2013) ISO 26000: International forum revisits the road travelled. [Online] Available from

http://www.iso.org/iso/home/news_index/news_archive/news.htm?refid=Ref1691 [Accessed: 2014-04-03]

Lee, N. \& Hassard, J. (1999) Organization unbound: actor-network theory, research strategy and institutional flexibility. Organization, 6(3): 391-404.

Lippert, I. (2013) Enacting environments: An ethnography of the digitalisation and naturalisation of emissions, Ph.D. thesis, PhilosophischSozialwissenschaftliche Fakultät. Augsburg University

Lynch, M. \& Woolgar, S. (1990) Representation in scientific practice: Cambridge, MA: MIT press.

Lyon, T. P. \& Maxwell, J. W. (2011) Greenwash: Corporate environmental disclosure under threat of audit. Journal of Economics \& Management Strategy, 20(1): 3-41.

Merriam Webster. (2015) Whitewash. [Online] Available from http://www.merriamwebster.com/dictionary/whitewash. [Accessed: 2015-03-03]

Mies, M. \& Shiva, V. (1993) Ecofeminism. London: Zed Books.

Mol, A. (1999) Ontological politics: a word and some questions. In: Law, J. \&

Hassard, J. (eds) Actor network theory and after, Oxford and Keele: Blackwell and the Sociological Review.

Mol, A. (2002) The body multiple: Ontology in medical practice. Durham, N. Ca., and London: Duke University Press.

Mol, A. (2008) The logic of care: Health and the problem of patient choice. London: Routledge.

Mol, A. (2010a) Actor-network theory: Sensitive terms and enduring tensions. Kölner Zeitschrift für Soziologie und Sozialpsychologie, 50(1): 253-269. 
Mol, A. (2010b) Care and its values: Good food in the nursing home. In: Mol, A., Moser, I. \& Pols, J. (eds.) Care in practice: Tinkering in clinics, homes and farms. Bielefeld: Transcript Publishers.

Mol, A. P. (2001) Globalization and environmental reform: the ecological modernization of the global economy. Massachusetts: MIT Press.

Mol, A., Moser, I., Piras, E. M., Turrini, M., Pols, J. \& Zanutto, A. (2011) Care in practice. On normativity, concepts, and boundaries. TECNOSCIENZA: Italian Journal of Science \& Technology Studies, 2(1): 73-86.

Mol, A., Moser, I. \& Pols, A. (2010) Care in practice: On tinkering in clinics, homes and farms. Bielefeld: Transcript Publishers.

Nordic Ecolabelling (2010) 080 Dishwasher detergents for professional use. [Online] Available from http://www.svanen.se/en/Criteria/Nordic-Ecolabelcriteria/Criteria/?productGroupID=46. [Accessed: 2014-02-01]

NORMAPME (2011) ISO 26000: NORMAPME User guide for european SMEs. [Online] Available from http://www.eubusiness.com/topics/sme/iso-26000-guide. [Accessed: 2014-04-03]

OECD (2005) Annual report. [Online] Available from http://www.oecd.org/about/34711139.pdf. [Accessed: 2013-04-02]

Patton, D. \& Worthington, I. (2003) SMEs and environmental regulations: a study of the UK screen-printing sector. Environment and Planning C: Government and Policy, 21(4): 549-566.

Puig de la Bellacasa, M. (2010) Ethical doings in naturecultures. Ethics, place and environment, 13(2): 151-169.

Puig de la Bellacasa, M. (2011) Matters of care in technoscience: Assembling neglected things. Social Studies of Science, 41(1): 85-106.

Puig de la Bellacasa, M. (2012) 'Nothing comes without its world': thinking with care. The Sociological Review, 60(2): 197-216.

Reijonen, S. \& Tryggestad, K. (2012) The dynamic signification of product qualities: on the possibility of "greening" markets. Consumption Markets \& Culture, 15(2): 213234.

Revell, A. \& Rutherfoord, R. (2003) UK environmental policy and the small firm: broadening the focus. Business Strategy and the Environment, 12(1): 26-35.

Rutherfoord, R., Blackburn, R. A. \& Spence, L. J. (2000) Environmental managment and the small firm. International Journal of Entrepreneural Behaviour \& Research, 6(6): 310-325. 
Saldana, J. M. (2009) The coding manual for qualitative researchers. Los Angeles, CA: SAGE Publications Ltd.

SAM (2012) Measuring intangibles. [Online] Available from

http://www.sustainability-indexes.com/images/sam-csa-methodology-en_tcm1071338252.pdf [Accessed: 2014-03-13]

Santos, M. (2011) CSR in SMEs: strategies, practices, motivations and obstacles. Social Responsibility Journal, 7(3): 490-508.

SCB (2012) Aktuell statistik ur företagsregistret. [Statics from the national business registry] [Online] Available from http://www.scb.se/Pages/List 259330 . [Accessed: 2014-04-09]

Schaper, M. (2002) Small firms and environmental management. International Small Business Journal, 20(3): 235-251.

Schulz, P. \& Zelezny, L. (1999) Values as predictors of environmental attitudes: evidence for consistency across 14 countries. Journal of Environmental Psychology, 19(3): 255-265.

Schwarz, B. \& Tilling, K. (2009) 'ISO-lating' corporate social responsibility in the organizing context: A dissenting interpretation of ISO 26000. Corporate Social Responsibility and Environmental Managment, 16(5): 289-299.

Simnett, R., Vanstraelen, A. \& Wai Fong, C. (2009) Assurance on sustainability reports: An international comparison. Accounting Review, 84(3): 937-367.

Singleton, V. (2012) When contexts meet feminism and accountability in UK cattle farming. Science, Technology \& Human Values, 37(4): 404-433.

Smith, D. E. (2001) Texts and the ontology of organizations and institutions. Studies in Cultures, Organizations and Societies, 7(2): 159-198.

Spaargaren, G. \& Mol, A. P. (1992) Sociology, environment, and modernity: Ecological modernization as a theory of social change. Society \& Natural Resources, 5(4): 323-344

Spradley, J. P. \& Baker, K. (1980) Participant observation. New York: Holt, Rinehart and Winston.

Svanen (2015) De 20 vanligaste frågorna om Svanen. [The twenty most common questions about Svanen] [Online] Available from http://www.svanen.se/Omoss/Fragor-och-svar/Svanen/. [Accessed: 2015-03-07]

Tamm Hallström, K. (2008) ISO expand its business into social responsibility. In: Boström, M. \& Garsten, C. (eds.) Organizing transnational accountability. Cheltenham: Edward Elgar. 
Taylor, J. S. (2008) On recognition, caring, and dementia. Medical Anthropology Quarterly, 22(4): 313-335.

The World Bank Group (2001) What is sustainable development? [Online] Available from http://www.worldbank.org/depweb/english/sd.html [Accessed: 2015-01-20]

Tilley, F. (2000) Small firm environmental ethics. How deep do they go? Business Ethics: A European Review, 9(1): 31-41.

Tronto, J. (1993) Moral boundaries: A political argument for an ethic of care. New York: Routledge.

Tzschentke, N. A., Kirk, D. \& Lynch, P. A. (2008) Going green: Decisional factors in small hospitality operations. International Journal of Hospitality Management, 27(1): 126-133.

Twigg, J. (2000) Carework as a form of bodywork, Ageing and Society, 20(4): 389411.

United Nations (2005) Resolution adopted by the General Assembly 60/1. [Online] Available from http://www.ifrc.org/docs/idrl/I520EN.pdf. [Accessed: 2013-05-17]

Watts, L. (2007) A future archaeology of the mobile telecoms industry. Ph.D. thesis, Department of Sociology. Lancaster: Lancaster University.

WECD (1987) Our common future. [Online] Available from http://www.undocuments.net/our-common-future.pdf. [Accessed: 2013-05-17]

Vernon, J., Essex, S., Pinder, D. \& Curry, K. (2003) The 'greening' of tourism microbusinesses: outcomes of focus group investigations in South East Cornwall. Business Strategy and the Environment, 12(1): 49-69.

Williams, F. (2001) In and beyond New Labour: towards a new political ethics of care. Critical social policy, 21(4): 467-493.

Williamson, D., Lynch-Wood, G. \& Ramsay, J. (2006). Drivers of environmental behaviour in manufacturing SMEs and the implications for CSR. Journal of Business Ethics, 67(3): 317-330.

Winance, M. (2010) Care and disability. In: Mol, A., Moser, I. \& Pols, J. (eds.) Care in practice: Tinkering in clinics, homes and farms. Bielefeld: Transcript Publishers.

Winthereik, B. R. \& Verran, H. (2012) Ethnographic stories as generalizations that intervene. Science Studies, 25(1): 37-51.

Yin, R. (2003) Case study research: Design and methods. London: SAGE

Publications, Inc. 